\title{
The effect of reservoir characteristics on methane production from hydrate bearing formations
}

\author{
Sachin Gandra \\ West Virginia University
}

Follow this and additional works at: https://researchrepository.wvu.edu/etd

\section{Recommended Citation}

Gandra, Sachin, "The effect of reservoir characteristics on methane production from hydrate bearing formations" (2006). Graduate Theses, Dissertations, and Problem Reports. 3245.

https://researchrepository.wvu.edu/etd/3245

This Thesis is protected by copyright and/or related rights. It has been brought to you by the The Research Repository @ WVU with permission from the rights-holder(s). You are free to use this Thesis in any way that is permitted by the copyright and related rights legislation that applies to your use. For other uses you must obtain permission from the rights-holder(s) directly, unless additional rights are indicated by a Creative Commons license in the record and/ or on the work itself. This Thesis has been accepted for inclusion in WVU Graduate Theses, Dissertations, and Problem Reports collection by an authorized administrator of The Research Repository @ WVU. For more information, please contact researchrepository@mail.wvu.edu. 


\title{
THE EFFECT OF RESERVOIR CHARACTERISTICS ON METHANE PRODUCTION FROM HYDRATE BEARING FORMATIONS
}

\author{
By \\ Sachin Gandra \\ Thesis submitted to the College of Engineering and Mineral Resources \\ at West Virginia University \\ in partial fulfillment of the requirements \\ for the degree of \\ Master of Science \\ in \\ Petroleum and Natural Gas Engineering
}

\author{
Approved by \\ Dr. H. Ilkin Bilgesu, Committee Chairperson \\ Dr. Daniel E. Della-Giustina \\ Prof. Samuel Ameri \\ Department of Petroleum and Natural Gas Engineering \\ Morgantown, West Virginia \\ 2006
}

Keywords: Methane Hydrate, Production, Porosity, Permeability, Thickness, Reservoir, Water Saturation, CMG, STARS 


\section{ABSTRACT \\ The Effect of Reservoir Characteristics on Methane Production From HYDRATE BEARING FORMATIONS}

\section{SACHIN GANDRA}

Demand for natural gas is ever increasing and according to DOE ${ }^{[1]}$, by 2040,10 $\mathrm{Tcf} / \mathrm{yr}$ of gas has to be imported. Interest in the potentially large deposits of natural gas hydrates and hydrate capped gas reservoirs is increasing because a conservative estimate of gas hydrate reserve potential of US exclusive economic zone is 200,000 Tcf $^{[2,3]}$. If $1 \%$ of this were recovered, that would be greater than the cumulative gas reserves of conventional gas sources (1000-1500 Tcf). Even $1 \%$ production of this recovered gas per year would make USA the exporter of gas.

Gas hydrates are solid, crystalline ice like inclusion compounds in which gas molecules are trapped inside voids in hydrogen bounded lattice structure of water molecules formed generally in high pressure and low temperature conditions. Generally, occur in the subsurface of many permafrost regions as well as in oceanic sediments. Approximately $180 \mathrm{scf}$ of gas is produced per unit volume of hydrate.

Currently, most of the work is based on the laboratory studies since an important part of developing commercial gas production technology is predicting the methane production rates for various field operating scenarios using models. The objective of the proposed work is to study the effect of various reservoir properties (water saturation, hydrate permeability, rock permeability, thickness of the reservoir, porosity) on the production of gas from a hydrate-bearing reservoir. A mathematical model was developed to study production concepts for natural gas hydrate accumulations. 


\section{Acknowledgements}

I would like to convey my deepest regards to my research advisor, chair of my advisory committee, Dr. H. Ilkin Bilgesu for his support, guidance and continuous help throughout my research. Besides the great effort and time he spent on this research, I am thankful to him for all the opportunities he provided.

I would like to thank Dr. Daniel E. Della-Giustina for serving as a member of the advisory Committee and professor Samuel Ameri, Chairperson, P.N.G.E department for his invaluable advice and help through out the program.

I express my gratitude and appreciation to the Petroleum Engineering Department for financial support in the form of assistantships.

I would like to dedicate this research to my family and friends without whose unconditional love and support, I would not have completed the program. 


\section{Table of Contents}

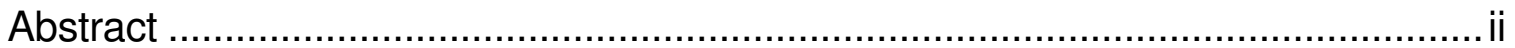



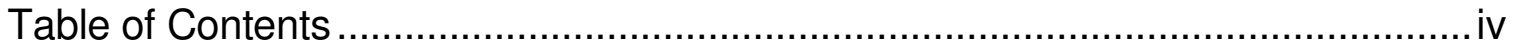

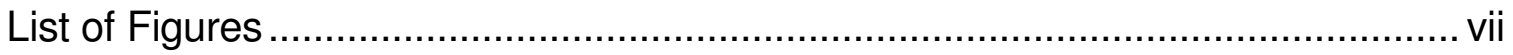

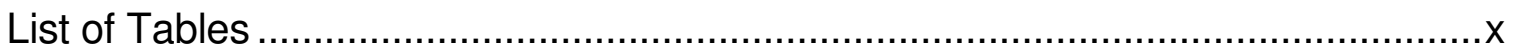

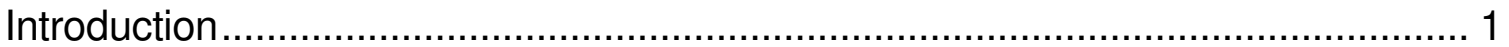

1. Literature Review

1.1 The Nature of Gas Hydrates …………….......................................... 3

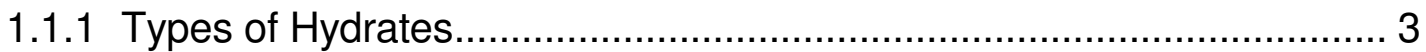

1.1.2 Nature of Hydrate Accumulations in the Field ....................................... 4

1.1.3 Hydrate Stability Conditions …………………................................ 4

$1.2 \quad$ A Brief History of Gas Hydrate Study ................................................ 6

1.3 Formation and Extent of Gas Hydrates ................................................ 7

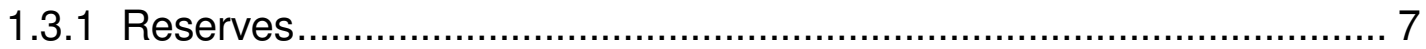

1.3.2 Detection of Hydrates ………..................................................... 8

1.4 Production of Hydrates Using Conventional Technology ...................... 10

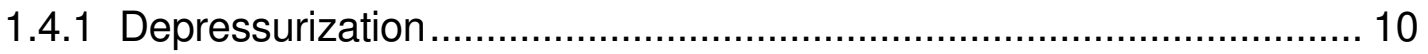

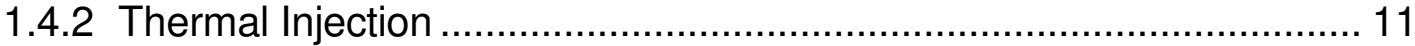

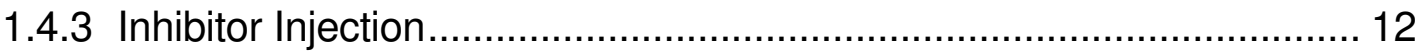

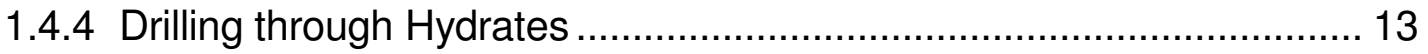

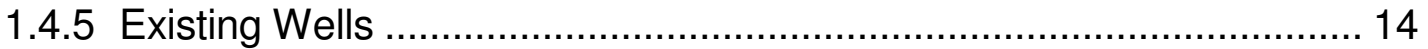

1.5 Existing Hydrate Dissociation Models ............................................. 15

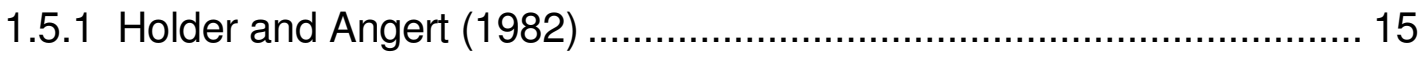

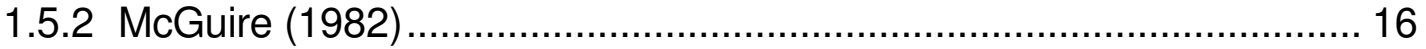

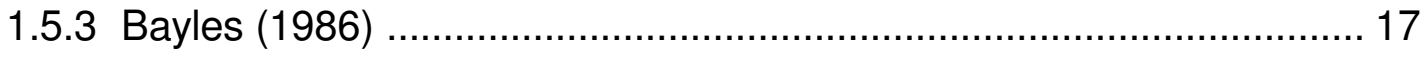

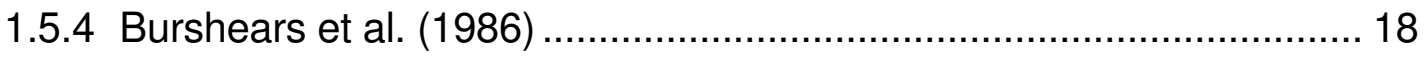

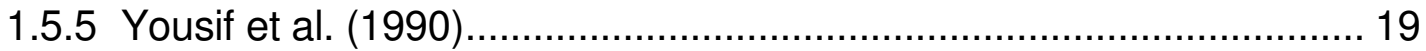

1.5.6 Moridis et al. (1998) .................................................................... 20 


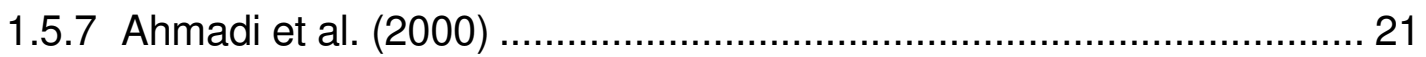

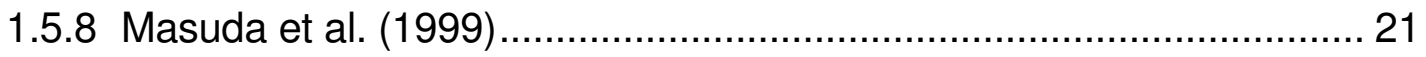

1.5.9 Swinkels and Drenth (2000) ....................................................... 21

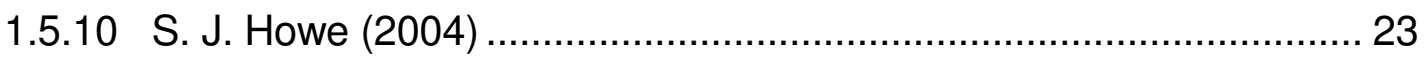

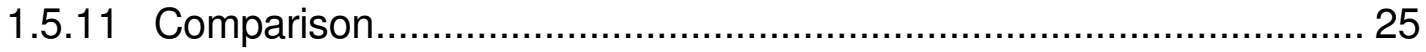

2. Modeling of STARS for Hydrate Dissociation

2.1 STARS Thermal Composition Simulator .............................................. 27

2.2 Design of a Hydrate Reservoir for Dissociation Simulations.................... 27

2.3 Construction of the Modeling Grid and Initialization of the Simulator ........ 28

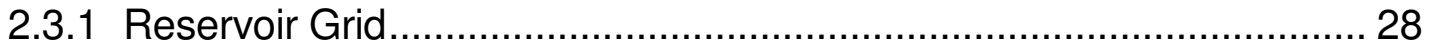

2.3.2 Temperature and Pressure............................................................. 29

2.3.3 Dissociation Reaction .................................................................. 30

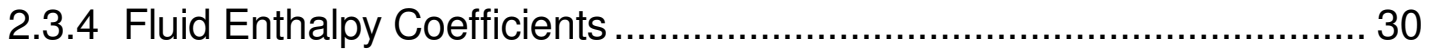

2.3.5 Relative permeabilities............................................................... 31

$2.4 \quad$ Production Wells and Completion ..................................................... 33

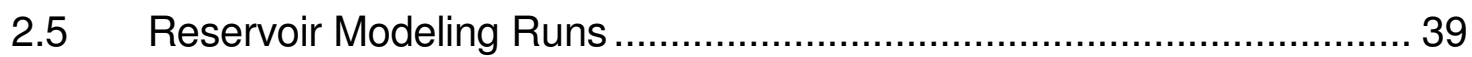

3. Results

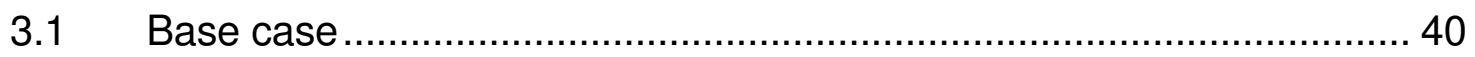

3.1.1 Gas In Place and Production.......................................................... 41

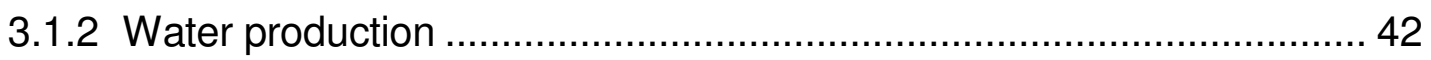

3.1.3 Pressure and temperature variation .................................................. 44

3.2 Effect of hydrates on total gas production ........................................ 45

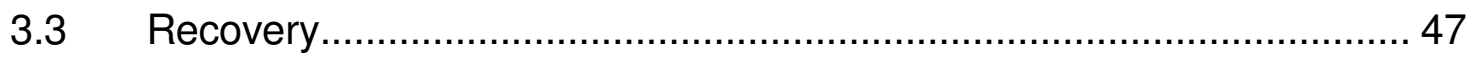

3.4 Effect of reservoir thickness .............................................................. 48

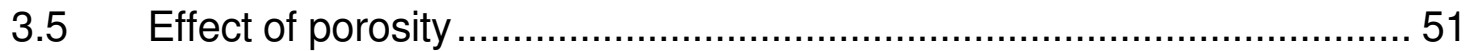



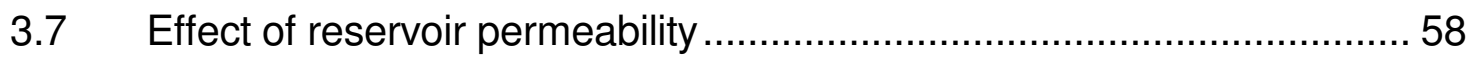

3.8 Effect of Hydrate Permeability ....................................................... 62 
4. Conclusion and Future Work

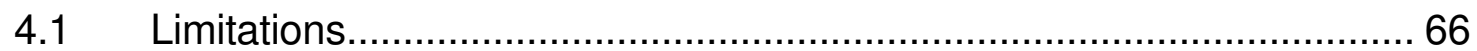

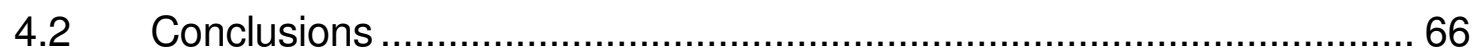

4.3 Recommendations for further work .................................................. 68

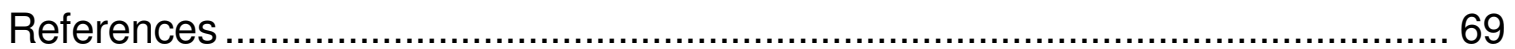




\section{List of Figures}

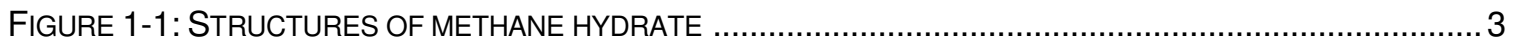

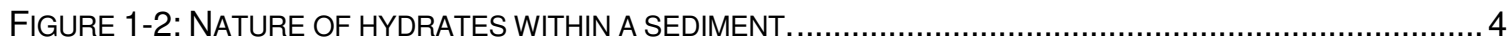

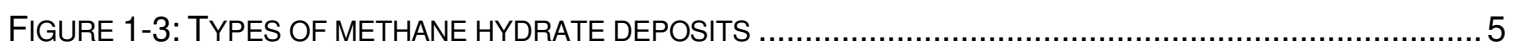

FiguRE 1-4: PRESSURE AND TEMPERATURE DEPENDENCE OF METHANE HYDRATE STABILITY .................... 5

FIGURE 1-5: WORLDWIDE HYDRATE POTENTIAL AREAS .................................................................

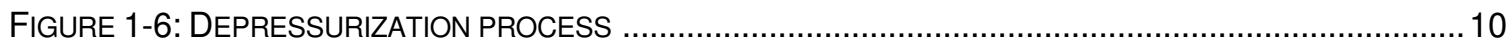

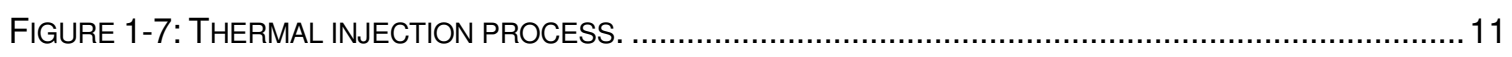

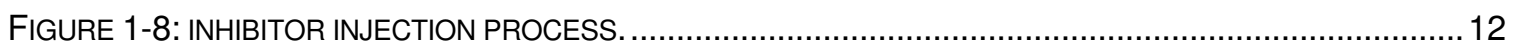

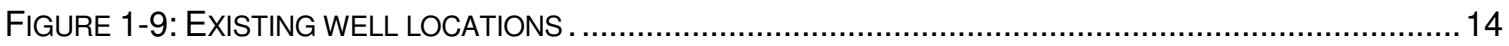

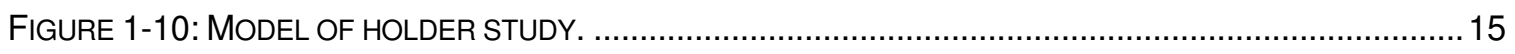

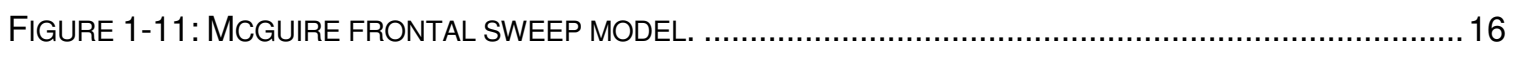

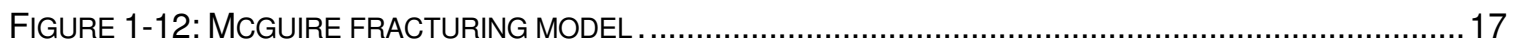

FIGURE 1-13: BAYLE'S SCHEMATIC OF THE CYCLIC STEAM INJECTION PROCESS ................................... 18

FIGURE 1-14: HYDRATE PHASE DIAGRAM ILLUSTRATING DISSOCIATION MECHANISMS ............................ 19

FIGURE 1-15: MODEL MATCH OF EXPERIMENTAL RESULTS ........................................................ 19

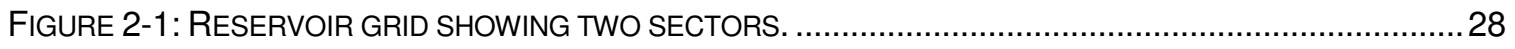

FIGURE 2-2: PRESSURE AND TEMPERATURE DEPENDENCE OF HYDRATE STABILITY ................................ 29

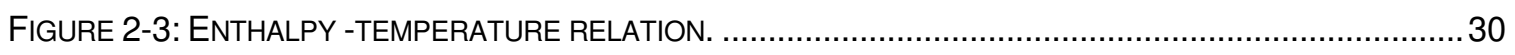

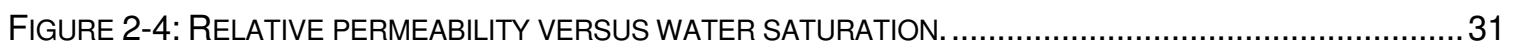

FIGURE 2-5: RELATIVE PERMEABILITY VERSUS LIQUID (HYDRATE) SATURATION. ................................... 32

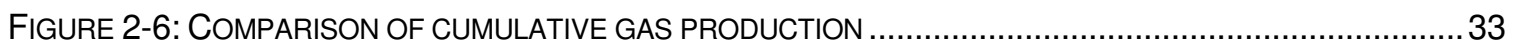

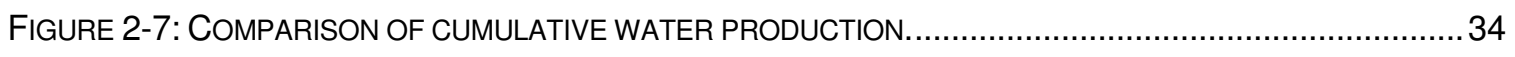

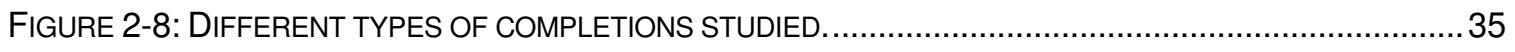

FIGURE 2-9: COMPARISON OF CUMULATIVE GAS PRODUCTION FOR DIFFERENT WELL COMPLETIONS. ......... 36

FIGURE 2-10: COMPARISON OF GAS PRODUCTION RATES FOR DIFFERENT WELL COMPLETIONS.................36

FIGURE 2-11: COMPARISON OF TOTAL WATER PRODUCTIONS FOR DIFFERENT WELL COMPLETIONS. ..........37 
FIGURE 2-12: COMPARISON OF WATER PRODUCTION RATES FOR DIFFERENT WELL COMPLETIONS.

FIGURE 3-1: SECTOR WISE CUMULATIVE GAS PRODUCTION VERSUS TIME (BASE CASE).. 41

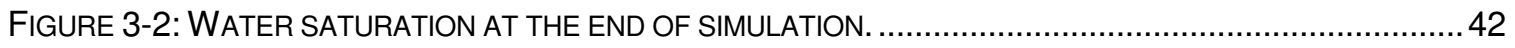

FIGURE 3-3: SECTOR WISE CUMULATIVE WATER PRODUCTION VERSUS TIME (BASE CASE)....................... 43

FIGURE 3-4: SECTOR WISE WATER VOLUME AS FUNCTION OF TIME (BASE CASE) ................................... 43

FIGURE 3-5: PRESSURE AND TEMPERATURE VARIATION WITH TIME (BASE CASE). ................................. 44

FIGURE 3-6: SECTOR WISE TEMPERATURE VARIATION WITH TIME (BASE CASE) .................................... 45

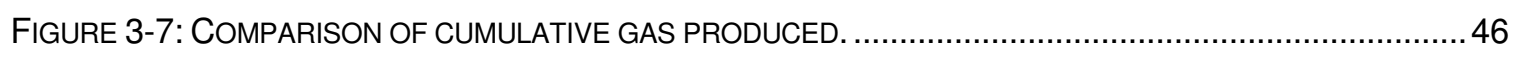

FIGURE 3-8: COMPARISON OF CUMULATIVE WATER PRODUCED...................................................... 46

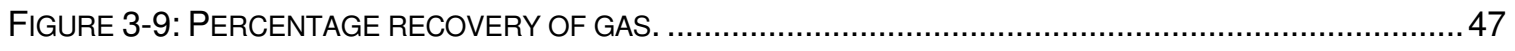

FIGURE 3-10: EFFECT OF RESERVOIR THICKNESS ON TOTAL GAS PRODUCTION. .................................... 48

FIGURE 3-11: EFFECT OF RESERVOIR THICKNESS ON SECTOR WISE GAS PRODUCTION........................... 49

FIGURE 3-12: EFFECT OF RESERVOIR THICKNESS ON GAS PRODUCTION RATE......................................50

FIGURE 3-13: EFFECT OF RESERVOIR THICKNESS ON TOTAL WATER PRODUCTION................................. 50

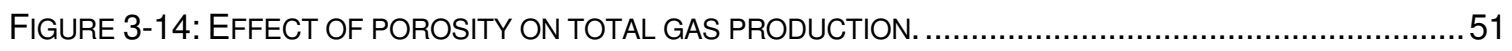

FIGURE 3-15: EFFECT OF POROSITY ON SECTOR WISE GAS PRODUCTION.......................................... 52

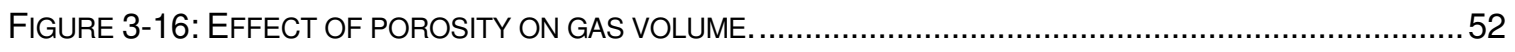

FIGURE 3-17: EFFECT OF POROSITY ON TOTAL WATER PRODUCTION. ............................................... 53

FIGURE 3-18: EFFECT OF WATER SATURATION ON TOTAL GAS PRODUCTION......................................... 54

FIGURE 3-19: EFFECT OF WATER SATURATION ON SECTOR WISE GAS PRODUCTION. ..............................55

FIGURE 3-20: EFFECT OF WATER SATURATION ON HYDRATE ZONE GAS PRODUCTION. .............................56

FIGURE 3-21: EFFECT OF WATER SATURATION ON TOTAL WATER PRODUCTION. ....................................57

FIGURE 3-22: EFFECT OF RESERVOIR PERMEABILITY ON TOTAL GAS PRODUCTION. ................................58

FIGURE 3-23: EFFECT OF RESERVOIR PERMEABILITY ON SECTOR WISE GAS PRODUCTION. .....................59

FIGURE 3-24: EFFECT OF RESERVOIR PERMEABILITY ON HYDRATE ZONE GAS PRODUCTION.....................60

FIGURE 3-25: EFFECT OF RESERVOIR PERMEABILITY ON TOTAL WATER PRODUCTION. ............................ 61

FIGURE 3-26: EFFECT OF RESERVOIR PERMEABILITY ON WATER PRODUCTION RATE............................... 61

FIGURE 3-27: EFFECT OF HYDRATE PERMEABILITY ON TOTAL GAS PRODUCTION ..................................... 62 
FIGURE 3-28: EFFECT OF HYDRATE PERMEABILITY ON HYDRATE ZONE GAS PRODUCTION. ....................... 63

FIGURE 3-29: EFFECT OF HYDRATE PERMEABILITY ON GAS ZONE GAS PRODUCTION. ................................64

FIGURE 3-30: EFFECT OF HYDRATE PERMEABILITY ON TOTAL WATER PRODUCTION. ...............................65 


\section{List of Tables}

TABLE 1-1: WORLDWIDE ESTIMATES OF GAS HYDRATES (IN TCF) BY COLLETT ....................................... 8

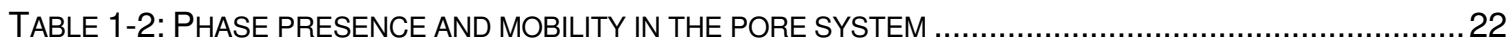

TABLE 1-3: RESERVOIR CHARACTERISTIC VALUES USED BY OTHER RESEARCHERS.................................24

TABLE 1-4: COMPARISON OF DEPRESSURIZATION HYDRATE MODELS. ................................................... 25

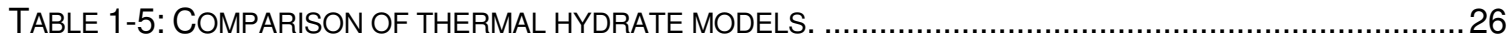

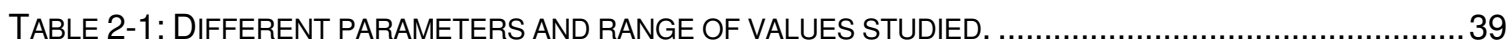

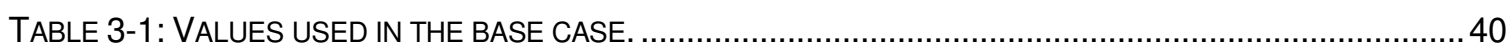

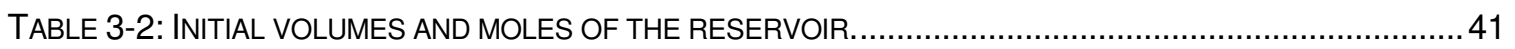




\section{Introduction}

Gas hydrates are crystalline solids consisting of gas molecules, usually methane, each surrounded by a cage of water molecules. Methane hydrates form naturally under conditions of high pressures and relatively low temperatures. Under these conditions, methane molecules are compressed into very tightly packed ice-crystal cages. The compact nature of the hydrate structure makes for highly effective packing of methane. A cubic volume of hydrate contains gas that will expand to somewhere between 150 and 180 cubic volumes at standard pressure and temperature.

Methane hydrates exist in large quantities in marine sediments in a layer several hundred meters thick directly below the sea floor and in association with permafrost in the Arctic. The pressures and relatively low temperatures allow high concentrations of methane to accumulate in the ice. Methane hydrates occur naturally in Arctic permafrost regions at depths greater than $200 \mathrm{~m}(656 \mathrm{ft})$, at ocean depths of $500 \mathrm{~m}(1,600 \mathrm{ft})$ or more where temperature hover near freezing point of water and the weight of the overlying water produces high pressures.

Interest in the potentially large deposits of natural gas hydrates ( globally $2 \times 10^{12}$ $\mathrm{TCF})^{[2,3]}$ and hydrate capped gas reservoirs is increasing because a conservative estimate of gas hydrate reserve potential of US exclusive economic zone is 200,000 Tcf. If $1 \%$ of this is recovered, that would be greater than the cumulative gas reserves of conventional gas sources (1000-1500 Tcf). Moreover, 1\% production of this recovered gas per year would make USA the exporter of gas.

However, there are significant practical and economic challenges to overcome before large scale production of hydrates could be considered. The US D.O.E ${ }^{[1]}$, realizing the value that hydrate production could contribute towards the nation's energy supply, is funding research to further understanding of hydrates and develop possible production techniques ${ }^{[4,5]}$. As an unproven process, a stepwise 
program of research and development is being undertaken. Currently, most work is based in the laboratory, except in the Mackenzie River delta of Canada's Northwest Territories where the world's first research well is drilled specifically to study the natural methane hydrate by the international consortium.

The objective of this work is to develop a model of a reservoir and study the effect of various reservoir properties on the production of gas from hydrate bearing reservoir. At present, little quantifiable data is published regarding the hydrate accumulations characteristics and no firm decision has been made to the exact location and size of the field. Accordingly, this study examines various scenarios of differing geologic characteristics, reservoir size and well configurations.

Section 1 contains the literature review to provide background information on gas hydrates and previous studies. Section 2 outlines the mathematical models that may be used to model the hydrate dissociation process, how a commercial reservoir simulator was modified to be able to model the process and a description of the proposed project and the data used to initialize the simulations is presented, with the output from the simulations discussed in section 3 . The conclusions and recommendations for further work are outlined in section 4 .

Note: within the thesis, any reference to 'hydrate(s)' refers to methane hydrates. 'Production of hydrates' is used as shorthand for the production of methane gas dissociated from hydrate accumulations. 'Gas' refers to methane gas. 


\section{Literature Review}

\subsection{The Nature of Gas Hydrates}

Gas hydrates are type of clathrates, with methane gas molecules trapped in a cage of water molecules. Methane hydrates form naturally under conditions of high pressures and relatively low temperatures. Under these conditions, methane molecules are compressed into very tightly packed ice-crystal cages. The compact nature of the hydrate structure makes for highly effective packing of methane. A cubic volume of hydrate contains gas that will expand to somewhere between 150 and 180 cubic volumes at standard pressure and temperature ${ }^{[3]}$.

\subsubsection{Types of Hydrates ${ }^{[6]}$}

The hydrates are grouped into two, due to their formation process.

1. Biogenic hydrates: These hydrates are formed by microbial activity in the upper several hundred meters of deep-sea sediment.

2. Thermogenic hydrates: These hydrates formed by thermal breakdown of organic material at greater depths.

Structure I Biogenic

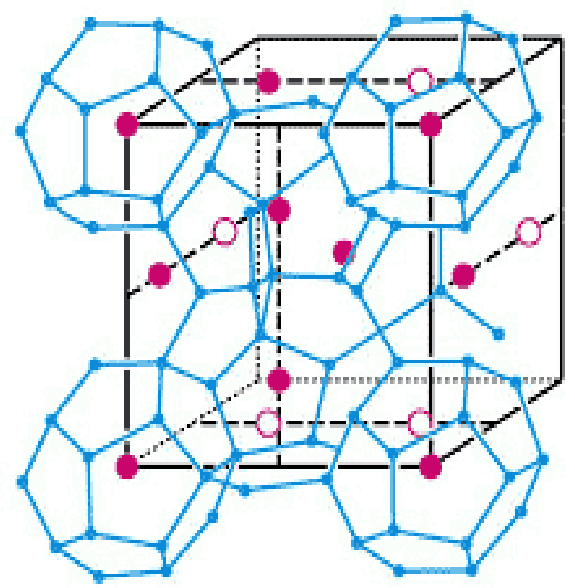

Structure II Thermogenic

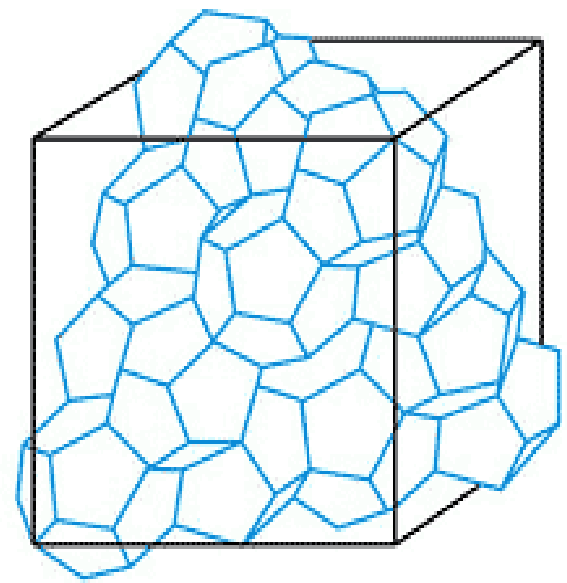

FigURE 1-1: STRUCTURES OF METHANE HYDRATE ${ }^{[6]}$. 


\subsubsection{Nature of Hydrate Accumulations in the Field}

Gas hydrate can be found as nodules, laminae, or veins within a sediment as shown in Figure 1-2.

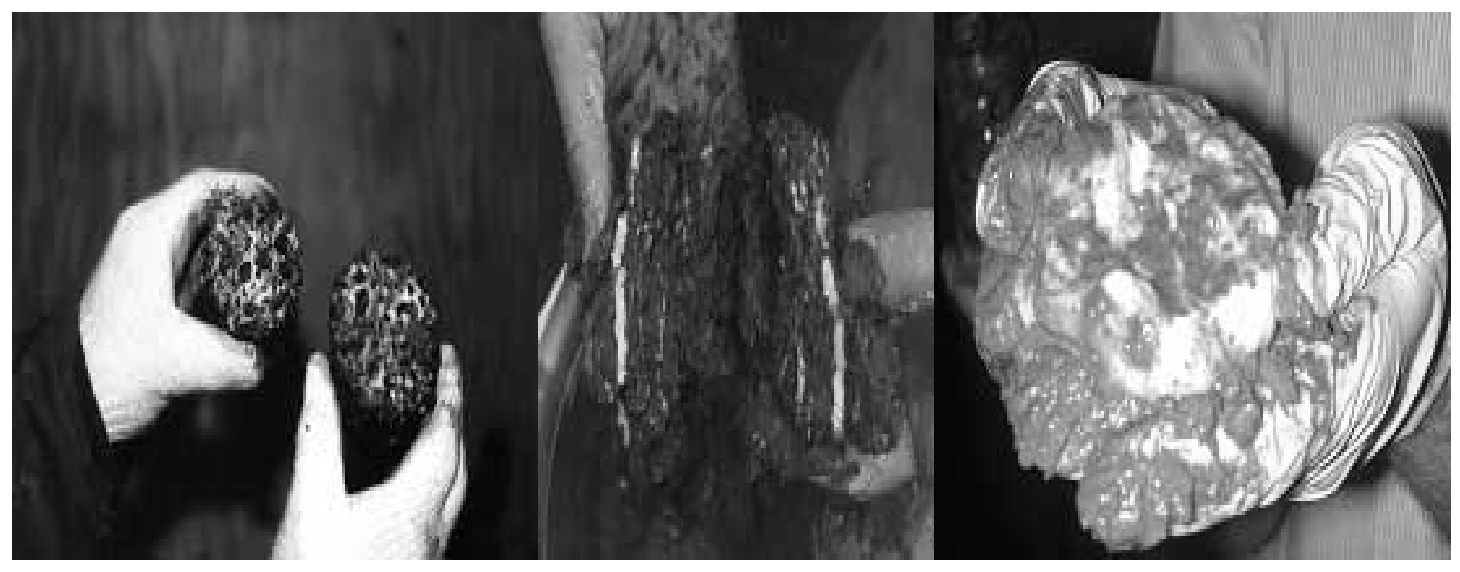

FIGURE 1-2: NATURE OF HYDRATES WITHIN A SEDIMENT ${ }^{[1,6]}$.

\subsubsection{Hydrate Stability Conditions}

Methane hydrates exist in large quantities in marine sediments in a layer several hundred meters thick directly below the sea floor and is association with permafrost in the Arctic. The pressures and relatively low temperatures allow high concentrations of methane to accumulate in the ice. Methane hydrates occur naturally in Arctic permafrost regions at depths greater than $200 \mathrm{~m}$ (656 ft). At ocean depths of $500 \mathrm{~m}(1,600 \mathrm{ft})$ or more where temperature is around freezing and the weight of the overlying water produces high pressures as shown in Figure 1-3. The depth, pressure and temperatures dependence of hydrate stability regions is shown in Figure 1-4. 


\section{Types of Gas Hydrate Deposits}

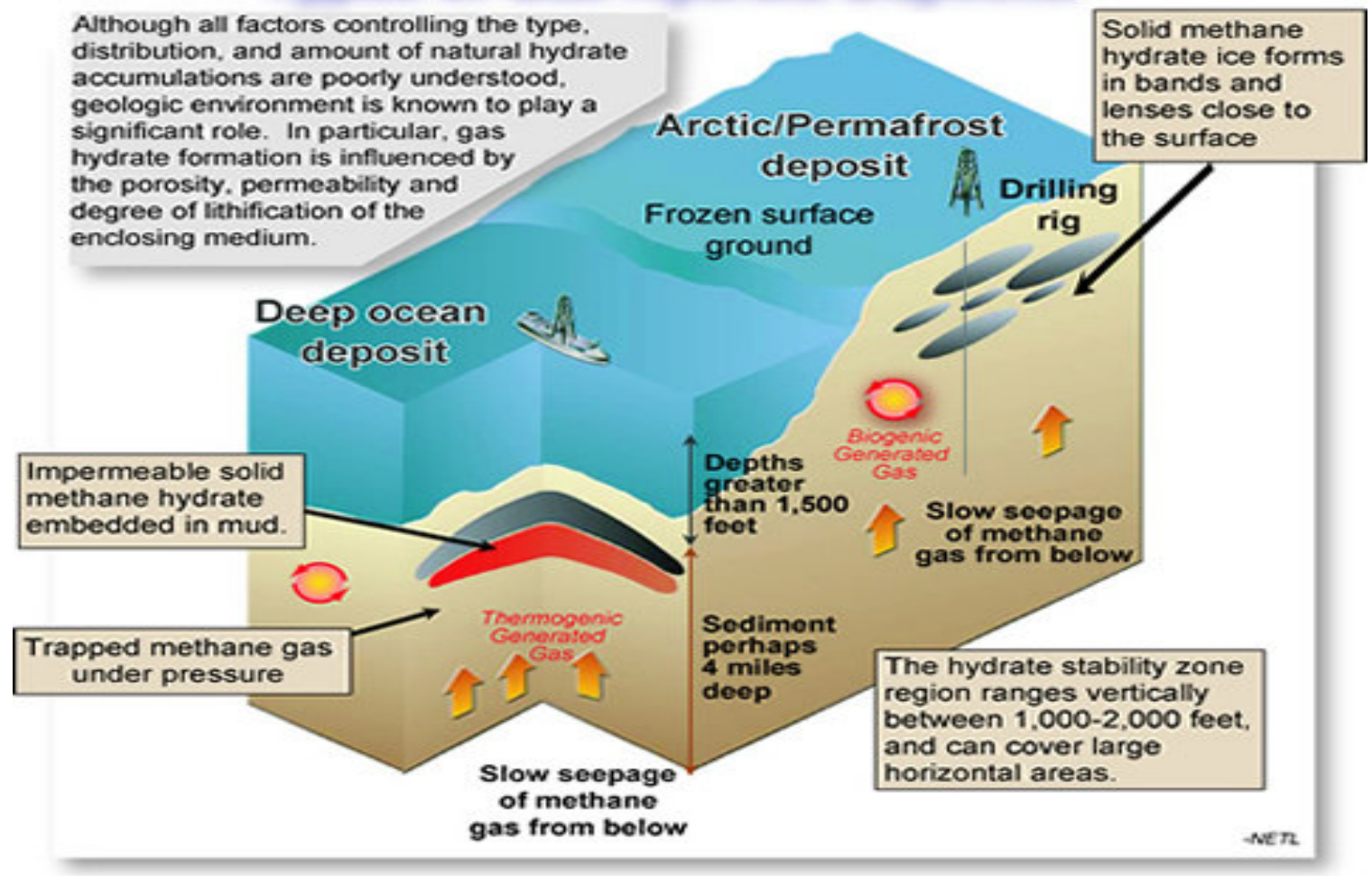

FIGURE 1-3: TYPES OF METHANE HYDRATE DEPOSITS ${ }^{[1]}$.

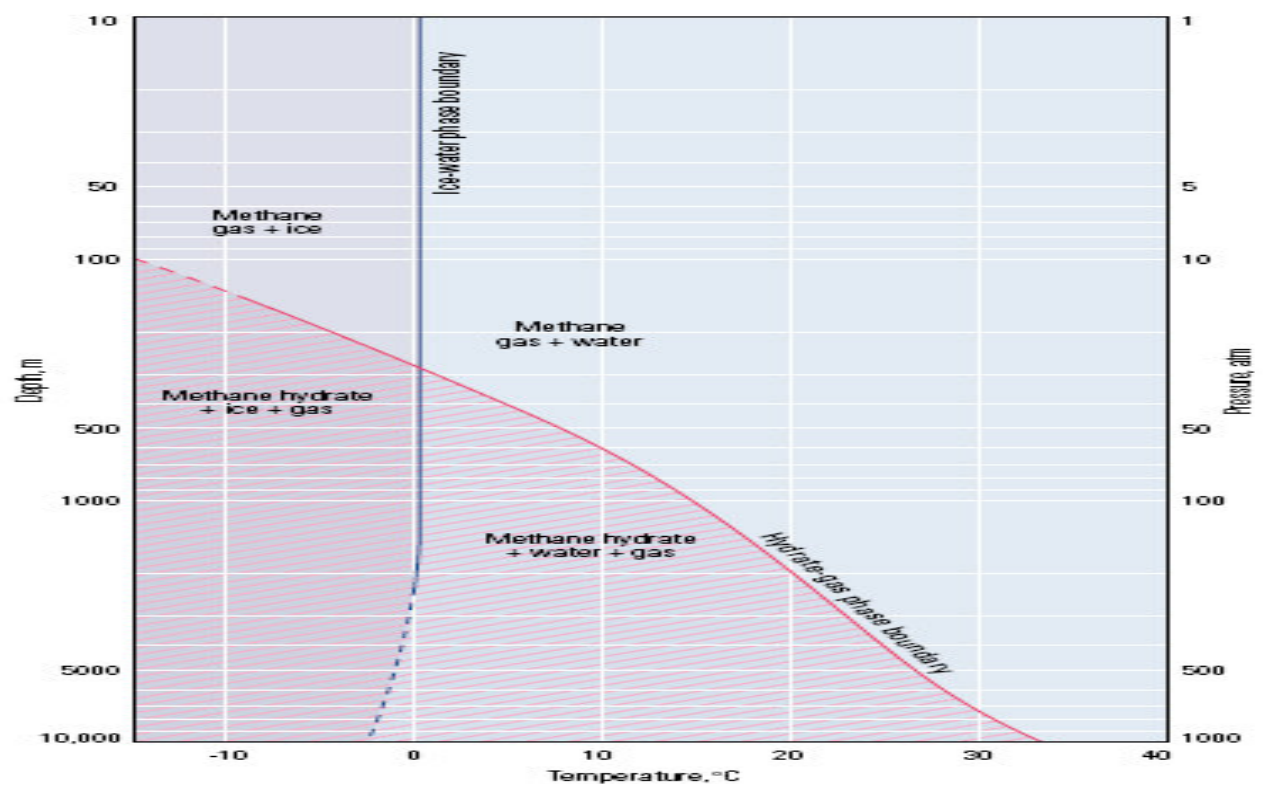

FIGURE 1-4: PRESSURE AND TEMPERATURE DEPENDENCE OF METHANE HYDRATE STABILITY ${ }^{[8]}$. 


\subsection{A Brief History of Gas Hydrate Study ${ }^{[1]}$}

Hydrates or clathrates in broader sense were first discovered in the early $1800 \mathrm{~s}$ during a scientific study by Humphrey Davy and Michael Faraday on chlorine and water. Interest in the study of hydrates arose when in the 1930s, E.G. Hammerschmidt determined that they are responsible for plugging of natural gas pipelines, particularly those located in cold environments. Subsequent studies and work was development of chemical additives and other methods to inhibit the hydrate formation. Drilling through hydrate regions resulted in large amounts of gas being evolved due to rapid dissociation of hydrates because of reduction in pressure and heat from drilling fluid and leading to devastating blowouts.

Global view on hydrates changed in the 1970s when solid methane gas was discovered in the subsurface of Messoyahka fields in Western Siberian basin above a free gas reservoir, which resulted in increased and longer production than anticipated indicating contribution of gas from hydrate dissociation due to pressure reduction. In the mid 1970s, it was speculated that low temperature and highpressure conditions necessary for hydrate formations exist around the globe not only in permafrost regions but also in deep oceans. In the early 1980s, the research vessel Glomar Challenger traveled the globe collecting cores as a part of tests. Many of the samples found chemical evidence of methane hydrates. During this time many authors had made efforts to numerically model the hydrate dissociation. Although restricted to simple models, the results of the simulations suggested production of gas could be feasible.

Large energy needs and limited domestic energy prompted many countries like U.S.A, Japan and India to begin aggressive hydrate programs in preparation for commercial production of methane. An international consortium was formed with scientists from various countries and work began in McKenzie River delta in North Western Canada. The success of first test well ${ }^{[7,9,10]}$ (Mallik-1) in 2002 confirmed the technical feasibility of methane production from hydrates. In early 2004, 15 
wells including one horizontal well were drilled by Japan and the results continue to be analyzed. In the recent years, widespread availability of computers and increased computing power has contributed to a remarkable growth in the complexity and the scope of numerical models used to study hydrates.

\subsection{Formation and Extent of Gas Hydrates}

\subsubsection{Reserves}

The conditions required for hydrate formation and stability are found in artic permafrost regions, deep marine floors of the outer continental shelf and shallow marine floors in artic areas. Worldwide hydrate potential areas are shown in Figure 1-5 and reserve estimates by region are given in Table 1-1.

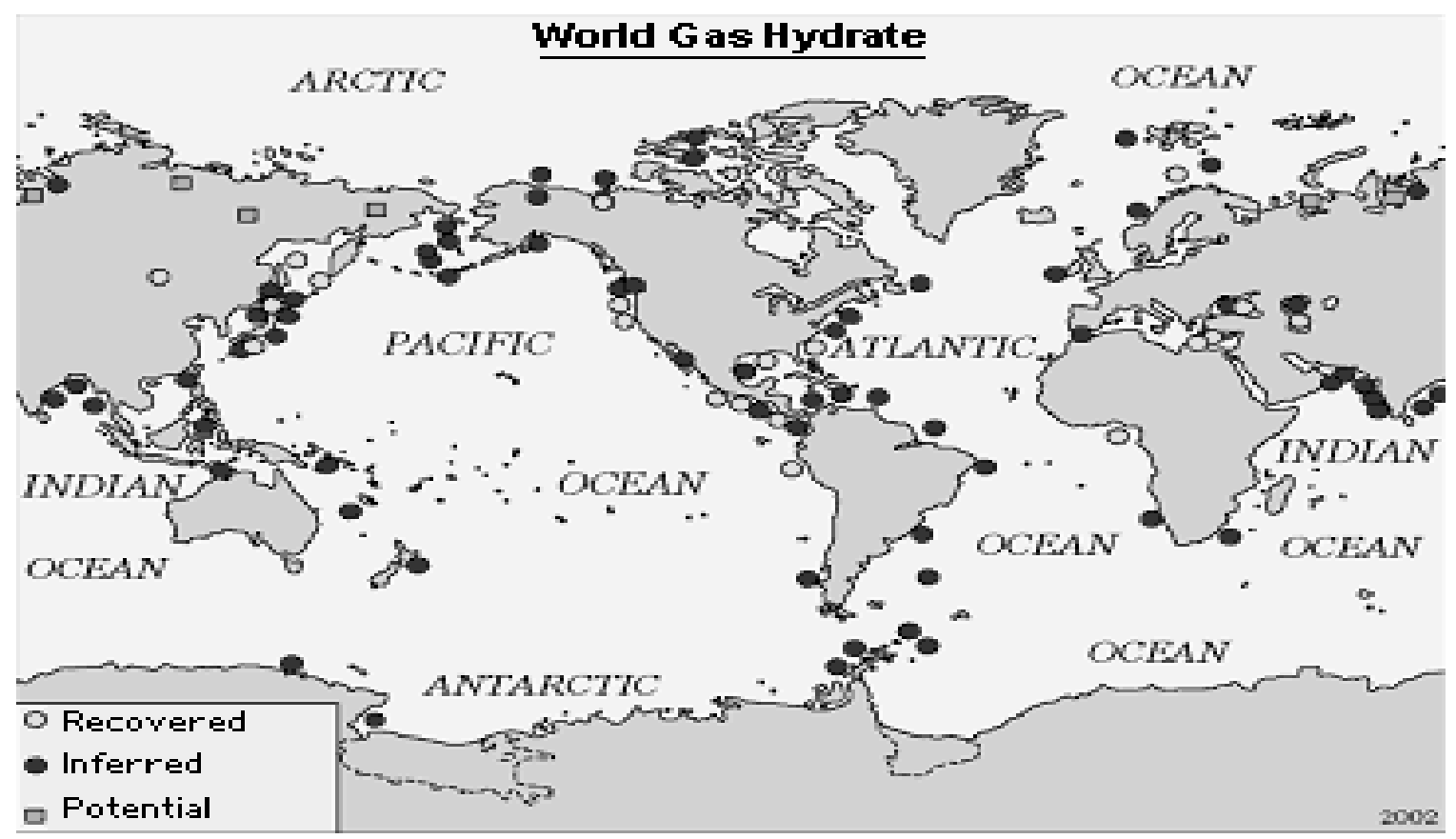

FIGURE 1-5: WORLDWIDE HYDRATE POTENTIAL AREAS ${ }^{[11]}$. 


\begin{tabular}{|l|l|}
\hline Hydrate Potential & Value, Tcf \\
\hline World - Oceanic Hydrate Potential & 30,000 to $49,100,000 \times 10^{12}$ \\
\hline World - Continental Hydrate Potential & 5,000 to $12,000,000 \times 10^{12}$ \\
\hline United States Hydrate Potential & $1,331 \times 10^{12}$ \\
\hline Alaska Hydrate Potential & $590 \times 10^{12}$ \\
\hline India Hydrae Potential & $4,307 \times 10^{12}$ \\
\hline Japan Hydrate Potential & $1,765 \times 10^{12}$ \\
\hline World Conventional Gas Resources & $13,000 \times 10^{12}$ \\
\hline
\end{tabular}

TABLE 1-1: WORLDWIDE ESTIMATES OF GAS HYDRATES (IN TCF) BY COLLETT ${ }^{[2]}$.

The amount of gas in the hydrate reservoirs worldwide exceeds the volume of known conventional gas resources. Recoverability of even a fraction of this would still be of great importance especially because of the world's increasing demand.

\subsubsection{Detection of Hydrates ${ }^{[1,12,13]}$}

Presence over large areas can be detected by acoustical methods, using seismicreflection profiles. Hydrate has a very strong effect on acoustic reflections because it has a high acoustic velocity (approximately $3.3 \mathrm{~km} / \mathrm{s}$ - about twice that of seafloor sediments), and thus grains cemented with hydrate produce a high-velocity deposit due to the mixing of hydrate with the sediment. Seismic reflection surveys are the most promising technology for a quick and accurate appraisal of large areas of the deep oceans. Scientists use sound waves to image the structures and properties of the Earth's interior. For decades, industry has conducted seismic surveys to identify promising subsurface geologic structures that may hold oil and gas. During the earlier stages of hydrate science, the bottom-simulator reflectors (BSR) were used as an indicator of hydrate presence. The BSR was known to coincide roughly with the base of the hydrate stability zone, and is a common feature of deepwater sediments. However, BSRs are now considered to have minimal diagnostic value, indicating only a horizon across which some percentage (potential very small) gives way to some percentage (perhaps equally small) of free methane. Seismic detection of hydrate is based on the fact that hydrate, in sufficient concentration, will stiffen the sediment, thereby altering the velocity at which seismic energy is transmitted. 
However compelling geophysical and geochemical evidence may be, it still provides only indirect indications of the properties of the subsurface. In order to truly know what is there, and to provide proper calibration for seismic studies, scientists must actually collect samples. The most common method of sampling the deep ocean is through piston coring. More often, however, the hydrate dissociates into free methane and water while the core is pulled up to the ship deck. As a result, scientists use sophisticated geochemical analyses of the remaining pore fluids to determine the quantity of hydrate originally present. Many researchers like Carolyn Ruppel ${ }^{[14]}$, John Toon ${ }^{[15]}$ and Jean Laherrere ${ }^{[16]}$ questioned the practicality of detection, production techniques and the consequences and problems associated with the production of gas from gas hydrates. 


\subsection{Production of Hydrates Using Conventional Technology}

Methane can be produced from hydrates either by changing the environment (pressure and temperature) surrounding the hydrate or introducing inhibitors to alter the hydrate stability. Three widely accepted mechanisms - depressurization, thermal injection, adding chemical inhibitor have been discussed.

\subsubsection{Depressurization}

Many researchers have indicated depressurization as a practical method. Gas from hydrates is produced by reducing the pressure in the well bore or formation below the hydrate stability pressure as shown in Figure 1-6. This approach has the advantage of using the most common existing production technologies and requires no energy input to the reservoir. This method is feasible only when associated free gas can be produced to decrease hydrate reservoir pressure. However, because of low permeabilities of hydrate accumulations, dissociation occurs only at the boundary between the gas and hydrates. In order to increase the production, this method could be coupled with others.

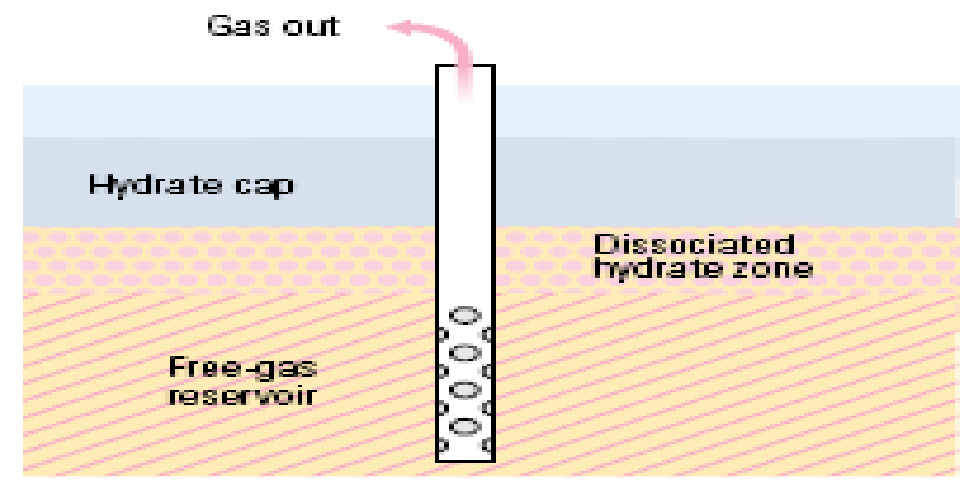

Deprassurization

FIGURE 1-6: DEPRESSURIZATION PROCESS ${ }^{[8]}$. 


\subsubsection{Thermal Injection ${ }^{[17]}$}

Hot fluid (steam or brine) is cyclically injected into the hydrate formation to cause dissociation as shown in Figure 1-7. In order to force hot fluids to the undissociated hydrate face, the dissociated formation would need to be flooded. At least a portion of this water must be removed to restore permeability to gas flow if gas is to be produced using this approach.

While this method should effectively dissociate gas hydrate, a source of excess heat is required to maintain economic viability. Such a heat source could include the produced water from nearby conventional oil operations or heating and reinjecting the produced water. The efficiency of this process is discussed by McGuire ${ }^{[25]}$ and Bayles ${ }^{[27]}$.

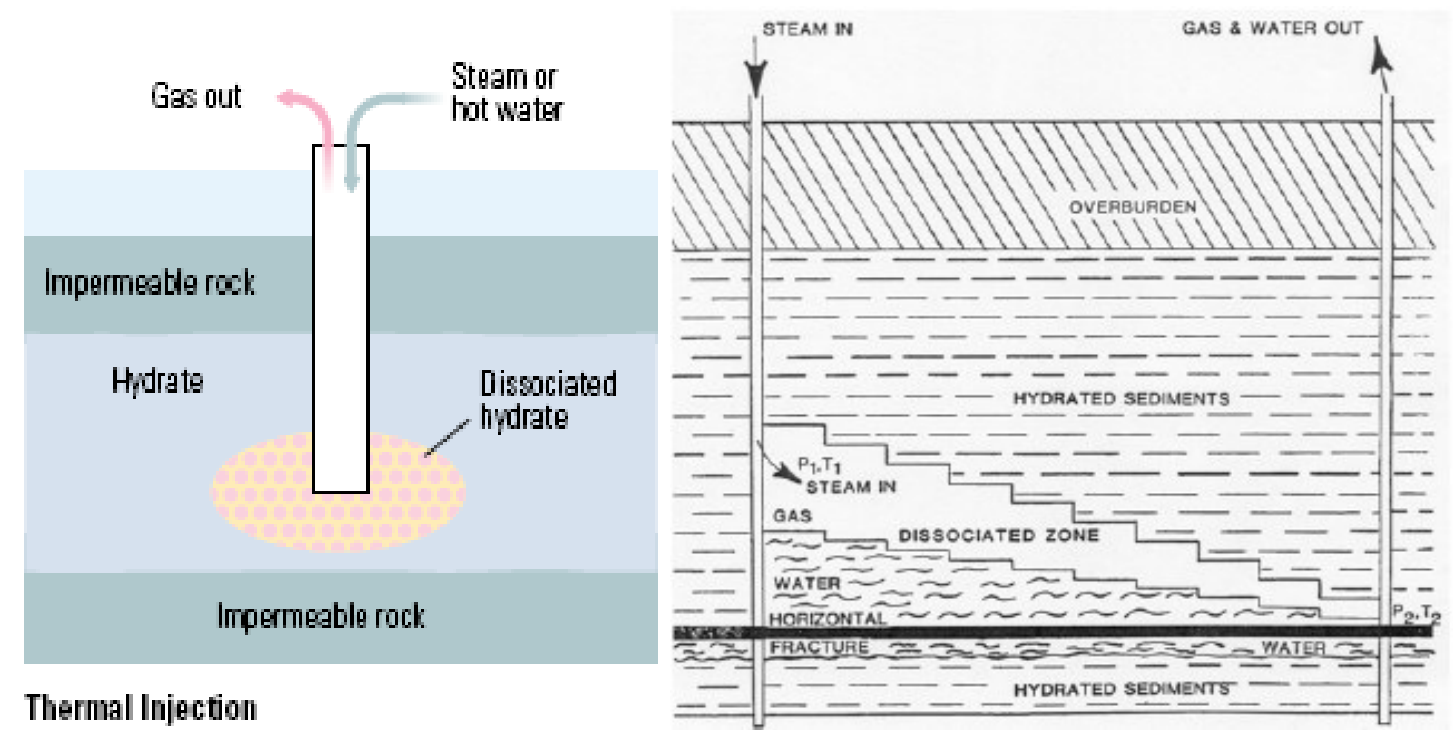

FIGURE 1-7: THERMAL INJECTION PROCESS ${ }^{[8]}$.

Islam $(1991)^{[18]}$ suggested introducing alternative energy source in the form of electromagnetic heating equipment in the wellbore or direct heating using down hole heaters though there are questions on the practicality of this approach. Once heated, the reservoir may be put under depressurization in order to produce gas by expansion. 


\subsubsection{Inhibitor Injection}

Injection of inhibitors ${ }^{[19]}$ such as methanol or glycol shifts the pressure-temperature equilibrium so that the hydrates are no longer stable at their normal conditions and methane is released as shown in Figure 1-8. This method is both expensive and could lead to such rapid dissociation of gas hydrates that fracturing of adjacent shales could occur, breaching the reservoir. While inhibitor injection might be used to initiate production from a gas hydrate reservoir, it is unlikely that it could be used on an on-going basis.

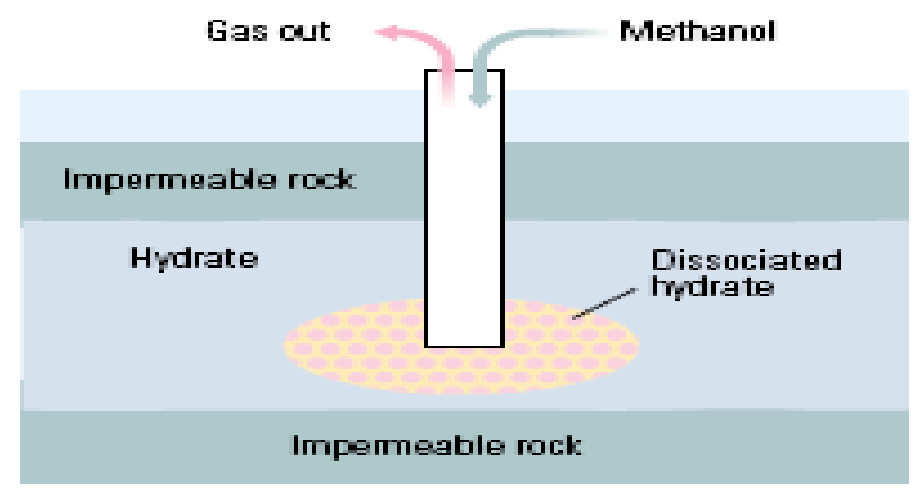

Inhibitor Iniection

FIGURE 1-8: INHIBITOR INJECTION PROCESS ${ }^{[8]}$.

Robert Hunter ${ }^{[20]}$ and McGrail ${ }^{[21]}$ suggested $\mathrm{CO}_{2}$ injection similar to that used in heavy oil reservoirs. Carbon dioxide can replace methane in the hydrate structure, and its heat of formation exceeds the heat lost in the dissociation of methane hydrate. It is not clear that such replacement is viable for entire reservoirs, and $\mathrm{CO}_{2}$ injection would require a source of $\mathrm{CO}_{2}$. The final production approach would involve the physical removal of the gas hydrate - essentially strip mining the seafloor. This approach is both economically unfeasible and environmentally unsound. The $\mathrm{CH}_{4}-\mathrm{CO}_{2}$ exchange mechanism was slow with induction times requiring several days. In addition, recovered methane would be contaminated with significant amounts $\mathrm{CO}_{2}$ that would have to be removed by cryogenic distillation or some other energy intensive separations method. It appears highly 
unlikely that practicable gas hydrate production can be accomplished using the method.

\subsubsection{Drilling through Hydrates ${ }^{[15,16,22]}$}

Production of gas from hydrate bearing reservoirs is difficult and dangerous at times due to the following:

i. The gas hydrates pose a potential threat to the safety of drilling platforms by triggering mass failure and landslides.

ii. There are substantial direct observational evidence that major seafloor collapses, submarine slides, and drilling hazards are linked to the presence of hydrate.

iii. The loss of seafloor equipment in industry drilling operations suggests that hydrate breakdown may have been a contributing cause.

iv. Hydrate processes influence seafloor stability by causing substantial changes in the physical properties of shallow sediments.

Gas recovery from hydrates is hindered because they occur as a solid in nature and are commonly widely dispersed in hostile Arctic and deep marine environments. Current technical issues and costs prohibit the recovery of these hydrates in an economical manner. Production of gas from a hydrate zone will require technology to produce from mostly unconsolidated formations that can be expected to collapse and flow when hydrates melt or dissociate. 


\subsubsection{Existing Wells ${ }^{[1]}$}

The existence of natural methane hydrate is inferred only from indirect evidence obtained through geophysical surveys or geochemical analyses of sediment samples. However, there are a growing number of sites where detailed information is being collected. Each of these localities, with their own unique geologic settings, is unveiling surprising information that questions the initial theories of hydrate formation and ultimately advances the general state of knowledge of natural gas hydrate. The major drilling sites are:

i. Messoyahka gas field in the northern West Siberian basin.

ii. Prudhoe bay-Alaska.

iii. Mallik 2L-38 well in Northern Canada.

iv. ODP Leg 164 wells at Blake Ridge on the Atlantic coast.

v. Keathley Canyon.

vi. Atwater Valley-within the Mississippi valley channel.

The existing well sites with major operations are shown in Figure 1-9.

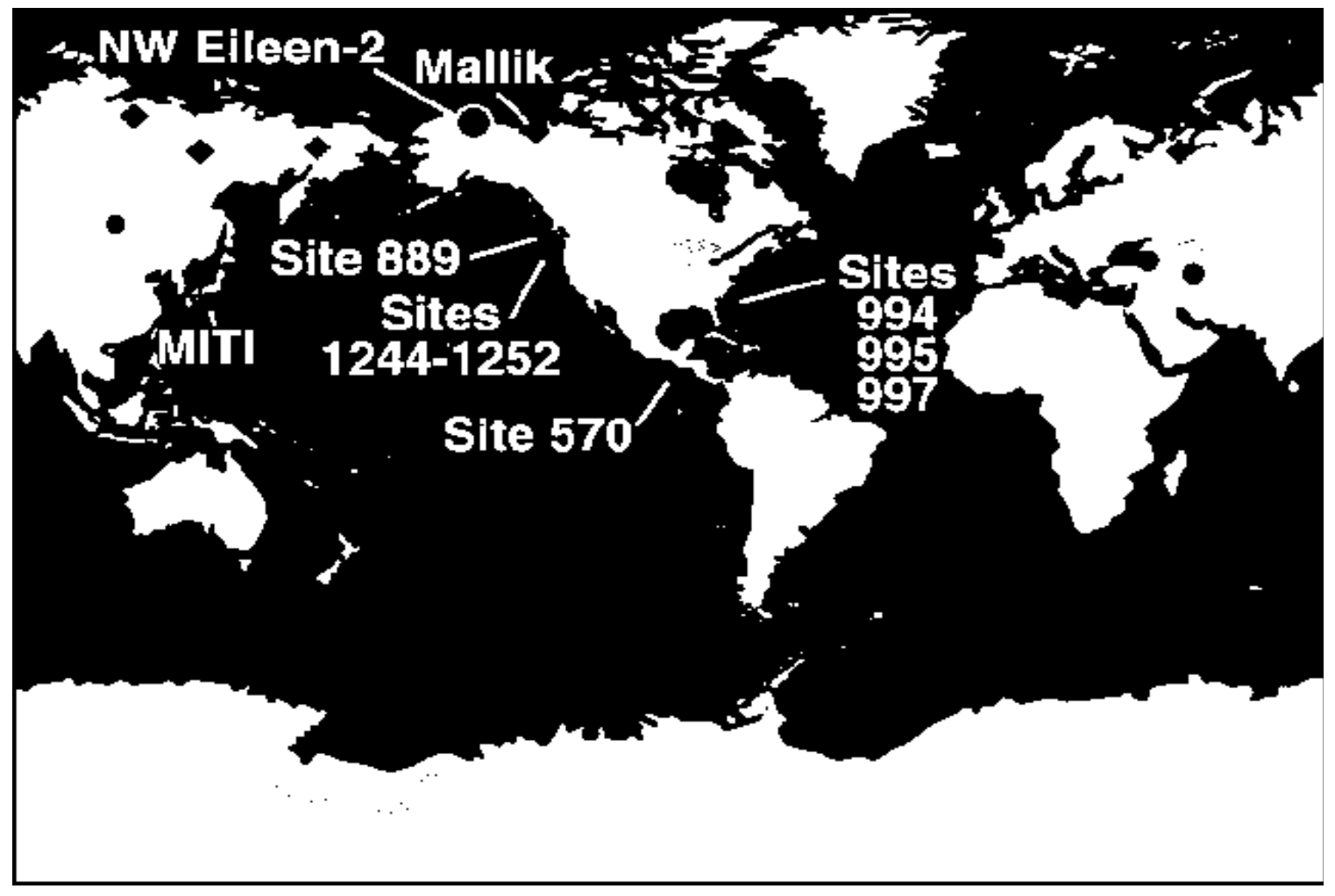

FIGURE 1-9: EXISTING WELL LOCATIONS ${ }^{[11]}$. 


\subsection{Existing Hydrate Dissociation Models}

Around 30 different models have been proposed over the last 50 years. The models have made a significant contribution towards the development of a practical, realistic, simulation model for hydrate gas production. Each model has focused on specific characteristics of the dissociation, migration, and production of methane from gas hydrates. Several models are discussed here in a chronological order to provide a historical perspective.

\subsubsection{Holder and Angert (1982) ${ }^{[23,24]}$}

In this model, one of the first to be developed and reported, a three-dimensional finite difference single-phase gas simulator was modified to simulate the production of gas from a hydrate zone adjacent to a conventional 250 acre, $100 \mathrm{ft}$ thick gas reservoir. The reservoir had equal thickness of gas and hydrate zones as shown in Figure 1-10 with a $15 \%$ porosity and 44-md permeability. 10-20 kilocalories (kcal) of heat energy must be added to the hydrate phase for each mole of dissociated methane. In their study, the recovery method used the sensible heat of the hydrate reservoir to provide energy necessary for the hydrate dissociation. Heat transfer by conduction was modeled within and adjacent to the conventional gas reservoir. Their study predicted that the hydrates near the well dissociate more rapidly and after a period of dissociation, the depth of the hydrategas interface would increase as the radial distance from the well increases and the production rate has very little effect on the cumulative production.

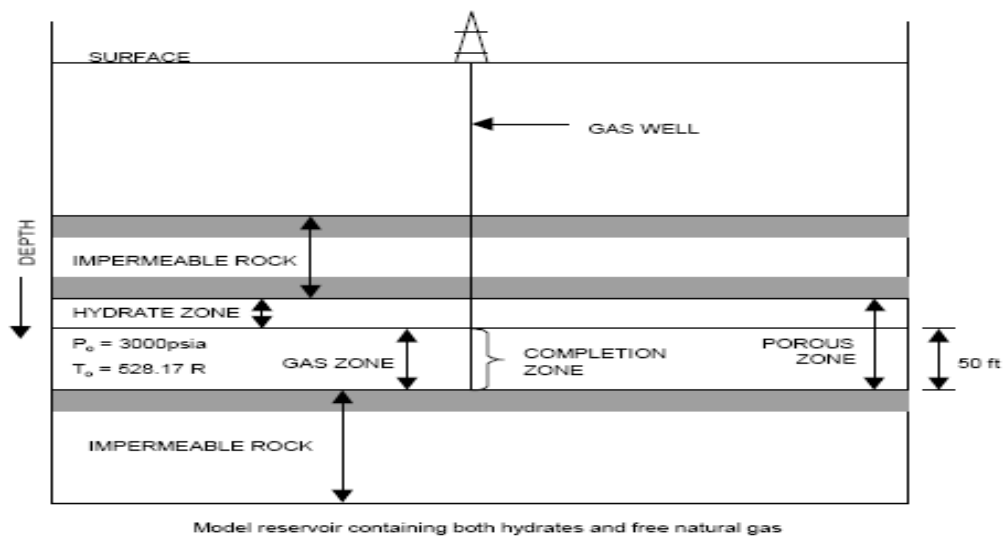

FIGURE 1-10: MODEL OF HOLDER STUDY ${ }^{[23]}$. 


\subsubsection{McGuire (1982) ${ }^{[25,26]}$}

This study examines two methods of producing gas from hydrate deposits by hot water or steam injection and the feasibility of hydraulic fracturing and assumes no free gas present either above or below the hydrates. Due to large amounts of energy (212 Btu/lb) required to dissociate the hydrate, McGuire asserted that thermal simulation technique might be required for commercial production.

In the first method, 30,000 bpd of hot water at $150^{\circ} \mathrm{F}$ was injected in the central well and the gas from the hydrates dissociated is produced through the surrounding wells (Figure 1-11). He assumed high permeability of hydrates, which was acknowledged later as untrue. The heat losses to the surroundings, recombination into hydrates by the gas during migration towards the production well, low permeabilities, low thermal efficiency were the limitations of this study.

In order to overcome the above limitations, fracturing of the wells was proposed and pumping hot supersaturated $\mathrm{CaCl}_{2}$ (Figure 1-12). The hot salt will first create a path by dissociating the hydrate along the way. As the salt cools, excess salt precipitates from the solution and together with salt proppant added would prevent the flow path from refreezing even if it is considerably diluted by the water released from the hydrate dissociation. He also suggested combining both methods.
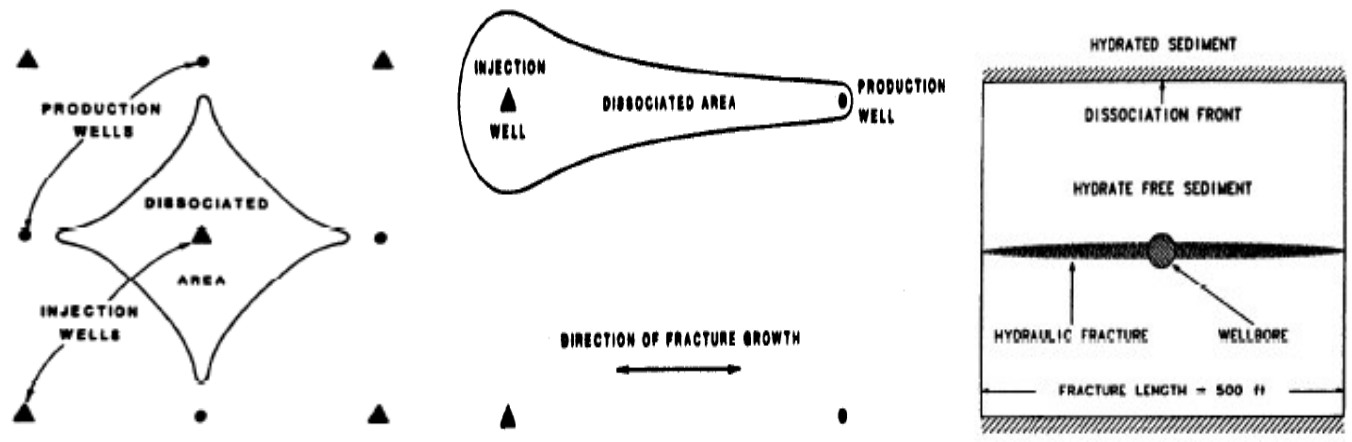

FIGURE 1-11: MCGUIRE FRONTAL SWEEP MODEL ${ }^{[25]}$. 


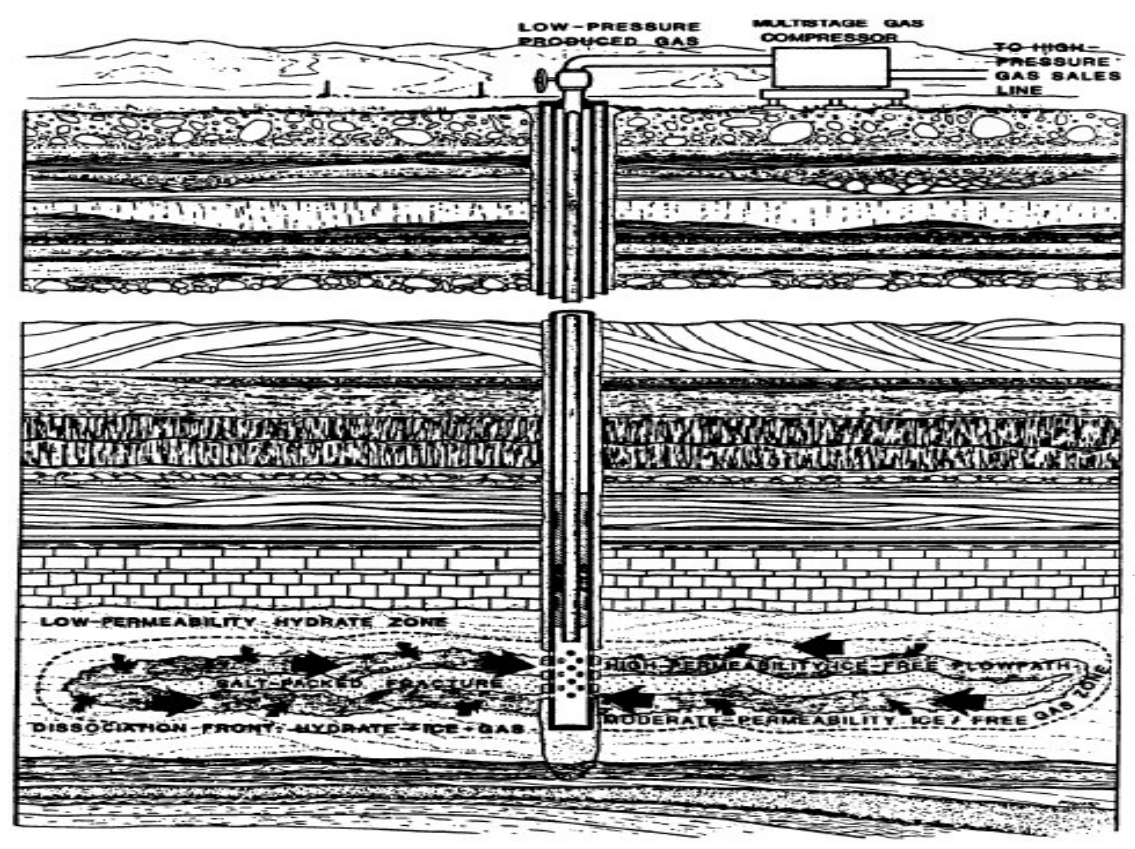

FIGURE 1-12: MCGUIRE FRACTURING MODEL ${ }^{[25]}$.

\subsubsection{Bayles (1986) ${ }^{[27]}$}

A thermal analytical model for steam cycling in a single well (Figure 1-13) was developed to study the upper and lower bounds on the energy efficiency ratio for various reservoir parameters. The three-stage process consisted of injection, soaking and production phases. Heat losses to surroundings were considered and the permeability of the dissociated zone was assumed sufficient to permit the steam injection and gas production. For the lower bound efficiency, it is assumed that the heat is conducted to the cap and the base rock during the soak phase. The upper bound efficiency is obtained by assuming no soak phase. Their study concluded that steam cycling might be a feasible production technique. 


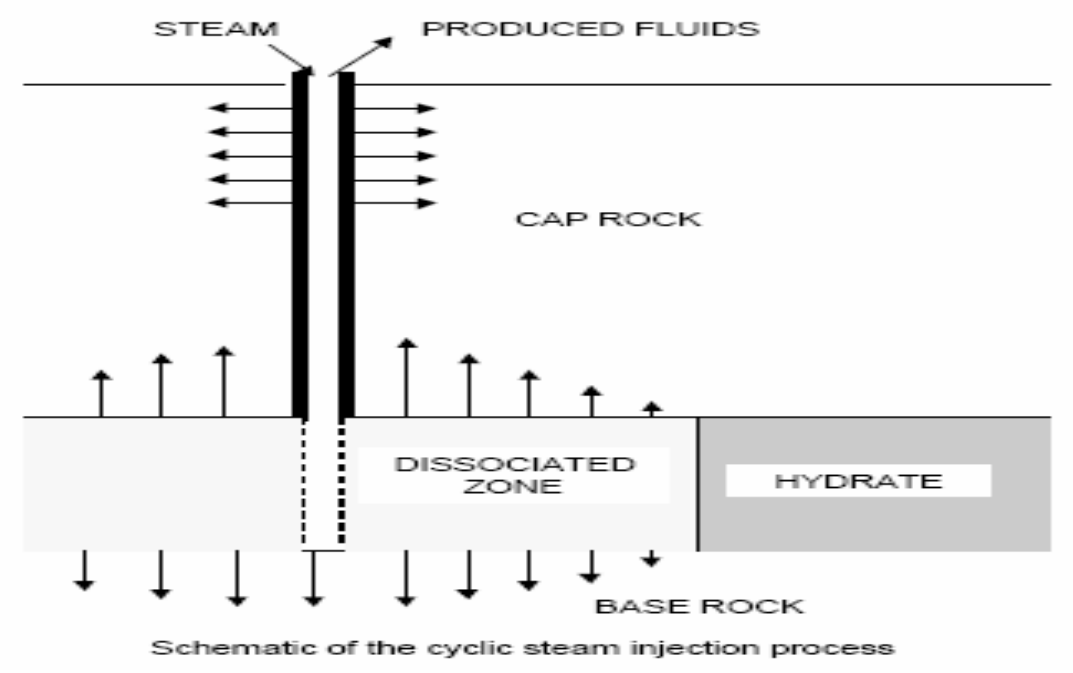

FIGURE 1-13: BAYLE'S SCHEMATIC OF THE CYCLIC STEAM INJECTION PROCESS ${ }^{[27]}$.

\subsubsection{Burshears et al. (1986) ${ }^{[28]}$}

A three-dimensional, two-phase gas-water simulator was used to study the hydrate dissociation above a free gas zone. A radial flow single well at the center of the reservoir is assumed. The model was used to simulate the dissociation of various hydrate bearing formations by varying total thickness $(30-80 \mathrm{ft})$, initial pressure (40-4000 psi), initial temperature $\left(32-90^{\circ} \mathrm{F}\right)$, hydrate permeability $(15-30 \mathrm{md})$ and reservoir permeability (15-100 md). The hydrate dissociates and cools the reservoir until the gas pressure reaches the equilibrium value at the new (colder) temperature. The resulting temperature gradient causes the flow of heat toward the gas-hydrate interface. It was concluded that depressurization is a feasible method for the production of gas from hydrate bearing formations and external energy is not required as the sensible heat of the reservoir provides the energy needed for dissociation. The produced gas-water ratios were not found to be high despite the volumes of water produced during the dissociation. However, it was cautioned that in reservoirs at near $32^{0} \mathrm{~F}$, the dissociated water might freeze, blocking the flow of gas. For that reason, Burshears suggested to use this method only in reservoirs deeper than $2300 \mathrm{ft}$, where the geothermal gradient results in higher ambient reservoir temperatures. Gas hydrate phase diagram illustrating the dissociation mechanism is shown in Figure 1-14. 


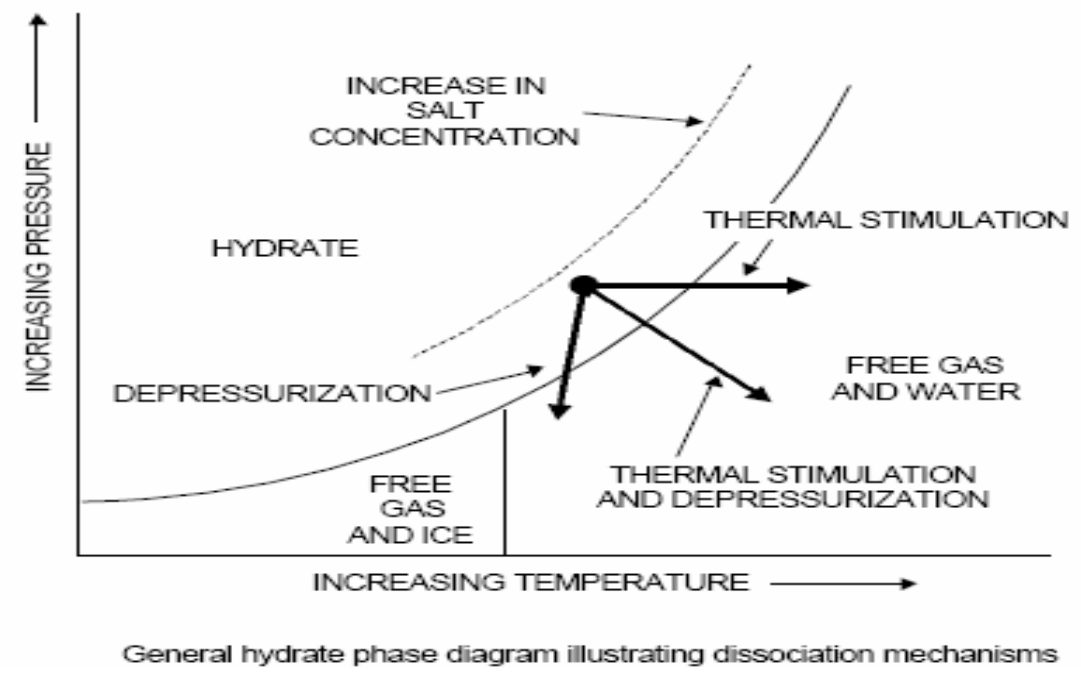

FIGURE 1-14: HYDRATE PHASE DIAGRAM ILLUSTRATING DISSOCIATION MECHANISMS ${ }^{[28]}$.

\subsubsection{Yousif et al. (1990) ${ }^{[29]}$}

A one-dimensional, three-phase (gas-water-hydrate), finite difference numerical simulator was developed to validate the actual laboratory experiments on gas production from hydrate in a Berea sandstone sample. The experimental setup consisted of a $15.2 \mathrm{~cm}$ long and $1.3 \mathrm{~cm}$ diameter cylindrical core with $18.8 \%$ porosity and 100-md permeability. The core had an initial water saturation of $17 \%$ and the experiments were conducted at a temperature of $33.5^{\circ} \mathrm{F}$ and an initial pressure of 460 psi. The results were in good agreement as shown in Figure 1-15.

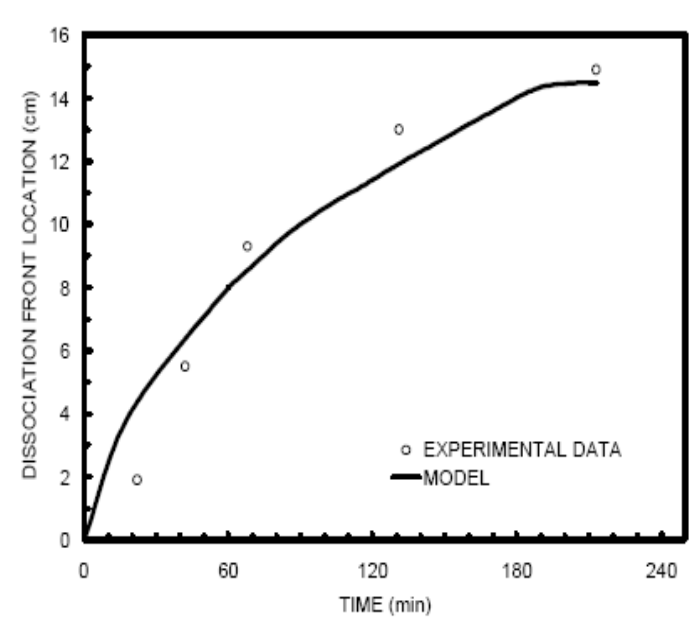

Model match of experimental results, location of hydrate-dissociation interface

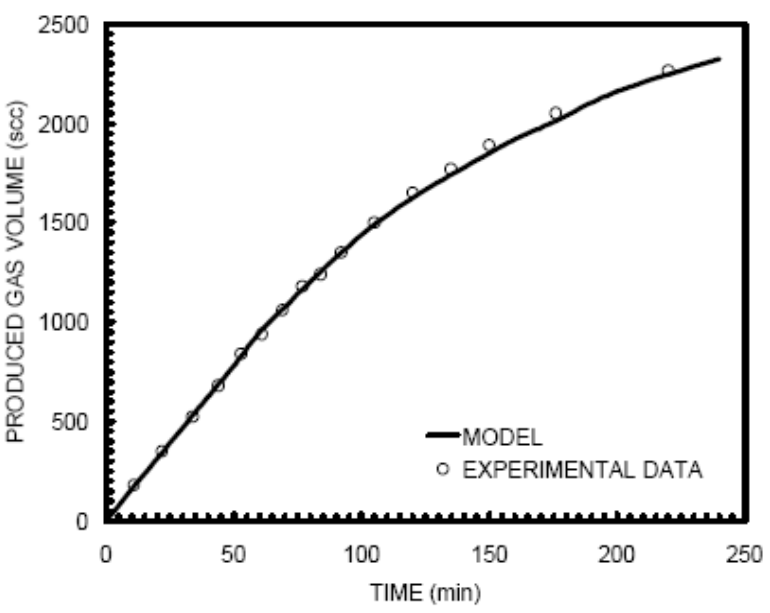

Model match of experimental results, cumulative gas produced

FIGURE 1-15: MOdeL MATCH OF EXPERIMENTAL RESULTS ${ }^{[29]}$. 


\subsubsection{Moridis et al. (1998) ${ }^{[30,31]}$}

A state of art thermal, fluid flow heat transfer TOUGH2 simulator, which has wide variety of application for modeling gas hydrates, was used. It combines many advanced features found in industry simulators with special characteristics of gas hydrates via the EOSHYDR2 module. It is capable of simulating both depressurization and thermal dissociation process. Simulations were conducted for two formations ( $\&$ B) with different initial pressures and temperatures. The hydrate-bearing zone was assumed to be trapped above by tight, thick sandstone and water occupies the lower section in Formation A. In the case of Formation B, the entire zone was assumed to be hydrate with boundaries of siltstone above and sandstone below. The pore space was assumed to be $80 \%$ gas hydrate and $20 \%$ immiscible water. Both reservoirs had a porosity of $28 \%$ and permeability of $20 \mathrm{md}$.

In all simulations of Formation A, production and injection wells were arranged in a conventional five spot pattern. The effects of hydrate saturation, production rate, initial hydrate temperature, injection temnperature were studied with the five-point model. For simulations of Formation B, two well system with an injection and a production well was used. The producer and injection wells are connected through fractures and all the wells are assumed to be on the same fracture plane. The water produced was heated and injected as either hot water or steam, hence, no net water withdrawal from the reservoir. It was concluded that gas due to depressurization produces initially at a greater rate but soon the gas produced due to thermal injection takes over, the pressure wave moves faster than heat wave since hydrate is an insulator. It was suggested that though depressurization is a feasible technique in itself, a tandem approach of depressurization combined with thermal simulation might yield better results. 


\subsubsection{Ahmadi et al. (2000) ${ }^{[32]}$}

In this study, a one-dimensional depressurization analytical model in a confined (no free gas zone) reservoir was used. Pressure and temperature distributions, convective heat transfer were calculated though the water released during hydrate dissociation was not considered. It was found that reservoir permeability affects the rate of convective heat transfer and gas production and gas production depends on reservoir pressure, temperature, permeability and well pressure.

\subsubsection{Masuda et al. (1999) ${ }^{[33]}$}

A two-phase, gas-water finite difference numerical simulator was developed based on kinetic theory of gas hydrates. Permeability is assumed as a function of hydrate saturation. Conduction and convention heat transfer within porous media was considered. Kim-Bishnoi equation is used to determine the dissociation rate. The numerical experiments conducted with a one foot long Berea sandstone core were in general agreement with laboratory experiments as with Yousif et al (1990) ${ }^{[29]}$.

\subsubsection{Swinkels and Drenth $(2000)^{[34]}$}

A three-dimensional, three-phase (Gaseous, Hydrate, and Water) thermal finite difference in house simulator developed by Shell International was used by the researchers. The simulator incorporates several aspects absent in other simulators such as heat transfer between reservoir fluids in the formation, geothermal gradients at different depths of the reservoir, PVT properties of the reservoir as a function of pressure decline, natural variations and architecture of real life reservoirs and reservoir compactions. Simulations were conducted assuming a $100 \mathrm{ft}$ thick reservoir with $20 \%$ porosity and 200 -md permeability at an initial pressure of $1160 \mathrm{psi}$ and an initial temperature of $62^{\circ} \mathrm{F}$. 
The energy in the system was incorporated as an extra energy component. It can be depressurization or thermal method. The researchers asserted that the dissociation of hydrate cap caused by pressure reduction will be slowed down considerably due to cooling at the hydrate gas interface and field scale production of hydrate gas would require large number of producing wells, handling considerable water volumes and considerable energy input in a thermal dissociation case. Figure 1-16 gives an overview of conditions considered by the researchers.

\begin{tabular}{|l|l|l|l|l|l|l|}
\hline Case & Hydrates & Water & $\begin{array}{l}\text { Free } \\
\text { gas }\end{array}$ & Ice & Occurrence & Consequence \\
\hline 1 & Hydrate & & & & $\begin{array}{l}\text { Pore volume is } 100 \% \\
\text { filled with solid hydrates }\end{array}$ & No mobile fluids. \\
\hline 2 & Hydrate & + Water & & & $\begin{array}{l}\text { Likely situation if } \\
\text { hydrates are created by } \\
\text { percolating gas through a } \\
\text { water bearing layer in the } \\
\text { Hydrate Stability Zone }\end{array}$ & $\begin{array}{l}\text { No mobile gas. Wells } \\
\text { will not flow without } \\
\text { energy supply to the } \\
\text { neighbourhood of the } \\
\text { well }\end{array}$ \\
\hline 3 & Hydrate & & + Gas & & $\begin{array}{l}\text { This situation would } \\
\text { develop if gas is } \\
\text { generated in-situ in } \\
\text { excess of the quantities } \\
\text { required to consume all } \\
\text { the pore water. }\end{array}$ & $\begin{array}{l}\text { No mobile water. By } \\
\text { blowing off the gas, a } \\
\text { large volume of } \\
\text { hydrates may be } \\
\text { exposed to } \\
\text { dissociation due to } \\
\text { under-pressure }\end{array}$ \\
\hline 4 & Hydrate & & + Ice & $\begin{array}{l}\text { This situation can } \\
\text { develop in arctic regions } \\
\text { under permafrost. }\end{array}$ & \\
\hline 5 & Hydrate & + Water & + Gas & & $\begin{array}{l}\text { This situation can } \\
\text { develop if hydrocarbon } \\
\text { components are present } \\
\text { in the gas phase for } \\
\text { which there is no "room" } \\
\text { in the hydrate lattice }\end{array}$ & $\begin{array}{l}\text { Two mobile phases in } \\
\text { addition to the solid } \\
\text { hydrate }\end{array}$ \\
\hline 6 & Hydrate & + Gas & + Ice & $\begin{array}{l}\text { Same as above, below } \\
\text { the freezing point }\end{array}$ & \\
\hline
\end{tabular}

TABLE 1-2: PHASE PRESENCE AND MOBILITY IN THE PORE SYSTEM ${ }^{[34]}$. 


\subsubsection{S. J. Howe (2004) ${ }^{[35,36]}$}

This study dealt with the economic analysis and feasibility study of gas production from Alaska North Slope gas hydrate resources. The objective of their work was to model the production profile of a pilot development scheme, analyze the resulting production profiles and evaluate the possible economics of such a project. A threephase multi-component thermal and steam additive simulator STARS (Steam, Thermal and Advanced processes Reservoir Simulator) developed by Computer Modeling Group (CMG) was used. The hydrate was assumed as oil phase with high viscosity and negligible relative permeability to approximate it to a solid. A one-mile wide, 4-mile long and $20 \mathrm{ft}$ thick reservoir block with free gas underlying the hydrate cap was chosen for their study. All reservoir characteristics were chosen based on local gradients. Two production wells were positioned below the gas hydrate to free gas interface, with an operating constraint of $25 \mathrm{mmscfd}$ and minimum BHP of 300 psi. Various cases were run with variations in absolute permeability, well spacing, production rate and hydrate saturations for a simulation period of 15 years. It was concluded in their study that depressurization technique is feasible. The analysis suggests that some of the cases with lower permeabilities and well flow rate were uneconomic as stand-alone projects, but could potentially be viable if several reservoir blocks could be developed at the same time. 


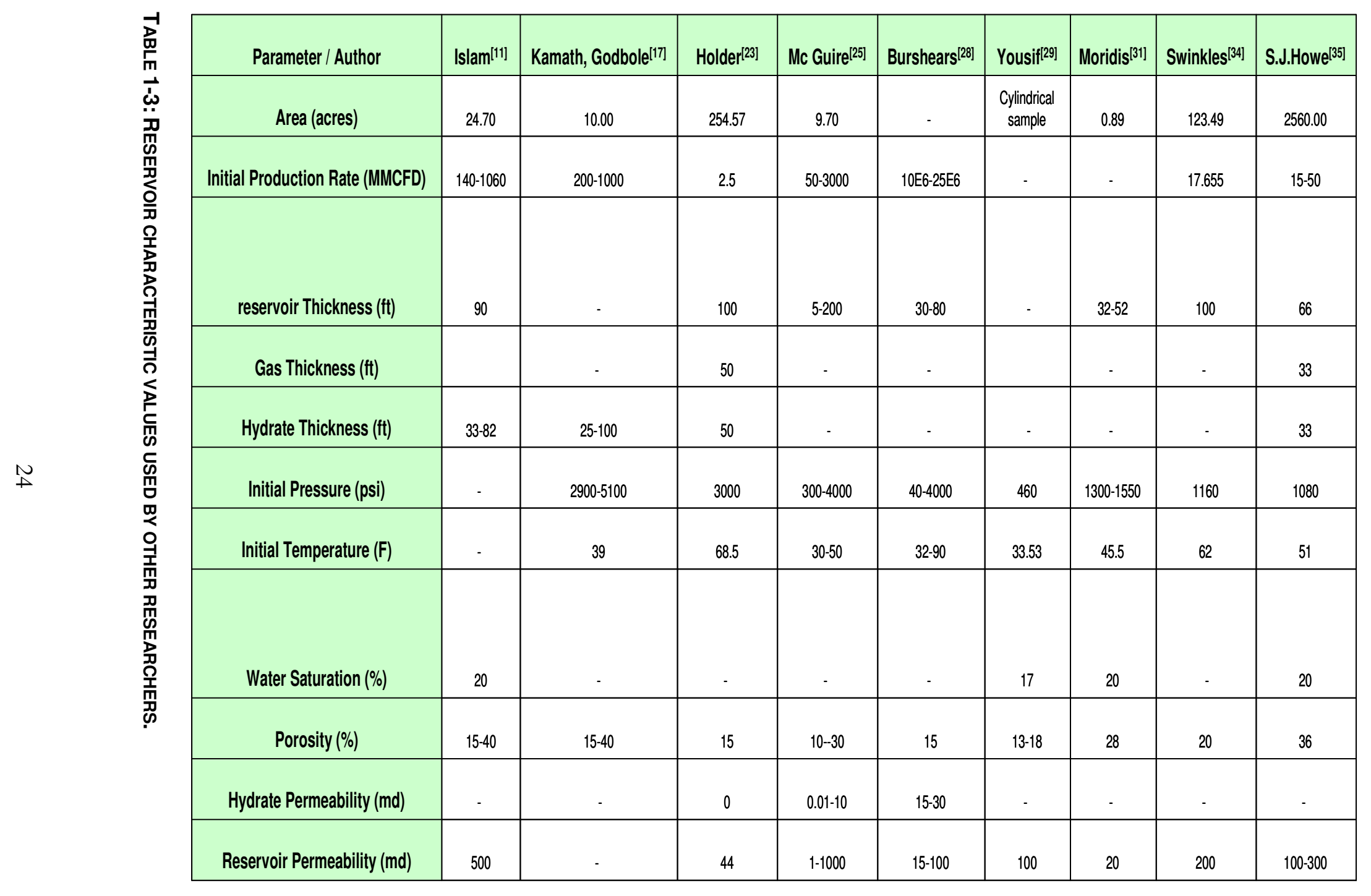




\subsubsection{Comparison}

Each of the models reviewed focus on either depressurization or thermal simulation to recover gas from hydrates. The models reviewed have made a significant contribution towards the development of a practical and realistic hydrate gas production model. All the above models discussed have been thoroughly reviewed and compared by W.K. Sawyer ${ }^{[37]}$. In his study, he concluded that there are six primary model features that are required for a full-featured, field scale hydrate simulator. The features are:

- Fluid flow in porous media

- Heat transfer to surrounding rock

- Dissociation kinetics

- Two-phase gas-water flow

- 3D cartesian reservoir geometry

- Field-scale, multi well capability

The comparisons based on the above criterion are shown in Figure 1-17 and Figure 1-18. None of the six-depressurization models evaluated had all the desired features.

\begin{tabular}{|c|c|c|c|c|c|c|c|}
\hline Desired Feature & $\begin{array}{c}\text { Model 1 } \\
\text { Holder[23] }^{[23}\end{array}$ & $\begin{array}{c}\text { Model } 2 \\
\text { McGuire[25] }\end{array}$ & $\begin{array}{c}\text { Model } 4 \\
\text { Burshears }^{[28]}\end{array}$ & $\begin{array}{l}\text { Model } 5 \\
\text { Yousif[29] }\end{array}$ & $\begin{array}{c}\text { Model } 7 \\
\text { Ahmadi[32] }\end{array}$ & $\begin{array}{c}\text { Model } 8 \\
\text { Masuda[33] }^{[3}\end{array}$ & $\begin{array}{c}\text { Model 10 } \\
\text { S. J. Howe }{ }^{[35,36]}\end{array}$ \\
\hline \multicolumn{8}{|l|}{ Porous Flow } \\
\hline \multicolumn{8}{|c|}{ Heat transfer to surrounding strata } \\
\hline \multicolumn{8}{|c|}{ Dissociation Kinetics } \\
\hline \multicolumn{8}{|c|}{ Two-phase gas-water flow } \\
\hline \multicolumn{8}{|c|}{ 3D Cartesian Geometry } \\
\hline Field Scale & & & & & & & \\
\hline
\end{tabular}

Model Incorporates this Feature

Model does not Incorporates this Feature

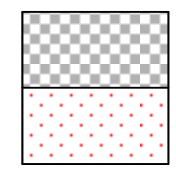

TABLE 1-4: COMPARISON OF DEPRESSURIZATION HYDRATE MODELS. 


\begin{tabular}{|c|c|c|c|c|}
\hline Desired Feature & $\begin{array}{c}\text { Model 2 } \\
\text { McGuire }{ }^{[25]}\end{array}$ & $\begin{array}{c}\text { Model 3 } \\
\text { Bayles }^{[27]}\end{array}$ & $\begin{array}{c}\text { Model 6 } \\
\text { Moridis }^{[31]}\end{array}$ & $\begin{array}{c}\text { Model 9 } \\
\text { Swinkles }^{[34]}\end{array}$ \\
\hline Porous Flow & & & & \\
\hline Heat transfer to surrounding strata & & & \\
\hline Dissociation Kinetics & & & \\
\hline Two-phase gas-water flow & & & \\
\hline 3D Cartesian Geometry & & & \\
\hline Field Scale & & & \\
\hline
\end{tabular}

Model Incorporates this Feature

Model does not Incorporates this Feature

TABLE 1-5: COMPARISON OF THERMAL HYDRATE MODELS.

The Tough2 model (Moridis ${ }^{[31]}$ ) developed at Lawrence Berkeley National Laboratory (LBNL) and Shell Model (Swinkles ${ }^{[34]}$ ) are two full featured industry models and only Tough2 model has all the desired features for a field scale hydrate reservoir simulator. 


\section{Modeling of STARS for Hydrate Dissociation}

\subsection{STARS Thermal Composition Simulator}

In this study, STARS (Steam, Thermal, and Advanced Processes Reservoir Simulator) is used to understand the production characteristics of hydrate reservoirs. STARS is an advanced processes simulator developed by Computer Modeling Group (CMG) ${ }^{[38]}$ for modeling the flow of three-phase, multi-component fluids. STARS adaptive implicit mode decides from time-step to time-step which grid blocks must be solved in fully implicit or explicit modes reducing the amount of time required to complete a simulator run while preserving the accuracy of the calculations. The grids may be cartesian, cylindrical or mixed coordinates with variable thickness/depths. Most of the physical properties can be defined via standard correlations and tables to minimize the data entry. The chemical and thermodynamic processes of different reactions feature is used to take into account of the nature of hydrates.

STARS is designed primarily for black oil models. To use it for the simulation of hydrate dissociation, few adjustments and assumptions to the input parameters had to be made. The hydrate is modeled as an oil phase with high viscosity and negligible relative permeability to approximate it as a solid and immobile ${ }^{[35,36]}$. The kinetics of hydrate dissociation is specified as an input and the reservoir is assumed homogenous throughout, although unlikely in reality.

\subsection{Design of a Hydrate Reservoir for Dissociation Simulations}

Many runs were carried out to effectively predict the effects of various kinetic parameters before finalizing them. Simulations were carried out based on the values of models of other researchers and were checked if they are in broad agreement. A base case was developed for a hypothetical reservoir with properties in broad agreement with the existing field data and data used for simulations by other researchers. Further runs were carried out by varying one reservoir 
parameters at a time in the selected range of values. The rock thermal properties are based on the default values suggested for fluid flow modeling using STARS manual. Details of the equations are provided in the current CMG STARS user manual. The values that were finally used are given in the next section.

\subsection{Construction of the Modeling Grid and Initialization of the Simulator}

\subsubsection{Reservoir Grid}

From the initial runs, it was clear that with increase in size and number of grid blocks there is an exponential increase in the simulation time. Considering this constraint a 155 acre and $40 \mathrm{ft}$ thick reservoir was chosen. The grid block size of $100 \mathrm{ft}$ by $100 \mathrm{ft}$ and the thickness of $4 \mathrm{ft}$ were finalized. The reservoir is divided into two equal sectors (by thickness) for easy input of data and for distinction between the hydrate and gas bearing zones (Figure 2.1).

Using the dimensions selected, 26 blocks in I-direction, 26 blocks in J-direction and 10 blocks in Z-direction are used. The total number of blocks was 2704 .

The reference depth was the hydrate layer top at $2300 \mathrm{ft}$ similar to Burshears ${ }^{[28]}$ for the greater geothermal gradients as the water from the dissociated hydrates may freeze and block the flow of gas.



FIGURE 2-1: RESERVOIR GRID SHOWING TWO SECTORS. 


\subsubsection{Temperature and Pressure}

The temperature and pressure of the reservoir was selected such that the hydrate zone lies in the generalized hydrate-forming zone as shown in Figure 2-2. The minimum temperature that can be modeled in STARS is $32{ }^{\circ} \mathrm{F}$ and many warnings were issued during the simulations indicating the actual temperature falling below the minimum value during the endothermic dissociation process.

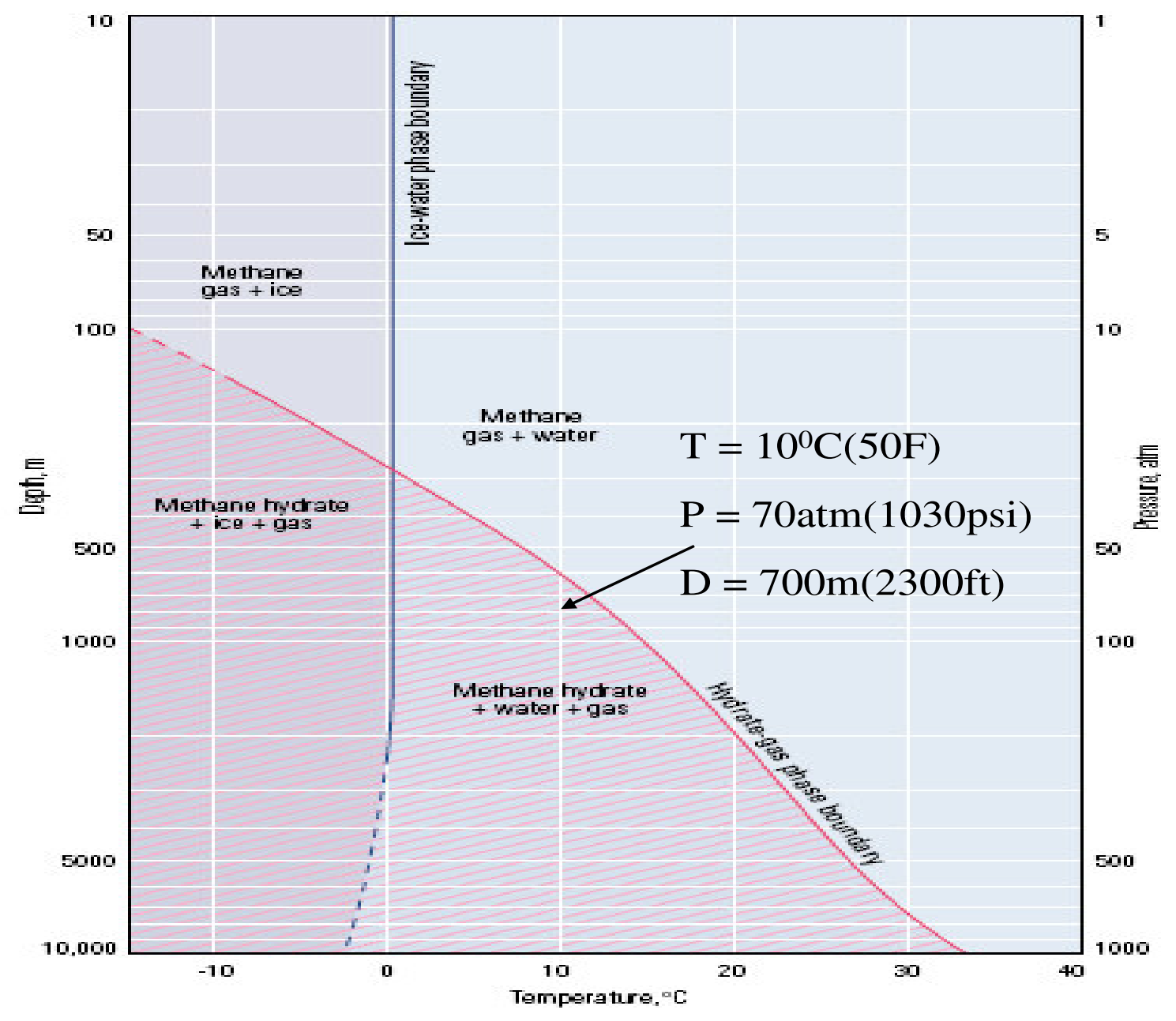

FiguRE 2-2: PRESSURE AND TEMPERATURE DEPENDENCE OF HYDRATE STABILITY ${ }^{[8]}$. 


\subsubsection{Dissociation Reaction}

The gas hydrate is modeled as an oil phase with a viscosity of 1000 centipoise in order to emulate an immobile phase. The gas hydrate dissociates into methane gas and water as the conditions change once the production starts. The dissociation process is given in lb-moles as:

1 Hydrate $\rightarrow 5.5126288$ WATER +0.93 METHANE

This reaction still had a mass balance error of $-9.48963 \mathrm{E}-7$. Since the dissociation reaction is endothermic, the enthalpy is negative (-22295 Btu/lb-mole) and the activation energy is $64582.26 \mathrm{Btu} / \mathrm{lb}$-mole.

\subsubsection{Fluid Enthalpy Coefficients}

The fluid enthalpy of methane for the desired temperature range was taken from the Yaws' Handbook of Thermodynamic and Physical Properties of Chemical Compounds ${ }^{[39]}$ and a polynomial curve (Figure 2-3) is plotted against the temperature to get the coefficients.

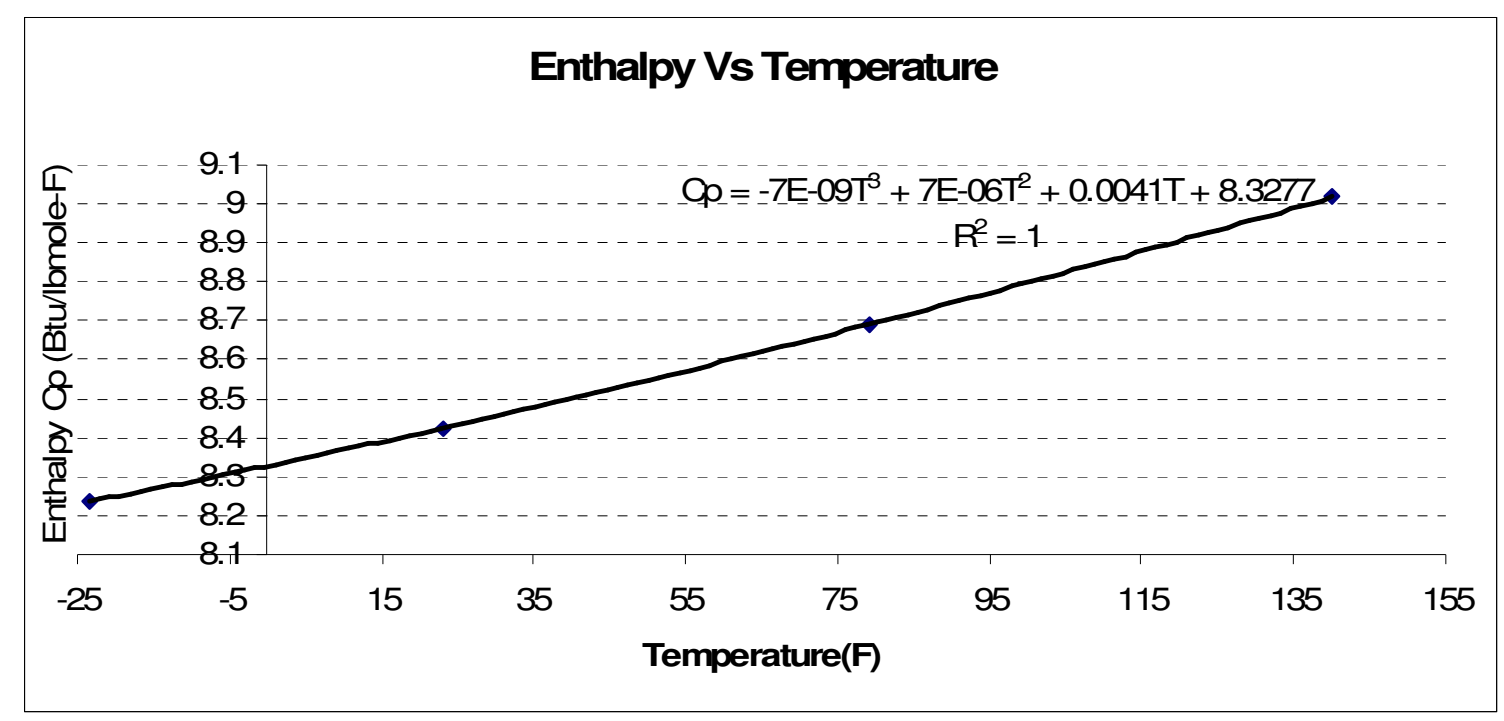

FIGURE 2-3: ENTHALPY -TEMPERATURE RELATION.

The obtained equation $\mathrm{C}_{p}=-7 \mathrm{E}-09 \mathrm{~T}^{3}+7 \mathrm{E}-06 \mathrm{~T}^{2}+0.0041 \mathrm{~T}+8.3277$ is compared with the standard equation $\mathrm{C}_{p}=\mathrm{C}_{p g} 4 \mathrm{~T}^{3}+\mathrm{C}_{\mathrm{pg} 3} \mathrm{~T}^{2}+\mathrm{C}_{\mathrm{pg} 2} \mathrm{~T}+\mathrm{C}_{\mathrm{pg} 1}$ and the coefficients $\left(\mathrm{C}_{p g 1}, \mathrm{C}_{\mathrm{pg} 2}, \mathrm{C}_{\mathrm{pg} 3}\right.$ and $\left.\mathrm{C}_{\mathrm{pg} 4}\right)$ in the gas heat capacity correlation are obtained. 


\subsubsection{Relative permeabilities}

Relative permeabilities for hydrates have not been published to date. The values used in the model are calculated using equations presented by Darvish ${ }^{[40]}$ and the Stone's II model. Since the hydrate is modeled as oil phase, a negligible relative permeability was used to emulate an immobile phase.

The hydrate and reservoir permeabilities are assumed same in both X-direction and Y-direction. In the case of vertical permeability, half of the hydrate permeability and one tenth of the reservoir permeability values were assumed.

The relative permeability curves used in the runs are shown in Figure 2-4 and Figure 2-5.

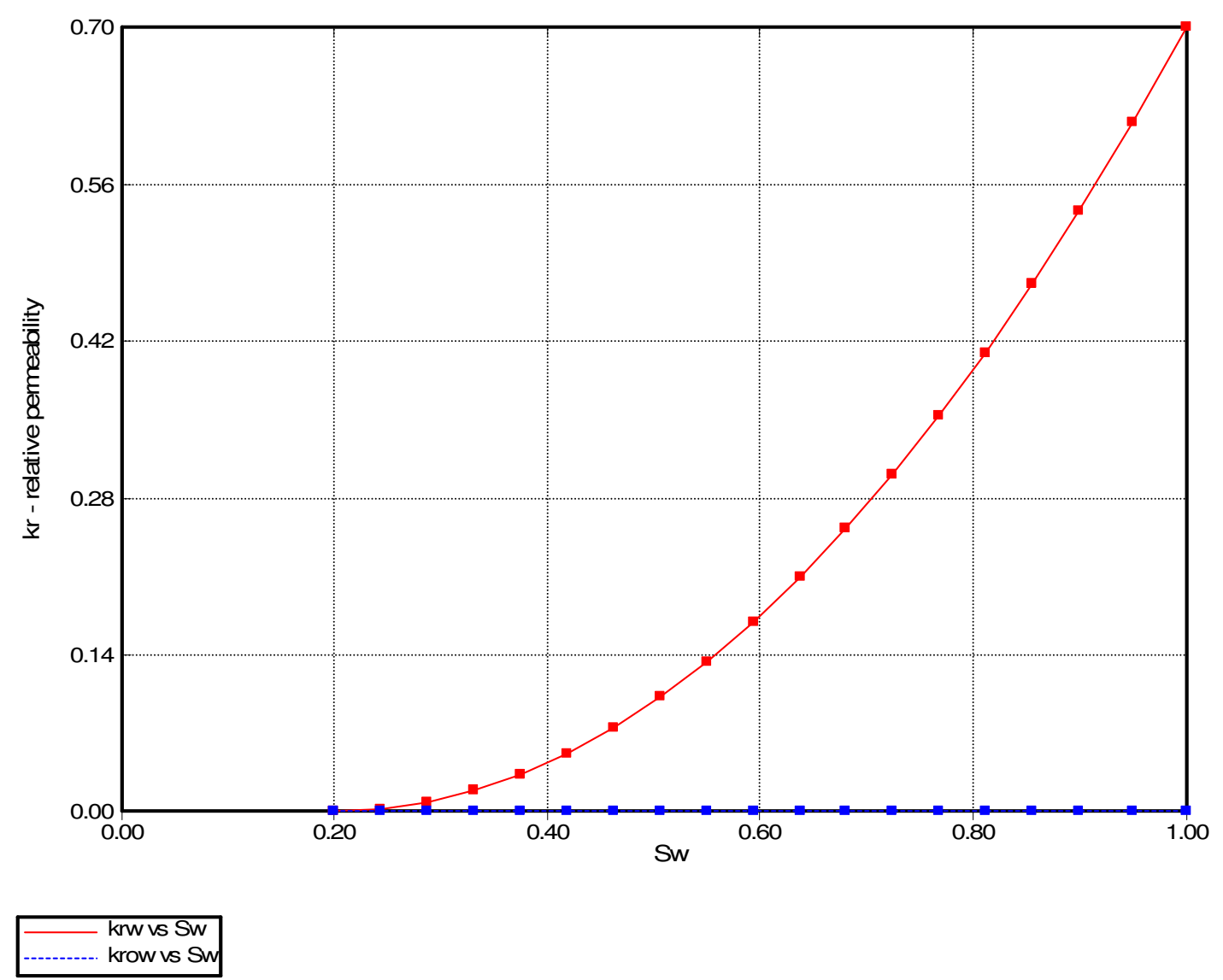

FIGURE 2-4: RELATIVE PERMEABILITY VERSUS WATER SATURATION. 


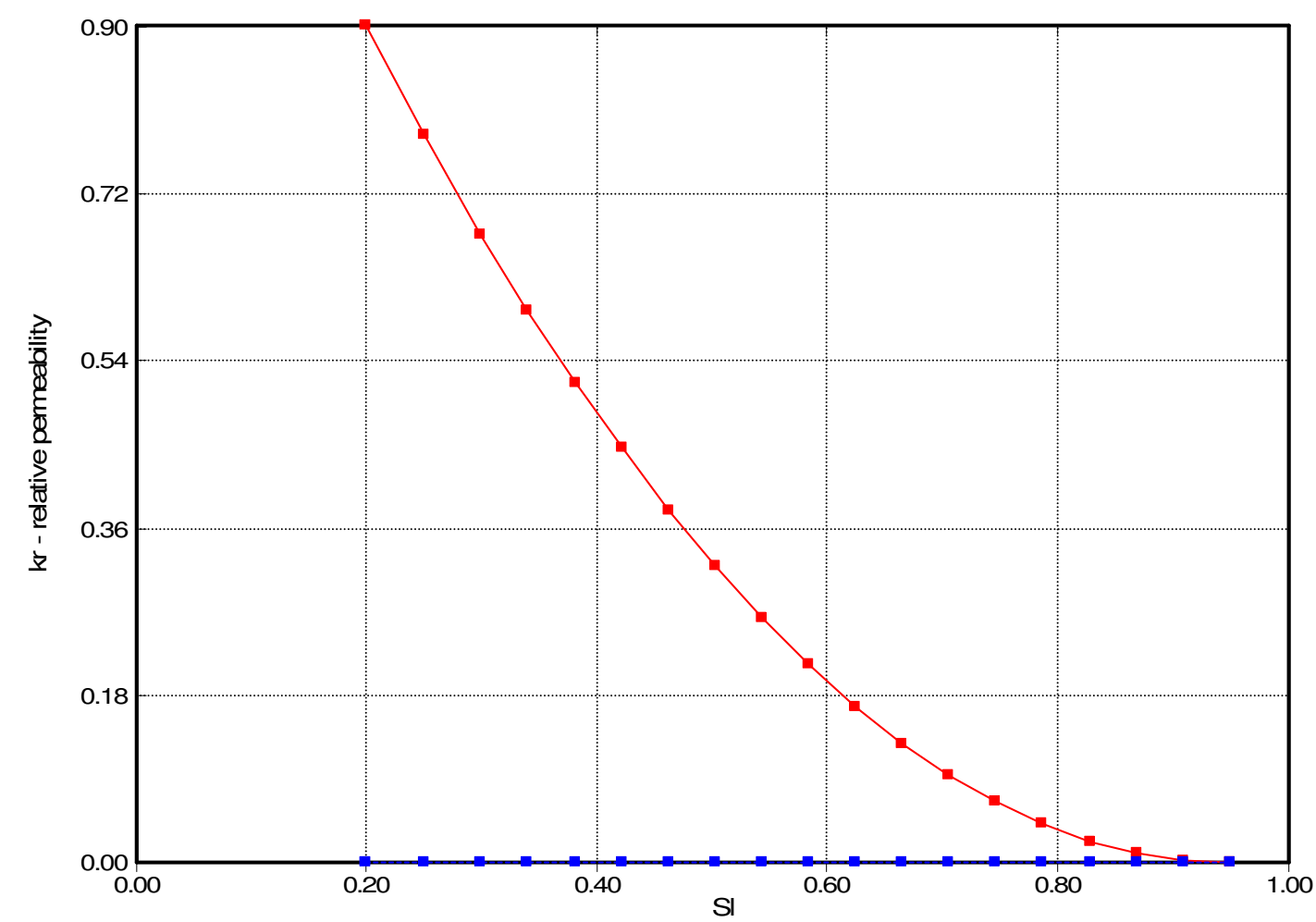

krg vs SI

krog vs SI

FIGURE 2-5: RELATIVE PERMEABILITY VERSUS LIQUID (HYDRATE) SATURATION. 


\subsection{Production Wells and Completion}

A single well is placed in the center of the reservoir. In order to select the well production specification, it was produced for 20 years, first with constant BHP (105 psi) and another simulation with maximum flow rate of 1 mmscfd. The total gas produced (Figure 2-6) was almost the same $(7.58 \mathrm{E}+08$ scf and $7.76 \mathrm{E}+08 \mathrm{scf}$ respectively) though, total water produced (Figure 2-7) significantly differed $(19,118$ bbls and 34,930 bbls respectively). All runs were made with constant BHP for 5 years as most of the gas is been produced by that time.

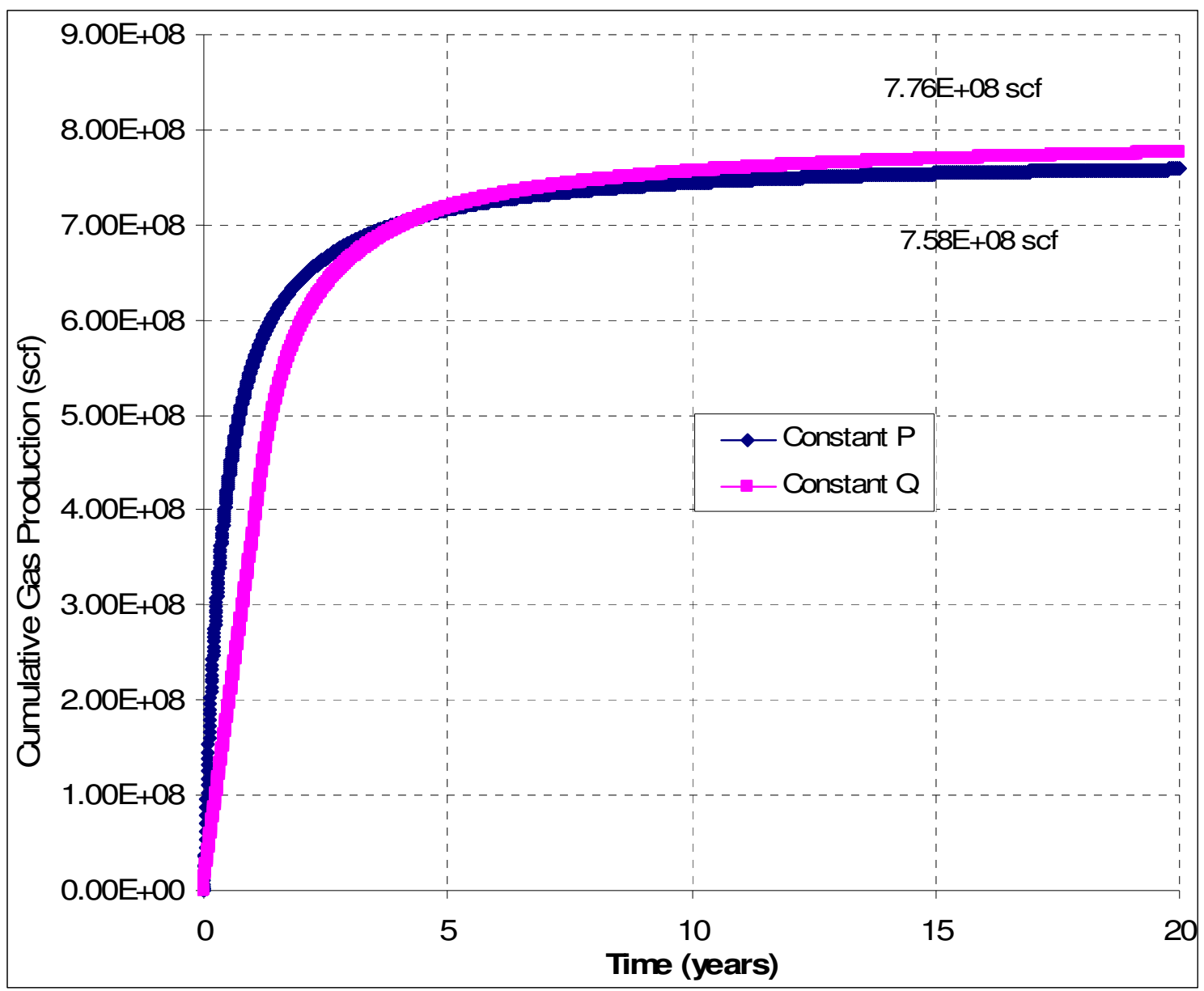

FIGURE 2-6: COMPARISON OF CUMULATIVE GAS PRODUCTION 




FIGURE 2-7: COMPARISON OF CUMULATIVE WATER PRODUCTION. 
The $40 \mathrm{ft}$ thick reservoir is divided into 10 layers of $4 \mathrm{ft}$ each. Various completion scenarios were tried as shown in Figure 2-8 and the gas and water productions are compared.

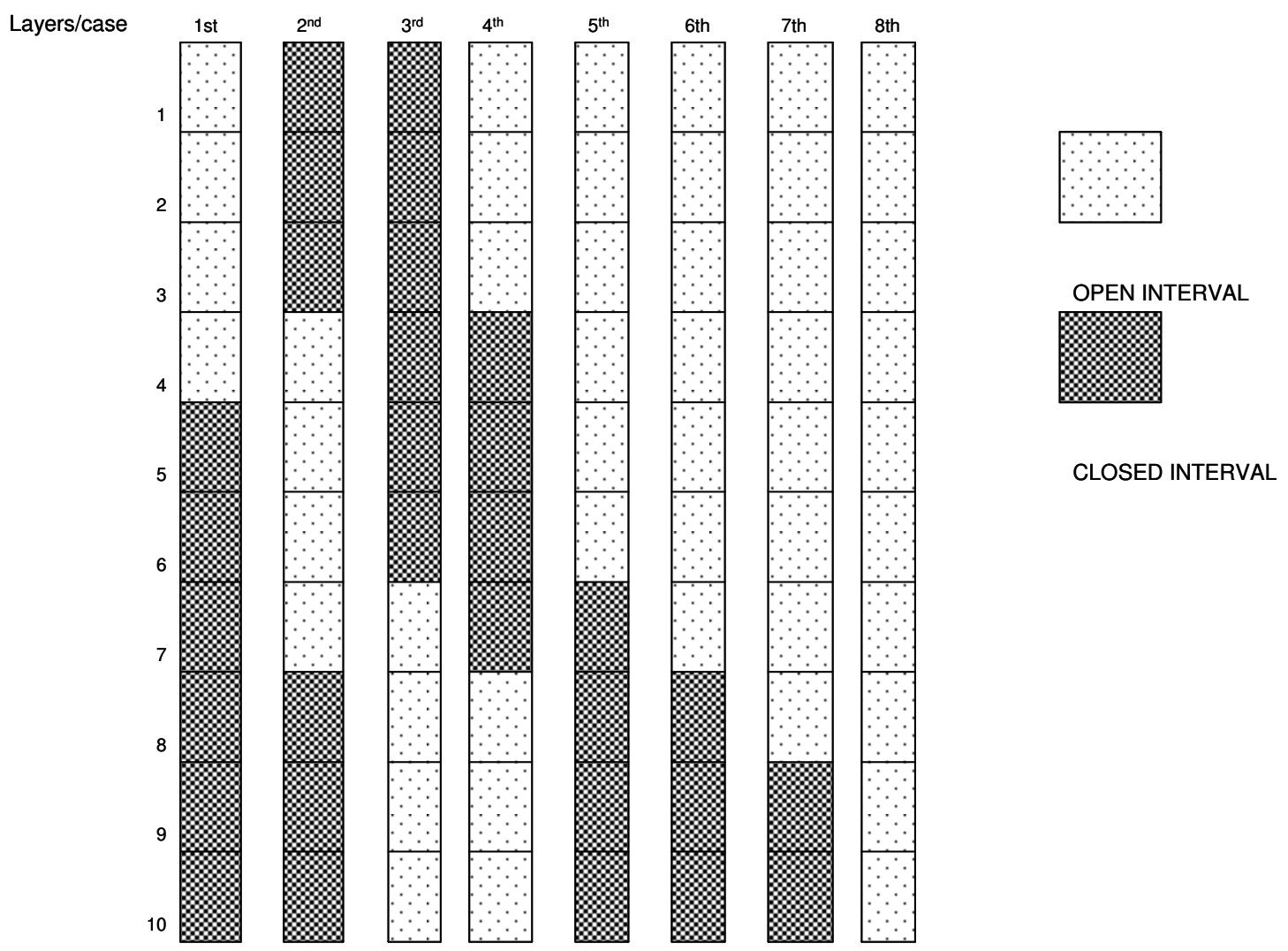

FIGURE 2-8: DIFFERENT TYPES OF COMPLETIONS STUDIED.

The total gas production in all the cases lie in the range of $6.6 \mathrm{E}+08$ to $7 \mathrm{E}+08 \mathrm{scf}$ except the first case in which the total gas production is $5.85 \mathrm{E}+08 \mathrm{scf}$ as seen in Figure 2-9. The gas production rates differ significantly for the first one year but are almost the same at later times as seen in Figure 2-10. 


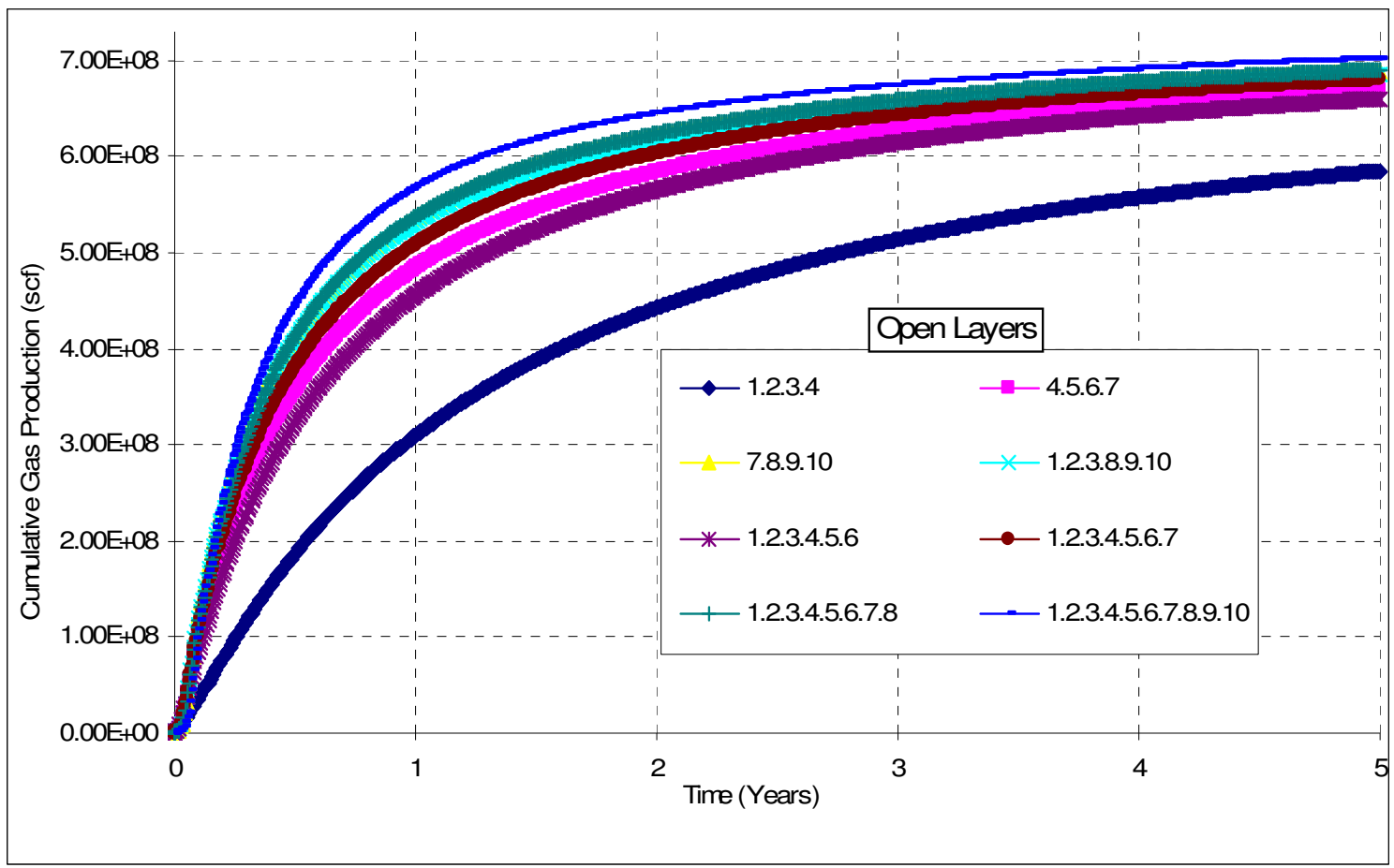

FIGURE 2-9: COMPARISON OF CUMULATIVE GAS PRODUCTION FOR DIFFERENT WELL COMPLETIONS.

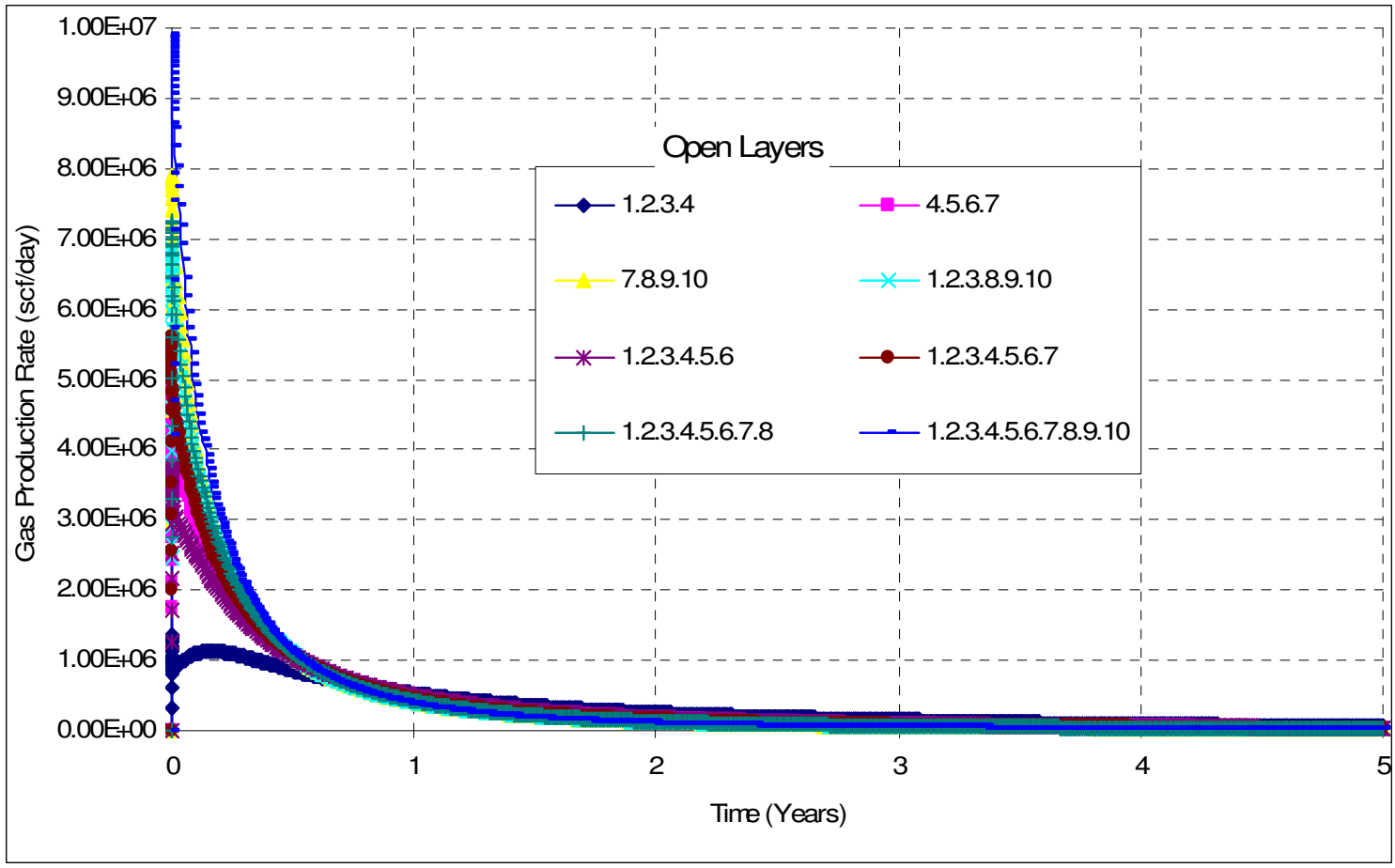

FIGURE 2-10: COMPARISON OF GAS PRODUCTION RATES FOR DIFFERENT WELL COMPLETIONS. 
Considerable increase in the total water production was observed when the well is completed beyond the sixth layer (Figure 2-11). Well completed with seven open layers (28 ft) was found to be most efficient. In the case of deeper completions, water from the bottom layers was clogging the wellbore and there was a negligible increase in gas production. The clogging of the well is due to the drop in temperature close to the freezing point of water near the wellbore because of Joule Thompson effect and the endothermic dissociation reaction. Moridis ${ }^{[31]}$ in a similar study (with different parameters) suggested that the large quantities produced during the hydrate dissociation will drain to the bottom of the reservoir and as such, the quantities of produced water will be low.

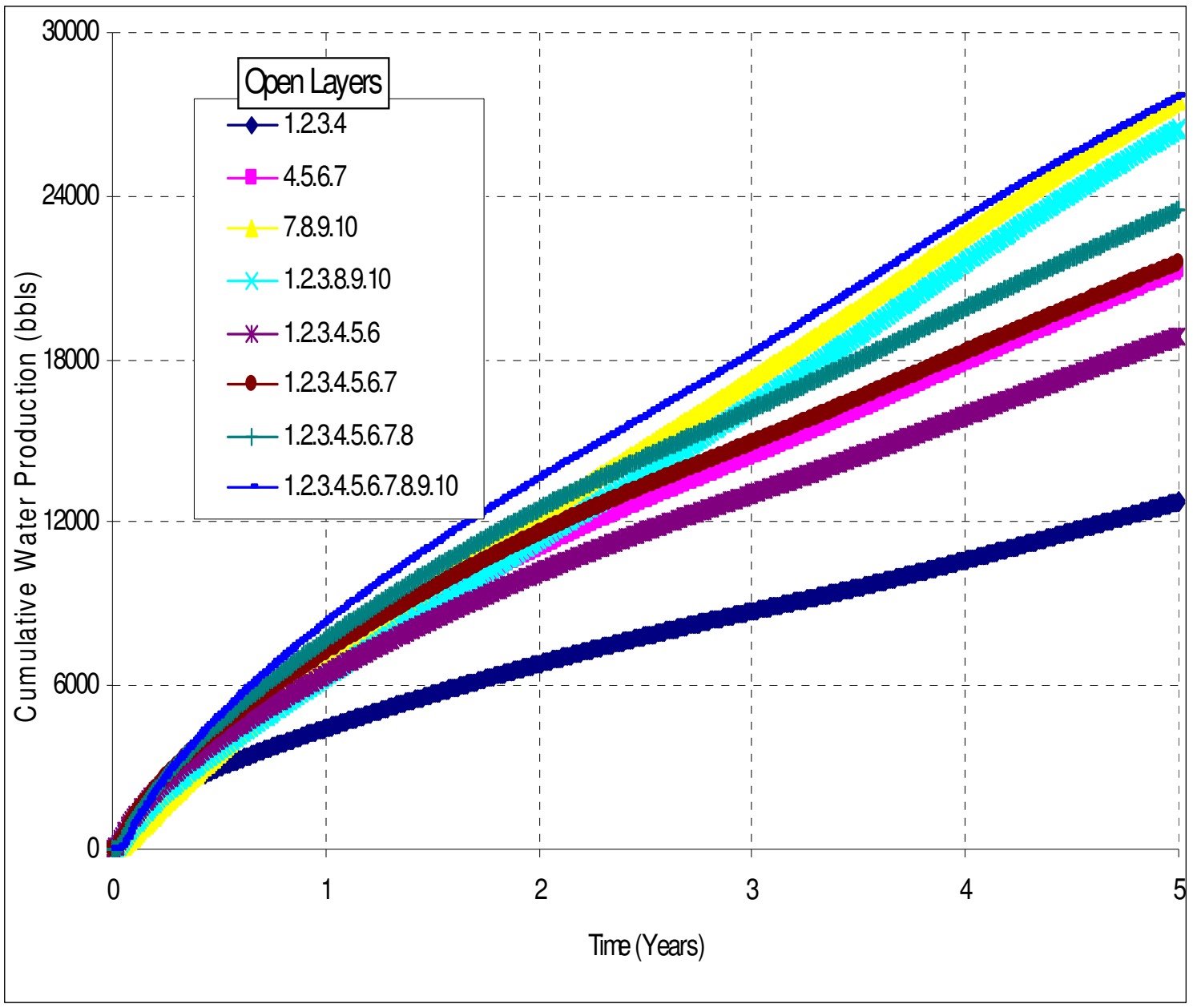

FIGURE 2-11: COMPARISON OF TOTAL WATER PRODUCTIONS FOR DIFFERENT WELL COMPLETIONS. 
Rapid decrease in the water production rates initially is observed but later stabilizes as shown in Figure 2-12.

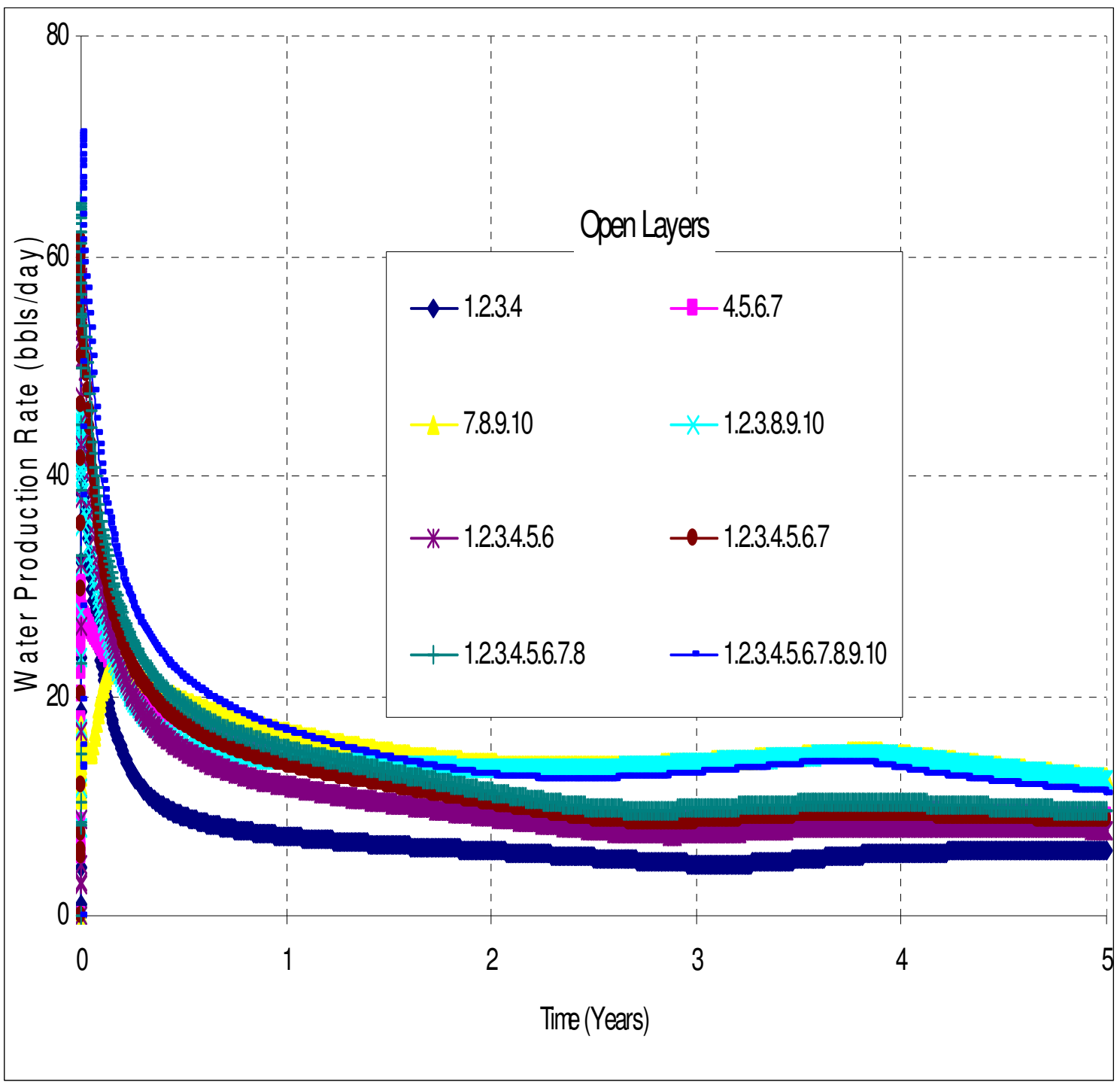

FIGURE 2-12: COMPARISON OF WATER PRODUCTION RATES FOR DIFFERENT WELL COMPLETIONS. 


\subsection{Reservoir Modeling Runs}

The first run was conducted with the base case values but assumed 40 layers of 1 $\mathrm{ft}$ thick blocks and completion through all layers. Since the simulation time was around $12 \mathrm{hrs}$, the number of layers was decreased to 10 increasing the thickness of each block to $4 \mathrm{ft}$. The water produced was clogging the well bore and most of the bottom layers were filled with water, hence the seven-layer completion was finalized. Simulation runs were carried out with different thickness, porosity, water saturation, hydrate and rock permeabilities values. The different values for the parameters studied are summarized in Table 2-1.

\begin{tabular}{|l|l|}
\hline Parameter & Values \\
\hline Reservoir Thickness, $\mathrm{ft}$ & 40,80 \\
\hline Porosity, \% & $15,20,30$ \\
\hline Water Saturation, \% & 20,30 \\
\hline Hydrate permeability, md & $0.01,0.1,1,10,100$ \\
\hline Reservoir permeability, md & 50,100 \\
\hline
\end{tabular}

TABLE 2-1: DiffERENT PARAMETERS AND RANGE OF VALUES STUDIED. 


\section{Results}

\subsection{Base case}

After many simulations, a set of values were selected and used as the values for the base case. The effect of parameters was studied by keeping all the values constant. The base case had following values:

\begin{tabular}{|c|c|c|}
\hline Parameter & \multicolumn{2}{|l|}{ Values } \\
\hline Reservoir Thickness, ft & \multicolumn{2}{|l|}{40} \\
\hline Porosity, \% & \multicolumn{2}{|l|}{20} \\
\hline Water Saturation, \% & \multicolumn{2}{|l|}{20} \\
\hline Hydrate layer permeability, md & \multicolumn{2}{|l|}{10} \\
\hline Reservoir permeability, md & \multicolumn{2}{|l|}{50} \\
\hline Wells and Location & \multicolumn{2}{|c|}{ Single, center of the reservoir } \\
\hline Pressure, psi & \multicolumn{2}{|l|}{1030} \\
\hline Temperature, ${ }^{0} \mathrm{~F}$ & \multicolumn{2}{|l|}{50} \\
\hline Completion Interval, $\mathrm{ft}$ & \multicolumn{2}{|l|}{28} \\
\hline \multicolumn{3}{|l|}{ Constraints } \\
\hline Minimum BHP, psi & \multicolumn{2}{|l|}{105} \\
\hline Minimum $\mathrm{Q}, \mathrm{ft}^{3} /$ day & \multicolumn{2}{|l|}{1000} \\
\hline Production type & \multicolumn{2}{|l|}{ Constant BHP } \\
\hline Initial saturations & Hydrate Zone & Gas Zone \\
\hline Water & $0 \%$ & $20 \%$ \\
\hline Hydrate & $70 \%$ & $0 \%$ \\
\hline Gas & $30 \%$ & $80 \%$ \\
\hline
\end{tabular}

TABLE 3-1: VALUeS USED IN THE BASE CASE. 


\subsubsection{Gas In Place and Production}

A porosity and initial water saturation of $20 \%$ each were assumed through out the reservoir for the base case. The hydrate phase has $70 \%$ hydrate and $10 \%$ gas and the gas zone has $80 \%$ gas. Initial volumes in $\mathrm{ft}^{3}$ and moles are given in Table 3-2

\begin{tabular}{|l|l|l|}
\hline & $\mathrm{ft}^{3}$ & Moles \\
\hline Gross formation volume: & $2.70 \mathrm{E}+08$ & \\
\hline Formation pore volume: & $5.41 \mathrm{E}+07$ & \\
\hline Aqueous phase volume: & $5.41 \mathrm{E}+06$ & $1.87 \mathrm{E}+07$ \\
\hline Hydrate phase volume: & $1.89 \mathrm{E}+07$ & $9.52 \mathrm{E}+06$ \\
\hline Gaseous phase volume: & $2.97 \mathrm{E}+07$ & $6.52 \mathrm{E}+06$ \\
\hline
\end{tabular}

TABLE 3-2: INITIAL VOLUMES AND MOLES OF THE RESERVOIR.

Once all the hydrate dissociates, $2.84 \mathrm{E}+09 \mathrm{scf}$ of gas is produced at surface conditions. Total gas potential of the reservoir is approximately $2.87 \mathrm{E}+09 \mathrm{scf}$. The $40 \mathrm{ft}$ thick reservoir is treated as two equal sectors where Sector 1 is the hydrate zone and the Sector 2 is the gas zone. The sector wise cumulative gas production with time for the base case is shown in the Figure 3-1.

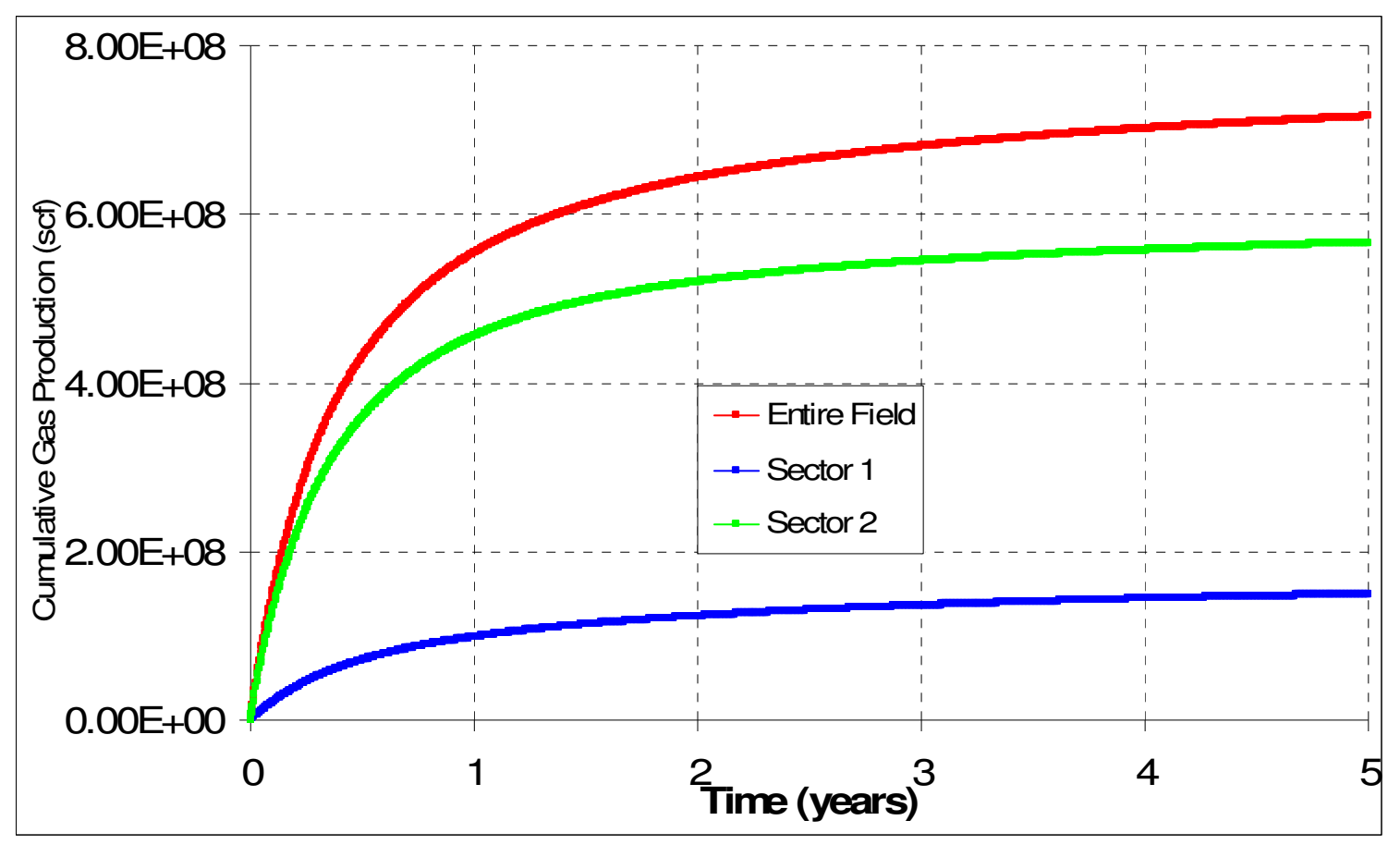

FIGURE 3-1: SECTOR WISE CUMULATIVE GAS PRODUCTION VERSUS TIME (BASE CASE). 
Most of the gas seems to be produced from the Sector 2. The gas produced from Sector 2 is greater than the amount of gas initially present due to the migration of dissociated gas from Sector 1. STARS cannot differentiate methane from different zones.

\subsubsection{Water production}

The large quantities of water from hydrate dissociation moves to the bottom of the reservoir according to a similar study by Moridis ${ }^{[31]}$. This can be also seen in the Figure 3-2.

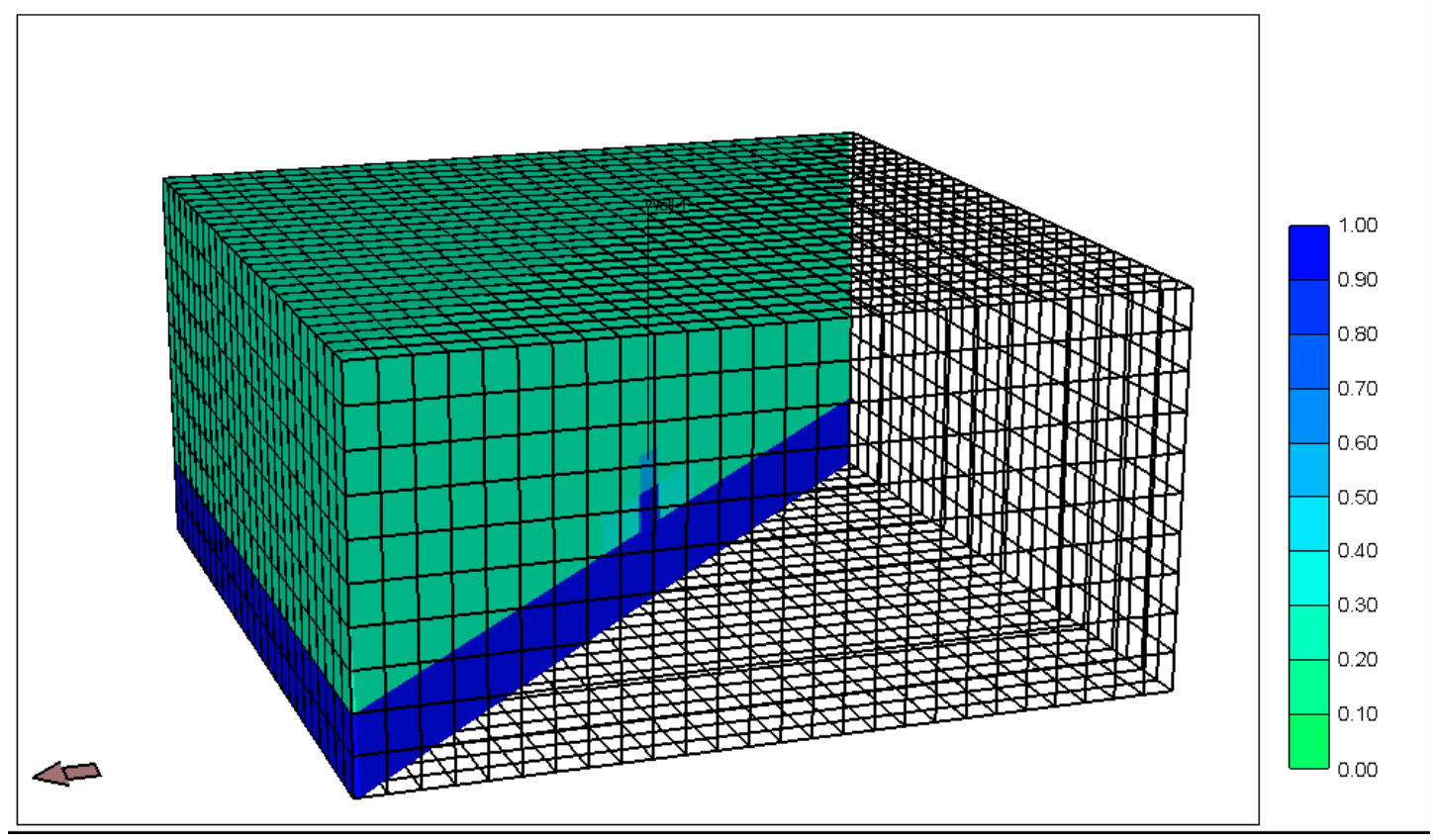

FIGURE 3-2: WATER SATURATION AT THE END OF SIMULATION.

Low quantities of water is produced (Figure 3-3) due to the conditions around the wellbore, where water freezes or at least becomes sluggish decreasing the mobility. 


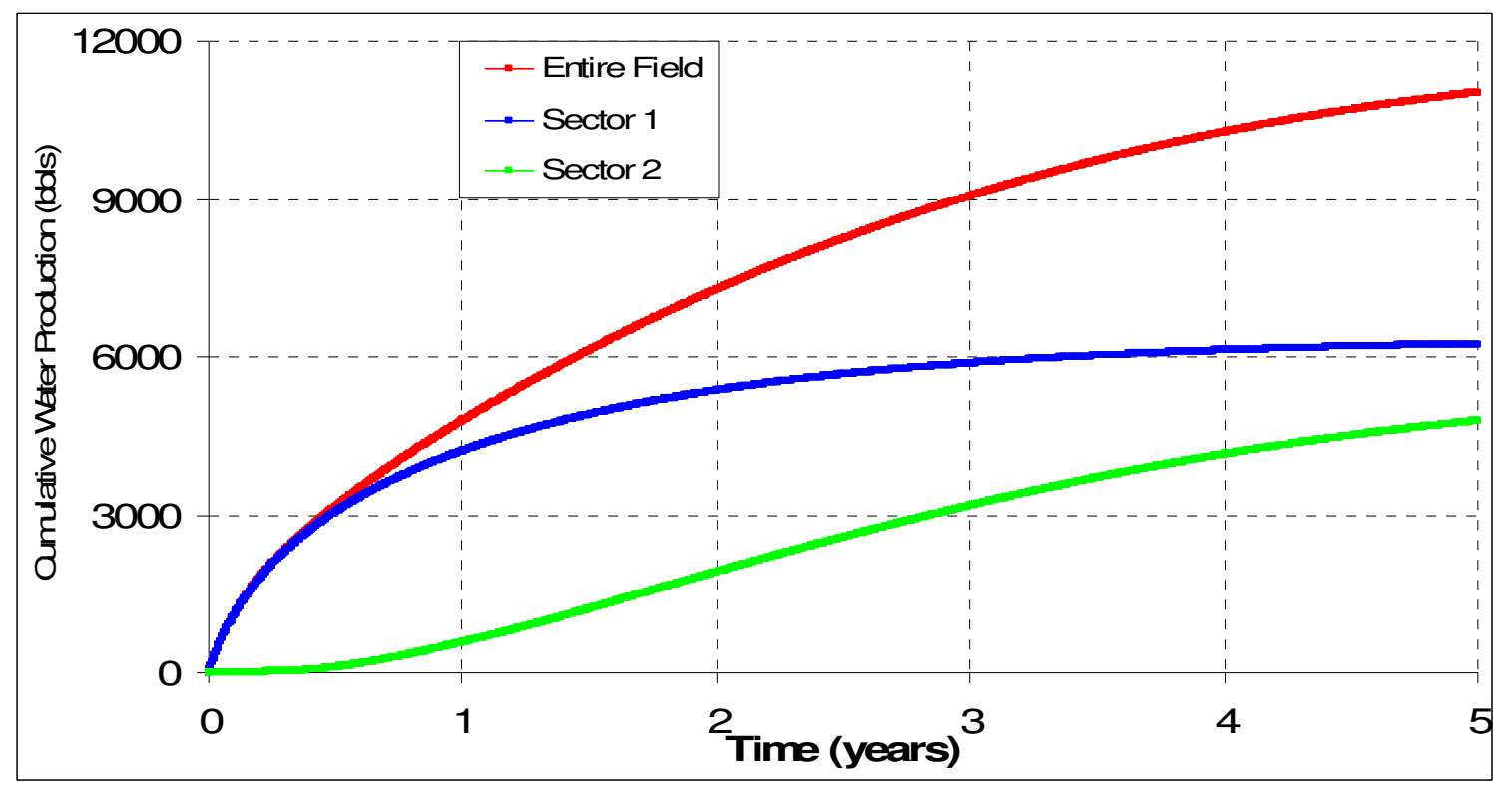

FIGURE 3-3: SECTOR WISE CUMULATIVE WATER PRODUCTION VERSUS TIME (BASE CASE).

The increase in the water production from Sector 2 after one year is due to the start of accumulation and migration of water from hydrate dissociation at the bottom of the reservoir. As seen in Figure 3-4 that the water content in the reservoir is almost constant and there is only migration taking place from Sector 1 to Sector 2.

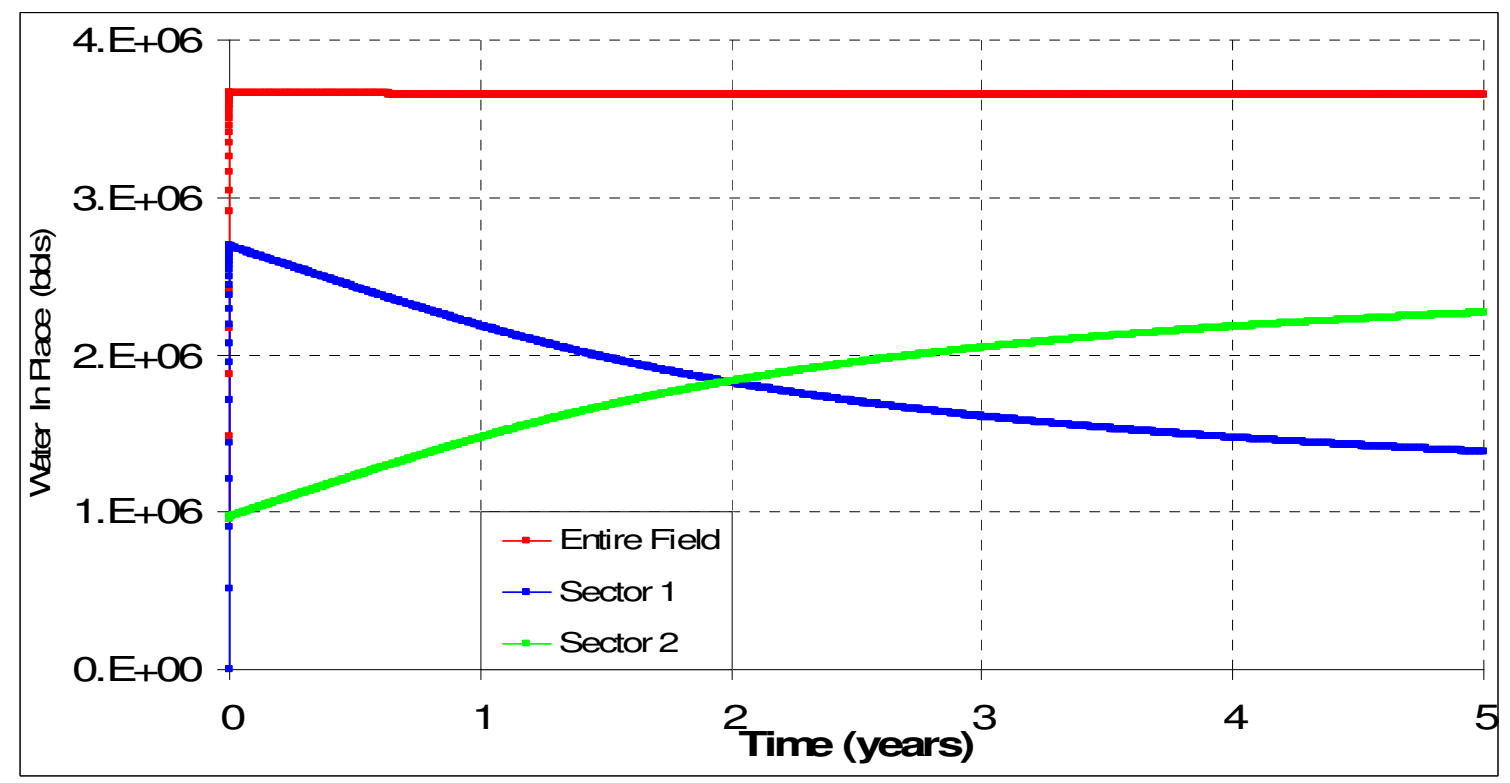

FIGURE 3-4: SECTOR WISE WATER VOLUME AS FUNCTION OF TIME (BASE CASE). 


\subsubsection{Pressure and temperature variation}

The average temperature of the reservoir becomes constant around $40{ }^{0} \mathrm{~F}$ after two years of production and the pressure drops down to approximately 200 psi by the end of third year (Figure 3-5). This explains the initial high production rates and stabilized rates at later times.

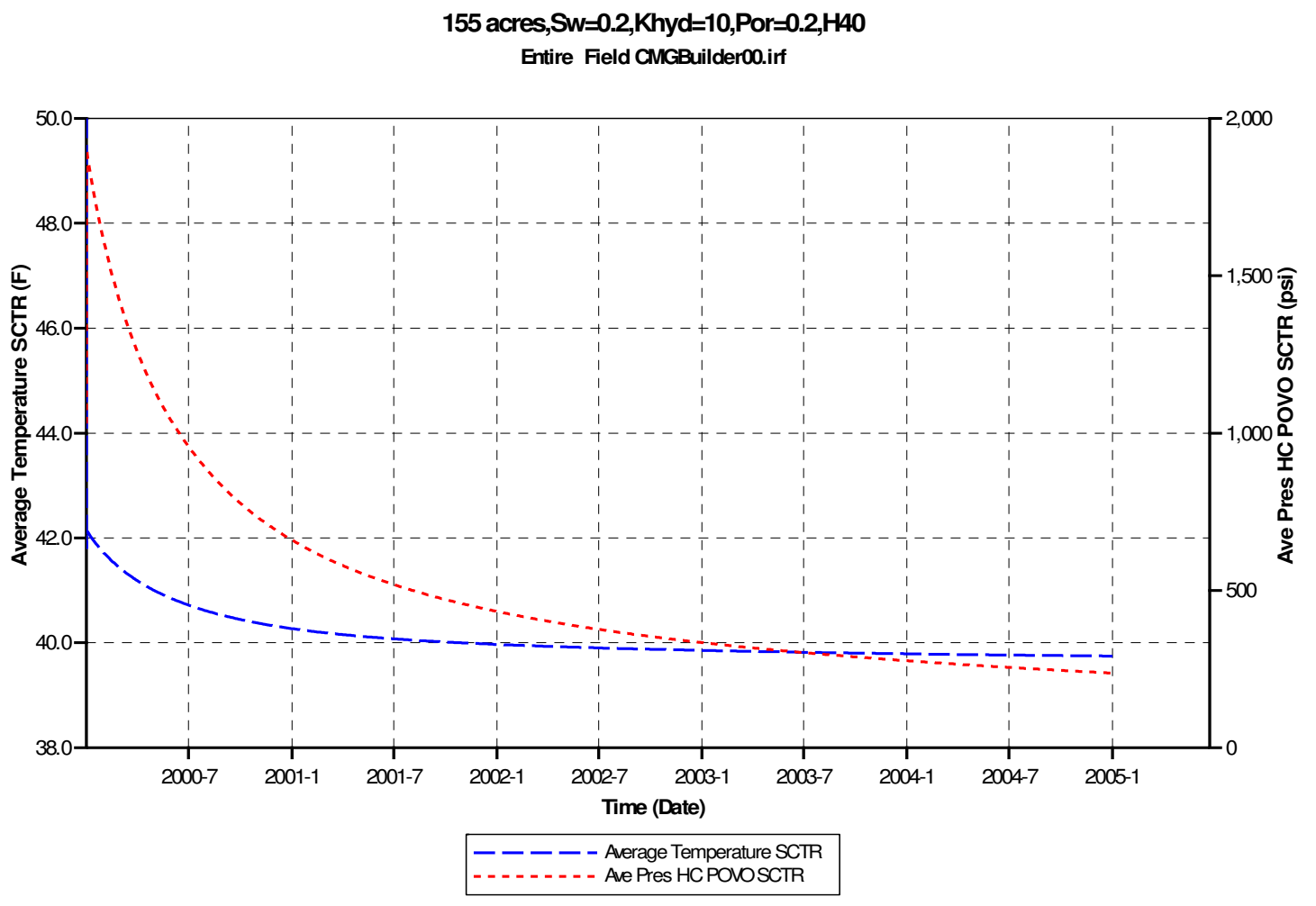

Figure 3-5: PREsSURE AND TEMPERATURE VARIATION WITH TIME (BASE CASE).

The temperature in the main area of hydrate dissociation has reduced to near freezing point of water and this is a limitation of STARS, which cannot operate below $33^{\circ} \mathrm{F}$. During the simulation, many warnings were received and STARS tried to recalculate the last time step so that the temperature remains above the minimum. In reality, the temperatures can fall below the freezing point of water and reduce or stop the dissociation, may even cause a reverse reaction.

After the dissociation of hydrate near the wellbore, the temperature starts to increase as heat flows from the surrounding rocks. The reduction of temperature of the reservoir is due to Joule Thompson effect as a result of free gas expansion and 
the endothermic reaction of hydrate dissociation. The temperature change overtime is shown in Figure 3-6.

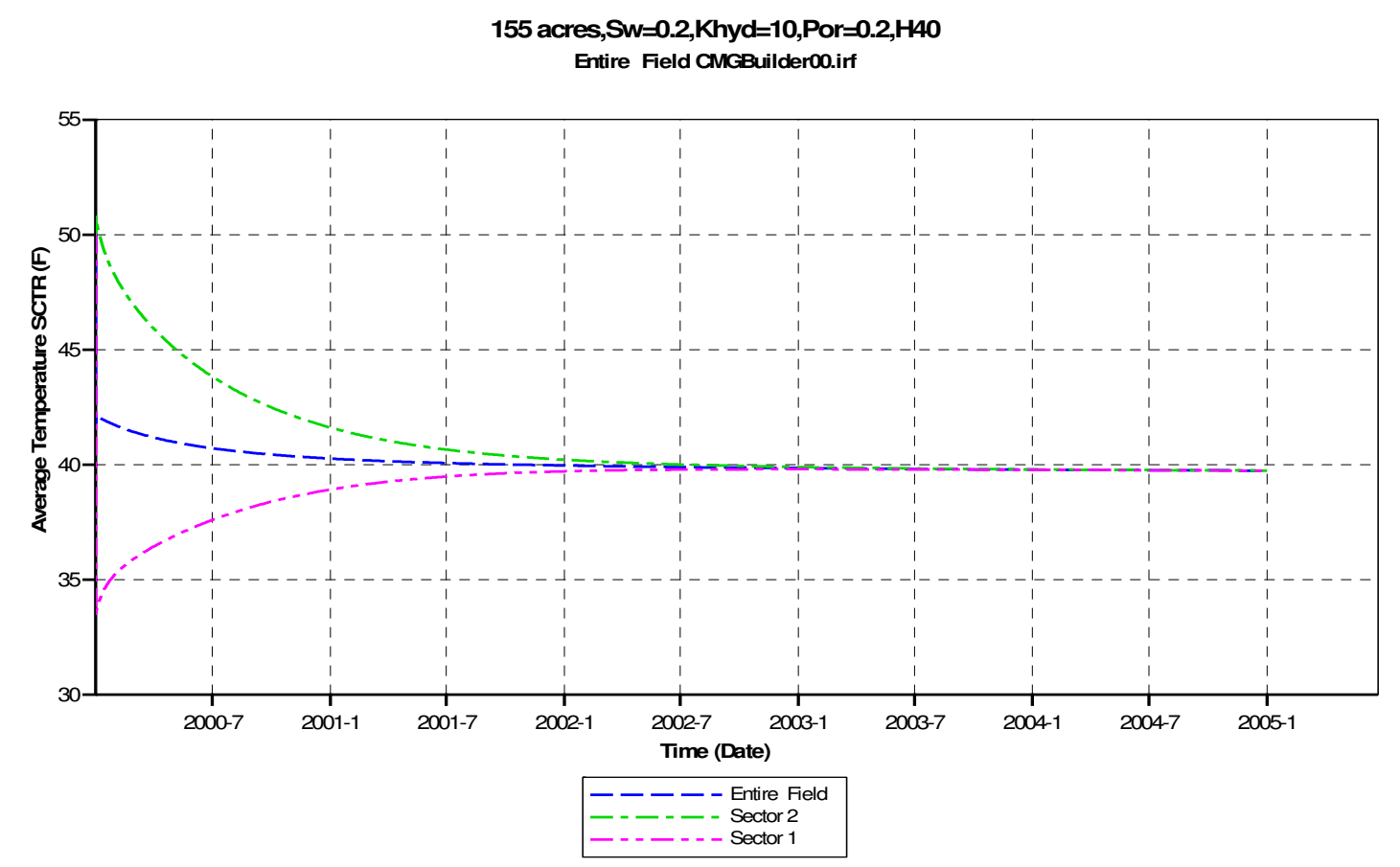

FIGURE 3-6: SECTOR WISE TEMPERATURE VARIATION WITH TIME (BASE CASE).

\subsection{Effect of hydrates on total gas production}

Two different gas reservoirs without hydrates are developed with same reservoir properties as the base case and runs were conducted to compare the gas productions with the base case. Using the thickness of the gas zone in the base case, first a gas reservoir $(\mathrm{H} 20)$ with $20 \mathrm{ft}$ thickness is modeled. Assuming no hydrate in the reservoir, a $40 \mathrm{ft}$ thick second gas reservoir $(\mathrm{H} 40)$ is modeled. The effect of hydrates on the gas production and water production for $20 \mathrm{ft}$ and $40 \mathrm{ft}$ thick gas reservoirs together with hydrate base case are shown in (Figure 3-7) and (Figure 3-8). 


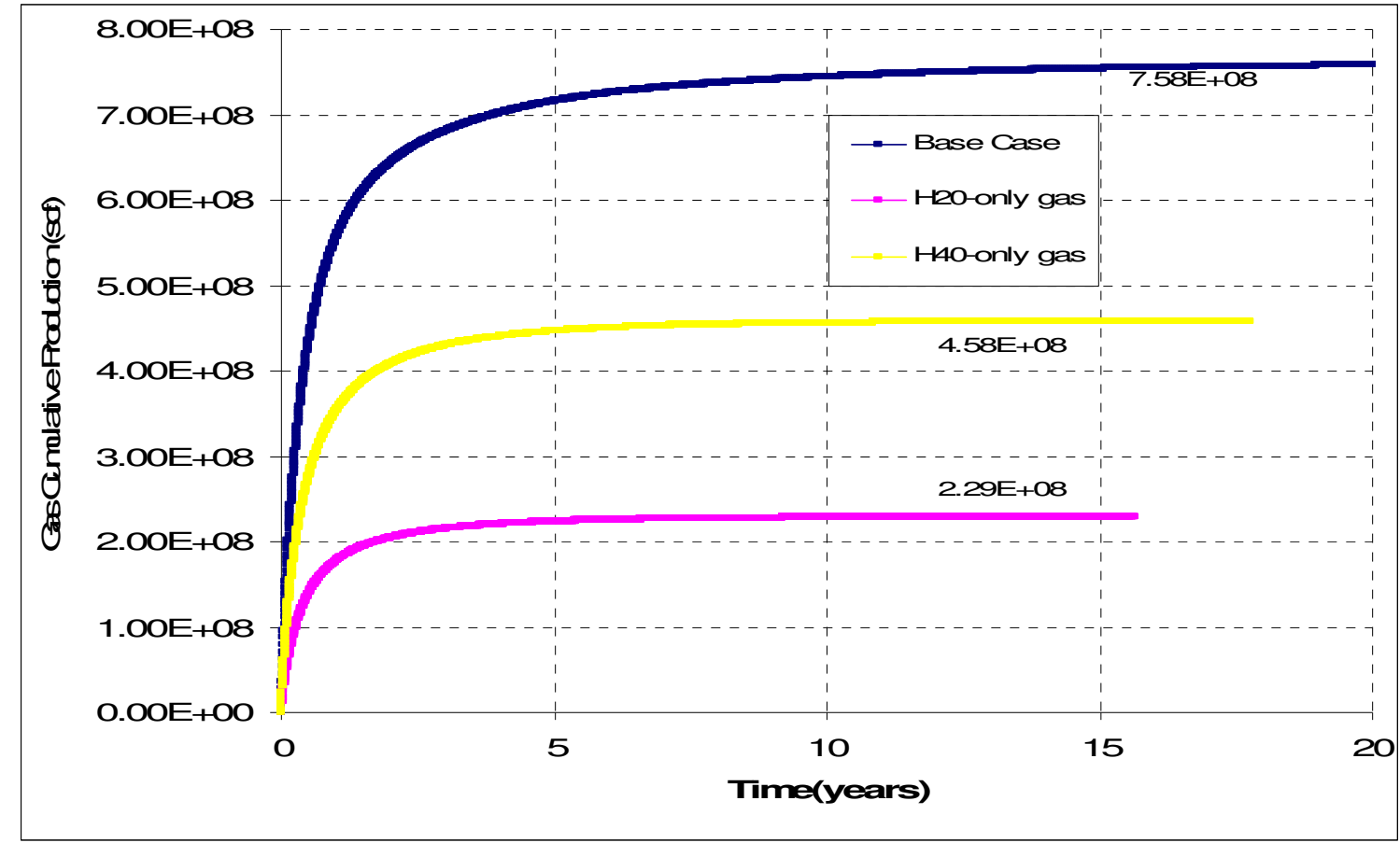

FIGURE 3-7: COMPARISON OF CUMULATIVE GAS PRODUCED.

As seen in Figure 3-7, the hydrate-bearing reservoir produces more gas than a gas reservoir of same pore volume. The total gas potential of the hydrate reservoir is approximately $2.87 \mathrm{E}+09 \mathrm{scf}$ once all the hydrate dissociates as compared to $4.3264 \mathrm{E}+07 \mathrm{scf}$ in a gas-bearing reservoir of similar dimensions.

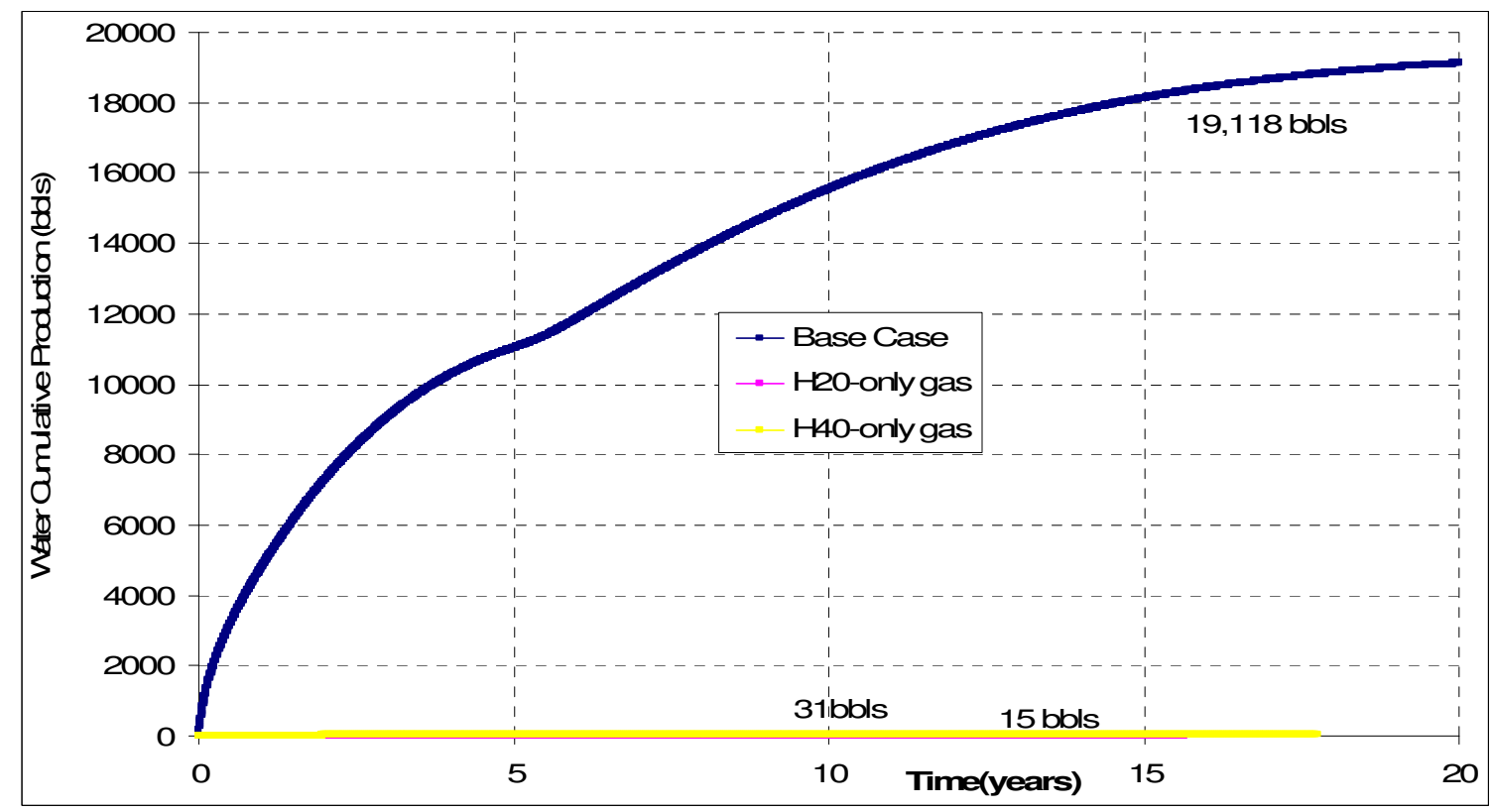

FIGURE 3-8: COMPARISON OF CUMULATIVE WATER PRODUCED. 
The cumulative water production in $\mathrm{H} 40$ and $\mathrm{H} 20$ cases are very low ( 31 bbls and 15 bbls respectively) whereas 19,118 bbls of water is produced in the base case as shown in Figure 3-8. Initial water saturation is assumed connate in all the cases. All the water produced in the base case is from the dissociation of gas hydrates.

\subsection{Recovery}

Though large amounts of gas is dissociated from the hydrates, only around $25 \%$ of the gas is recovered (Figure 3-9) from the reservoir because of the stabilizing temperature and pressure. It is suggested to either close the well for the pressure to build up or use injector wells to produce the remaining gas or drill more wells.



Figure 3-9: Percentage ReCOVERY OF GAS. 


\subsection{Effect of reservoir thickness}

To compare the effect of reservoir thickness on the cumulative gas production and gas production rate, simulations were made with an $80 \mathrm{ft}$ thick reservoir having the same properties as the base case and the results were compared. The gas produced doubled (Figure 3-10) in the second (80 ft) case and the height doesn't have any impact on the production except for the volume change associated with increase in thickness. Similar effect is seen in the sector wise total gas production (Figure 3-11), the gas production rate (Figure 3-12) and the cumulative water production (Figure 3-13)

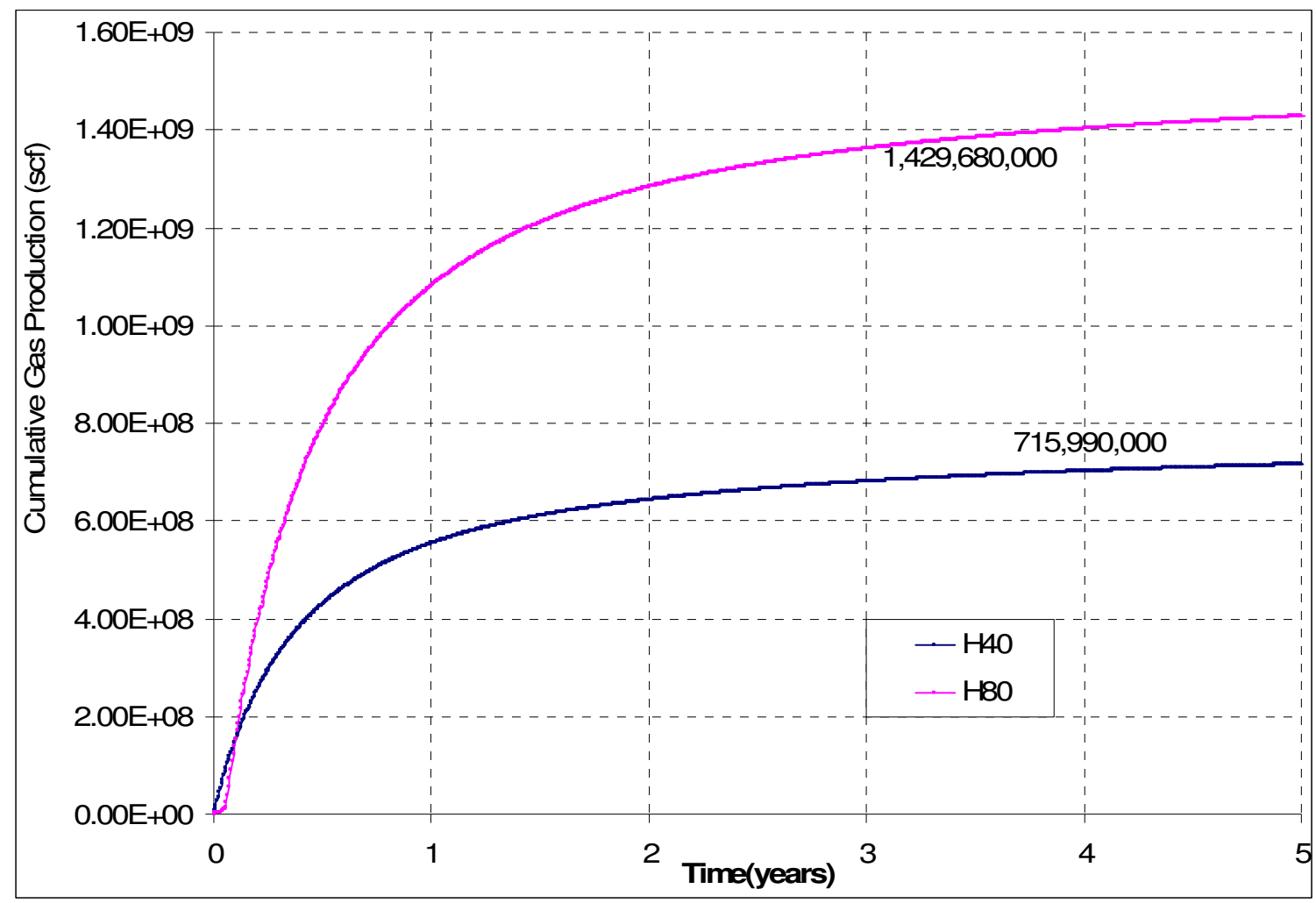

FIGURE 3-10: EFFECT OF RESERVOIR THICKNESS ON TOTAL GAS PRODUCTION. 




FIGURE 3-11: EFFECT OF RESERVOIR THICKNESS ON SECTOR WISE GAS PRODUCTION. 


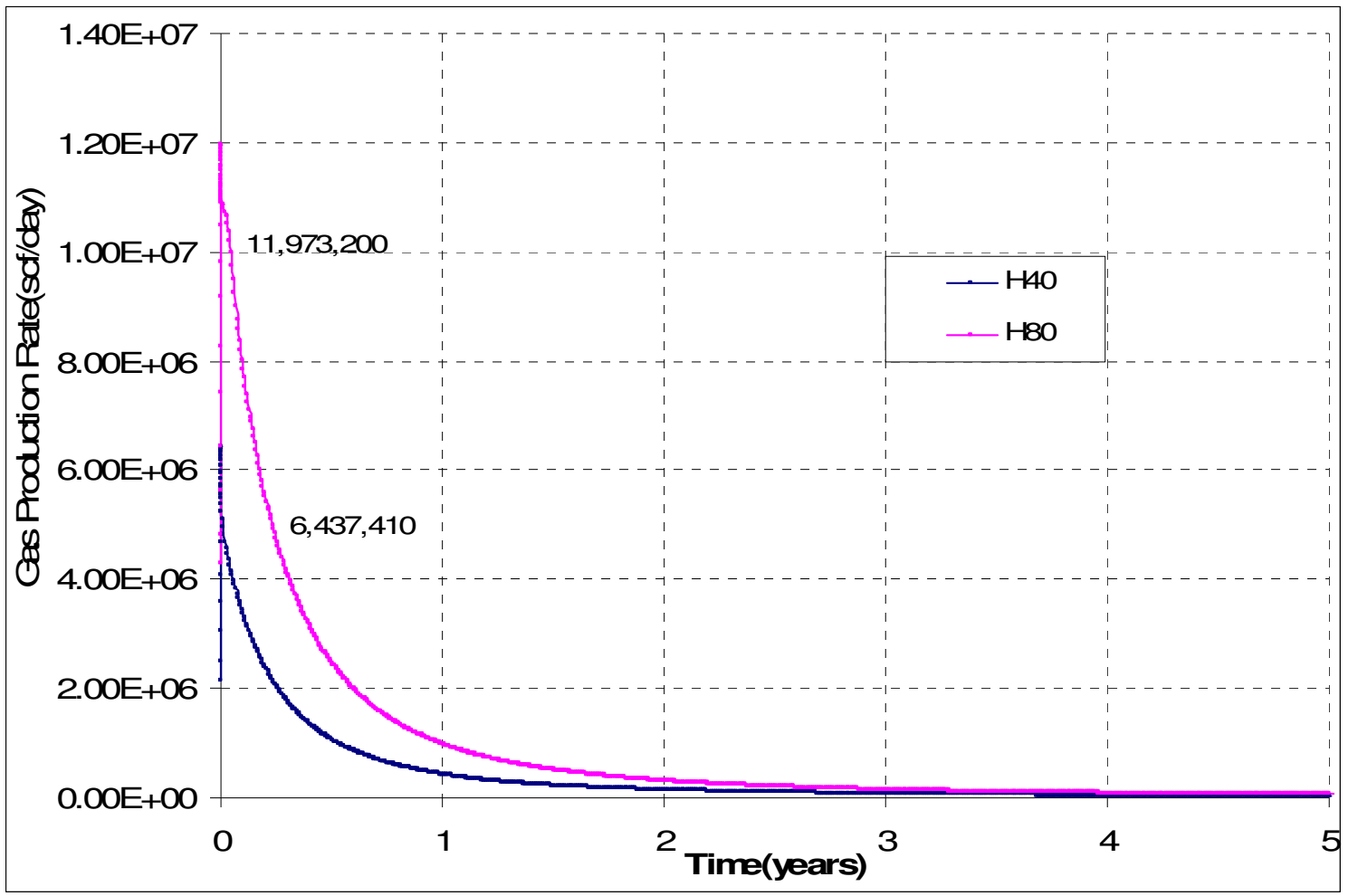

FIGURE 3-12: EFFECT OF RESERVOIR THICKNESS ON GAS PRODUCTION RATE.

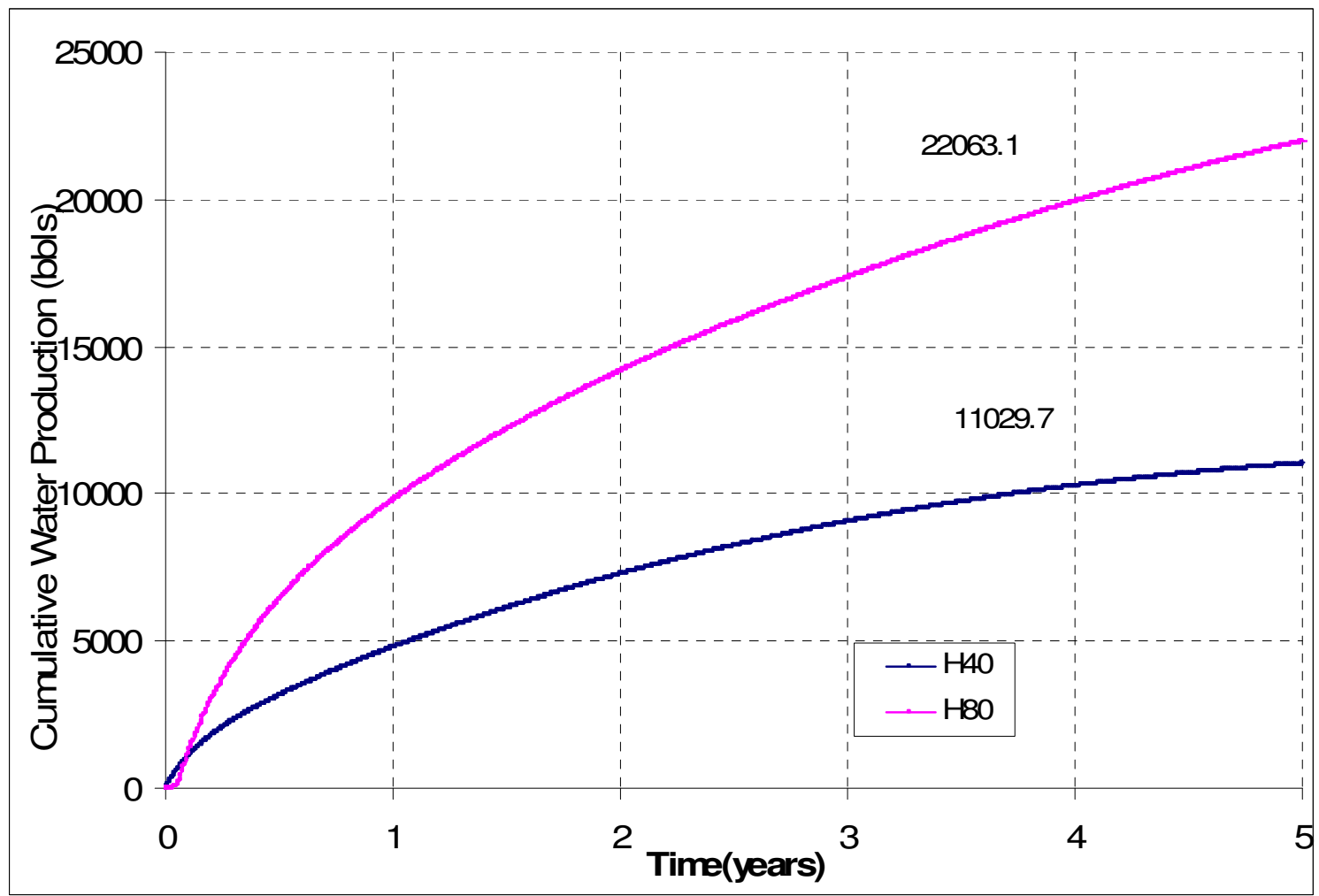

FIGURE 3-13: EFFECT OF RESERVOIR THICKNESS ON TOTAL WATER PRODUCTION. 


\subsection{Effect of porosity}

To study the effect of porosity, simulations were made with $15 \%$ and $30 \%$ and the results for cumulative gas production are compared with the base case (Figure 314). Change in porosity results in change of formation pore volume and hence proportional production increase is observed.

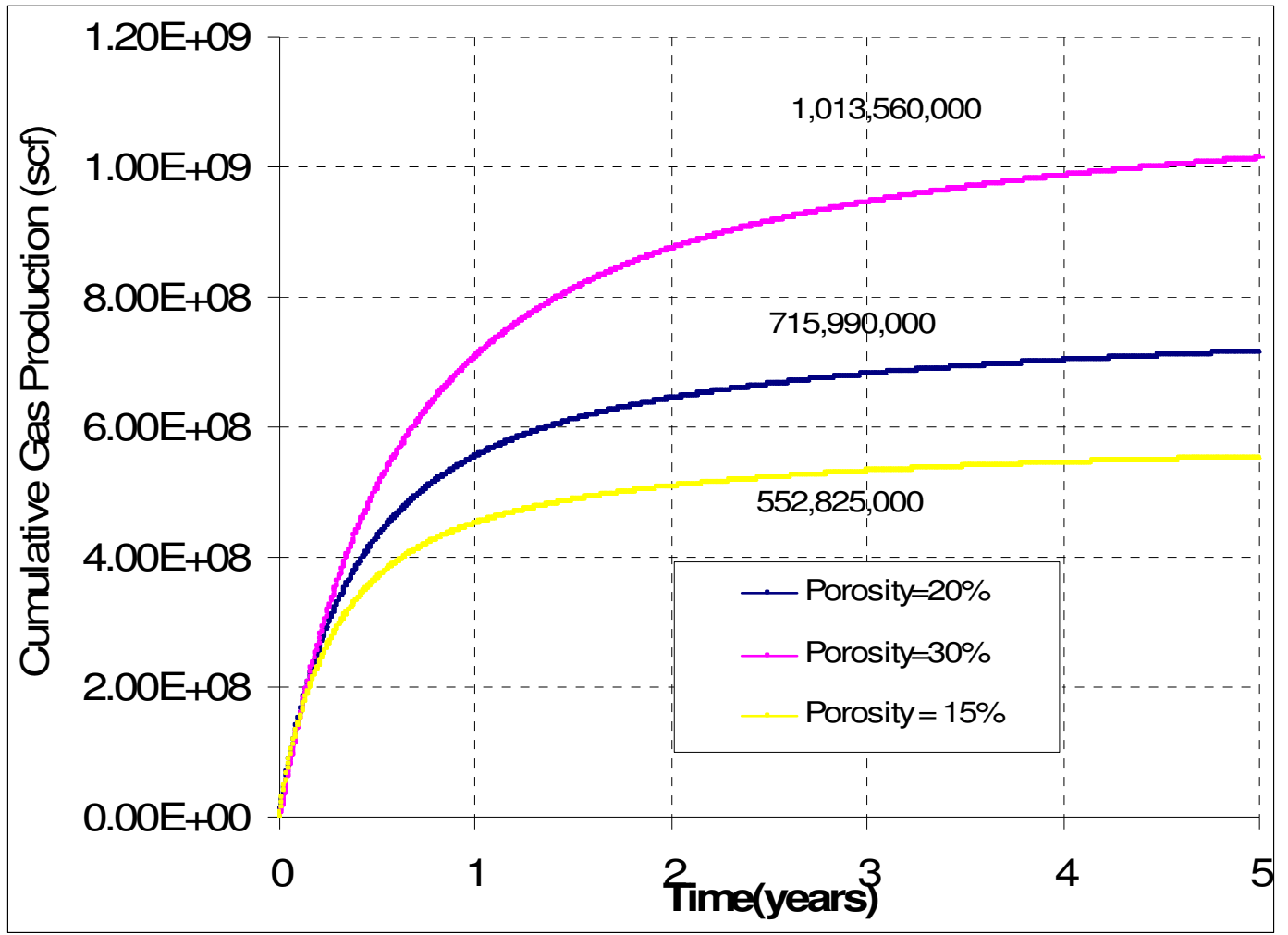

FIGURE 3-14: EFFECT OF POROSITY ON TOTAL GAS PRODUCTION.

The sector wise gas production for formation porosities of $15 \%, 20 \%$ and $30 \%$ are shown in Figure 3-15. The gas in place and water production curves at any given time is shown in Figure 3-16 and Figure 3-17. 


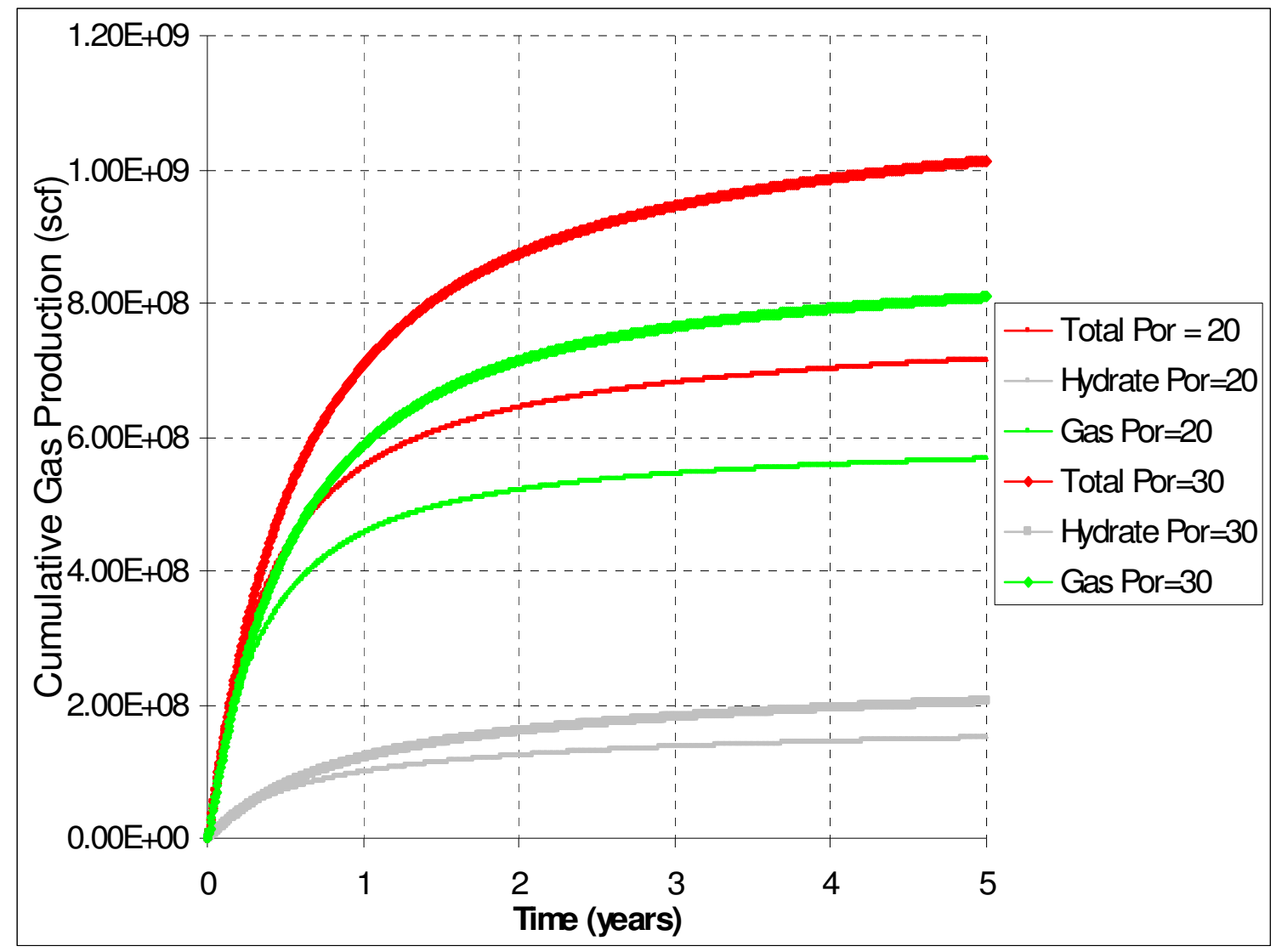

FIGURE 3-15: EFFECT OF POROSITY ON SECTOR WISE GAS PRODUCTION.



FIGURE 3-16: EFFECT OF POROSITY ON GAS VOLUME. 


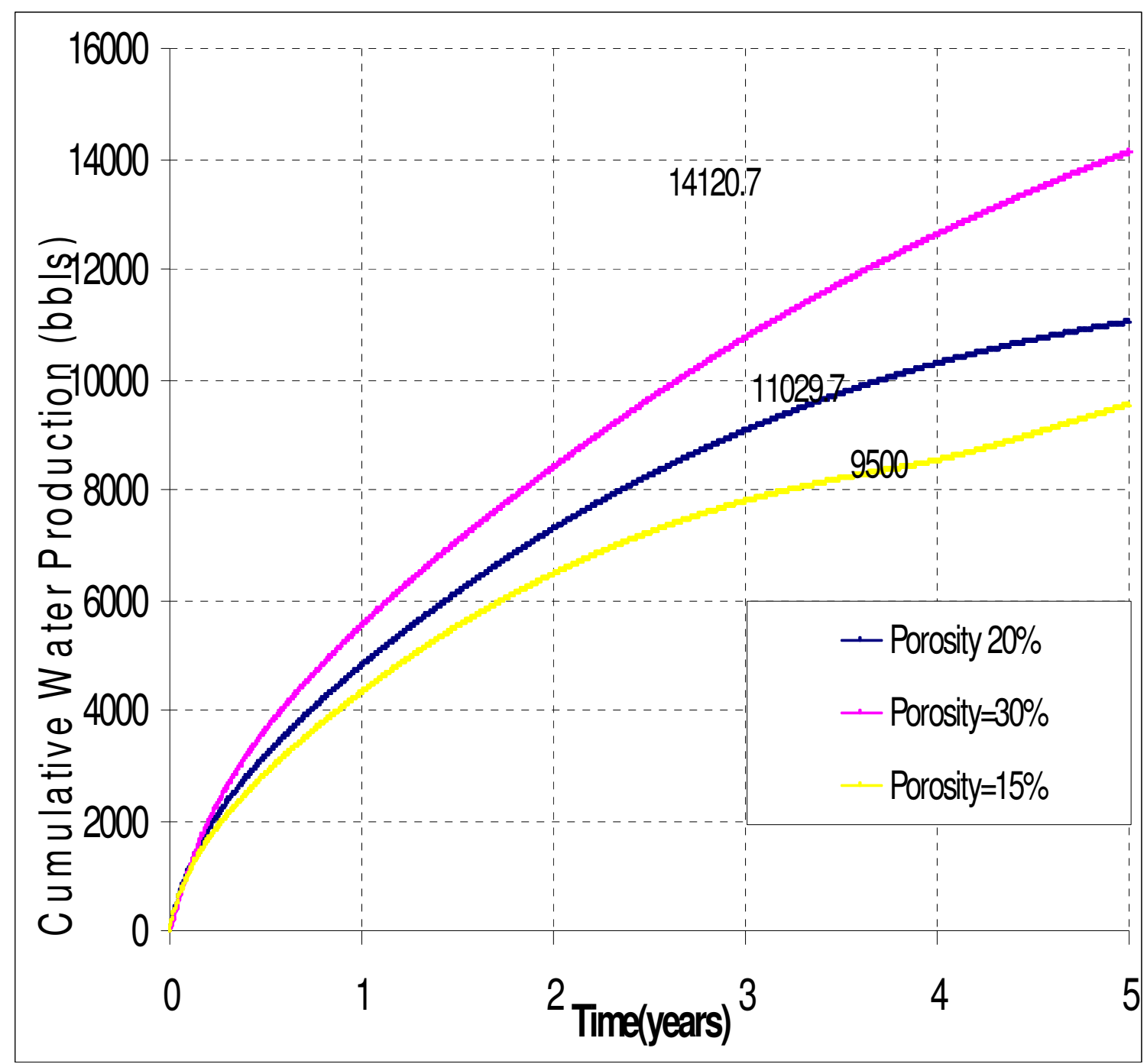

FIGURE 3-17: EFFECT OF POROSITY ON TOTAL WATER PRODUCTION.

It is clear that the porosity and reservoir thickness has similar effects in terms of total gas and water production due to changes in the initial volumes in place. 


\subsection{Effect of Water Saturation}

To study the effect of initial water saturation $\left(S_{w}\right)$ on the gas production, simulations were run with $20 \%$ (base case) and $30 \%$ saturations. The total gas produced was $3.16 \mathrm{E}+07 \mathrm{scf}$ greater when the initial water saturation was $20 \%$ compared to $30 \%$ water saturation as shown in Figure 3-18.

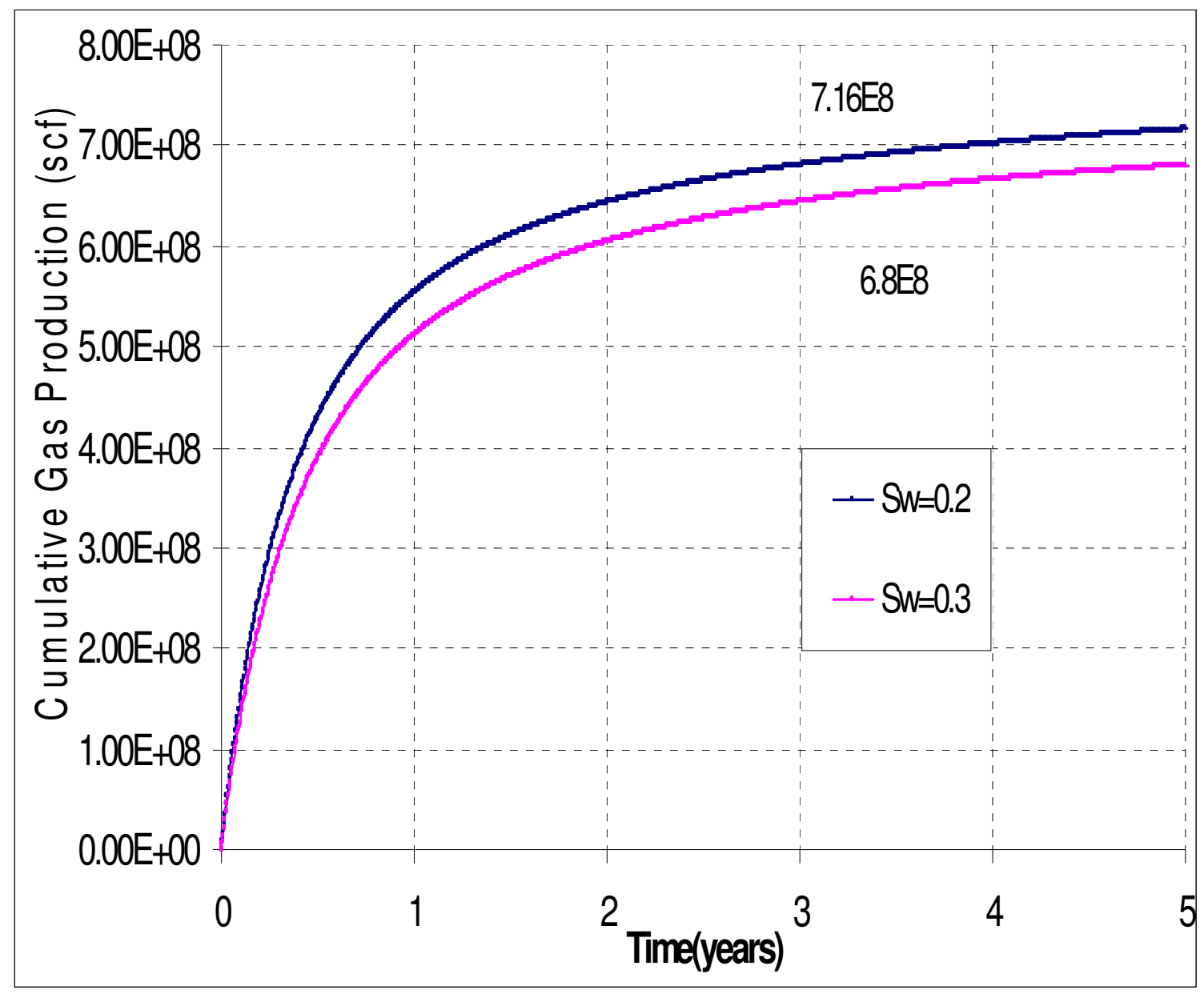

FiguRE 3-18: EFFECT OF WATER SATURATION ON TOTAL GAS PRODUCTION.

The gas production from the total reservoir and the gas zone however, show an increase in gas production with decrease in water saturation (Figure 3-19). Similar trends were not observed for the hydrate zone (Figure 3-20). 


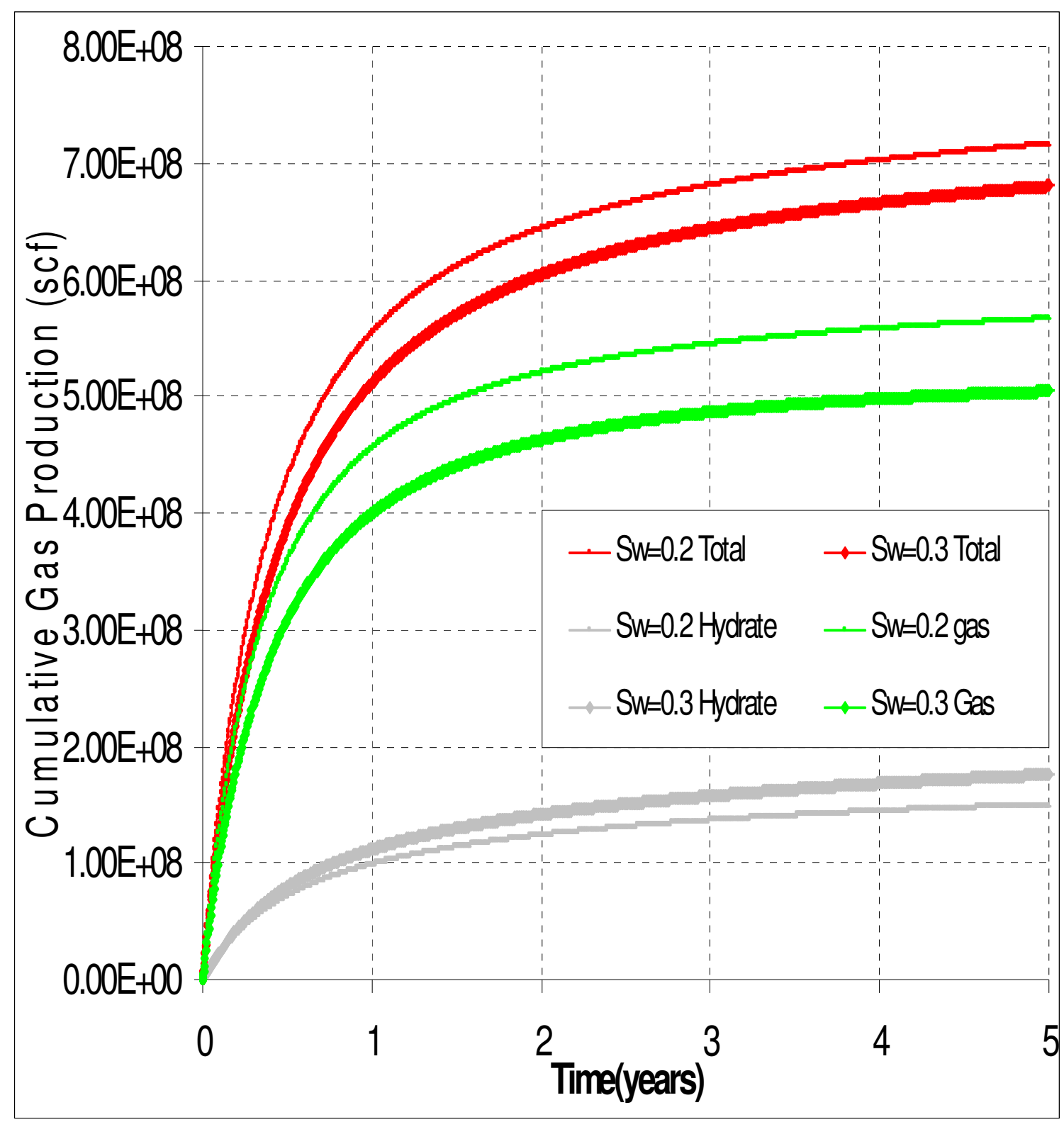

FIGURE 3-19: EFFECT OF WATER SATURATION ON SECTOR WISE GAS PRODUCTION. 


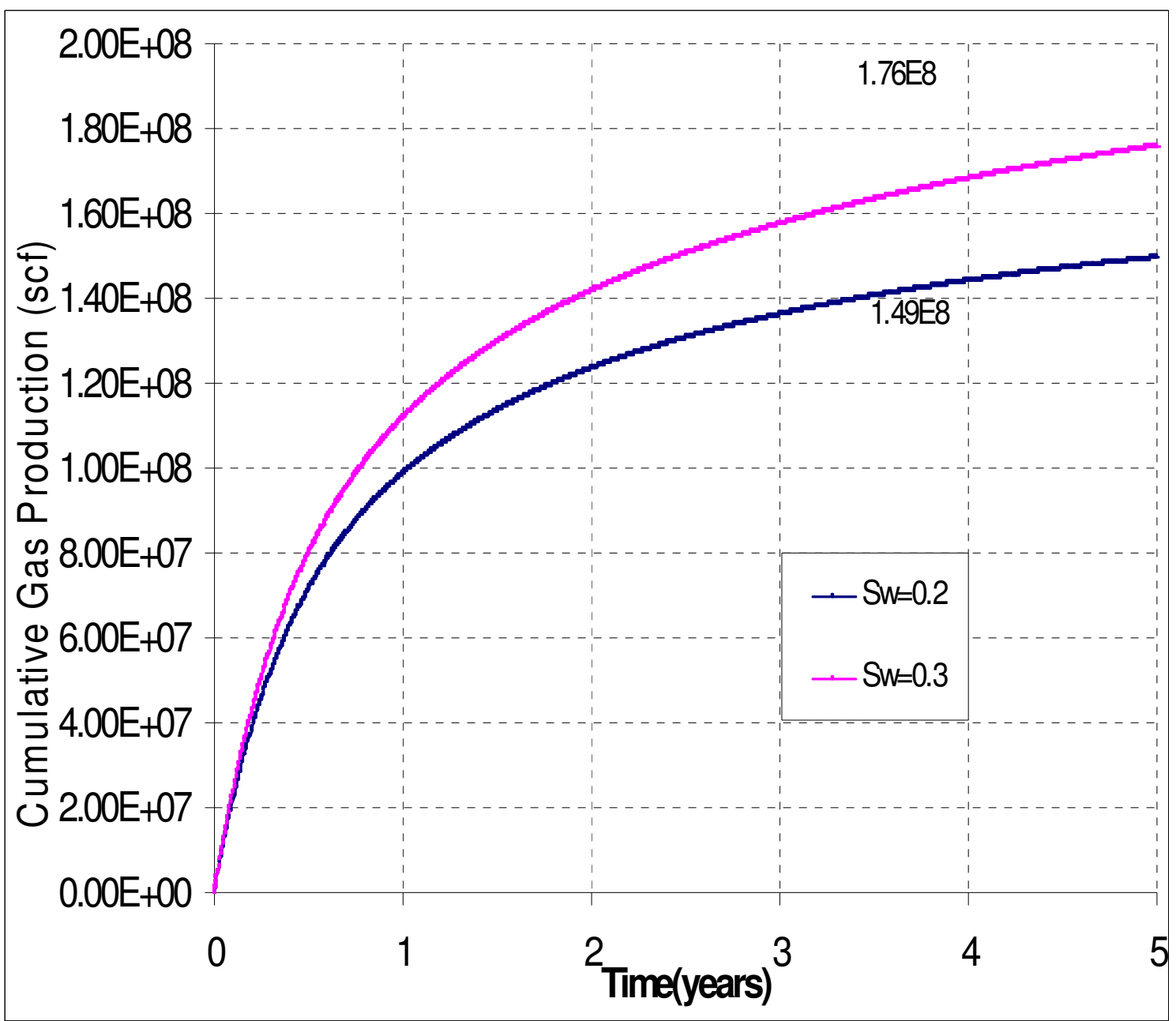

FIGURE 3-20: EFFECT OF WATER SATURATION ON HYDRATE ZONE GAS PRODUCTION.

Due to the presence of more water at the bottom of the reservoir when the initial water saturation is $30 \%$, the migration of gas from Sector 1 to Sector 2 is reduced and instead gas is produced from the hydrate zone. Increase in initial water saturation, increases the water production as shown in Figure 3-21. 


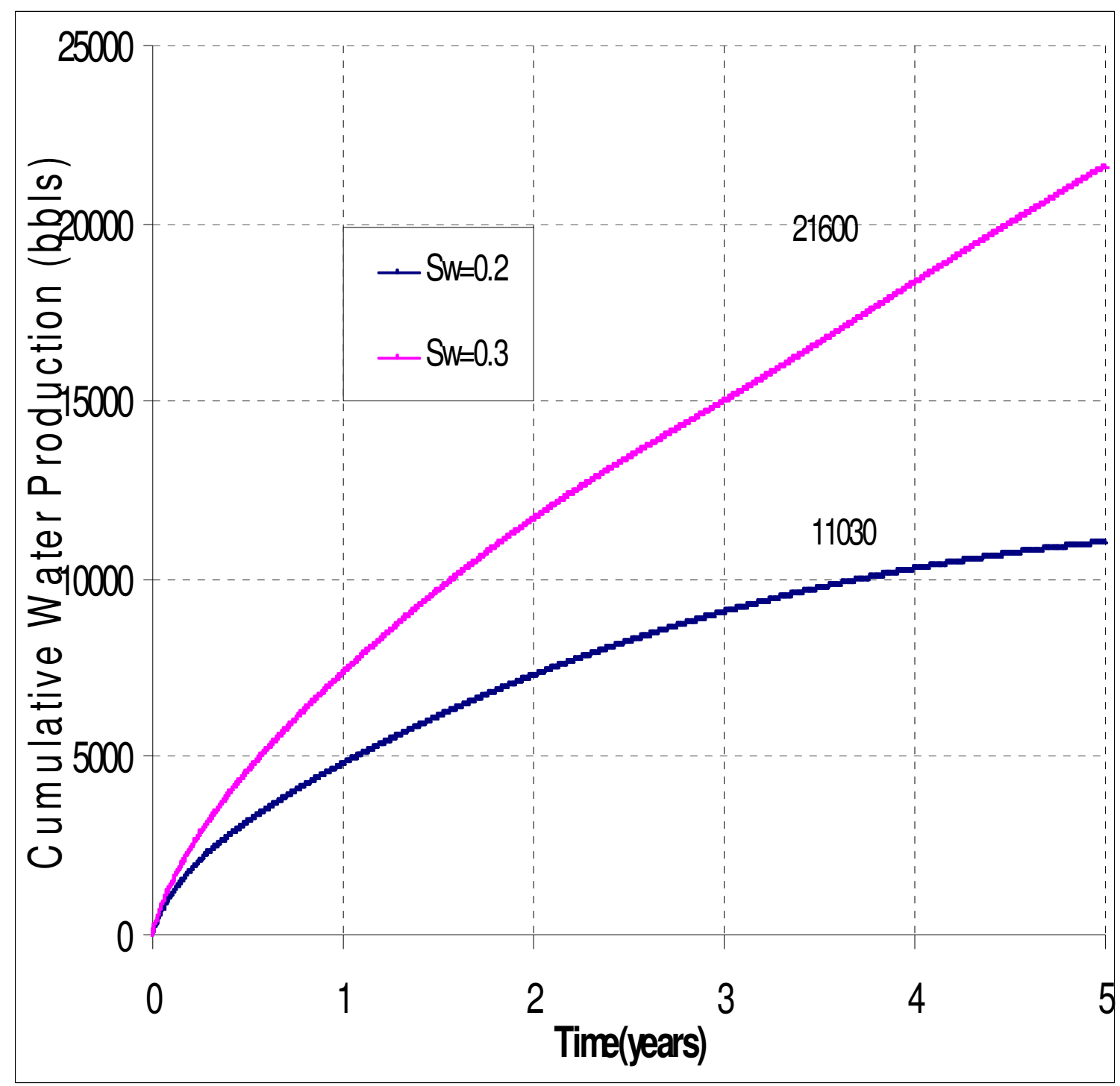

FIGURE 3-21: EFFECT OF WATER SATURATION ON TOTAL WATER PRODUCTION.

The water saturation has limited effect on the gas production, however, the water production increased proportionally with increase in initial water saturation. 


\subsection{Effect of reservoir permeability}

To study the effect of reservoir permeability, simulations are conducted with $50 \mathrm{md}$ (base vase) and $100 \mathrm{md}$ reservoir permeability.

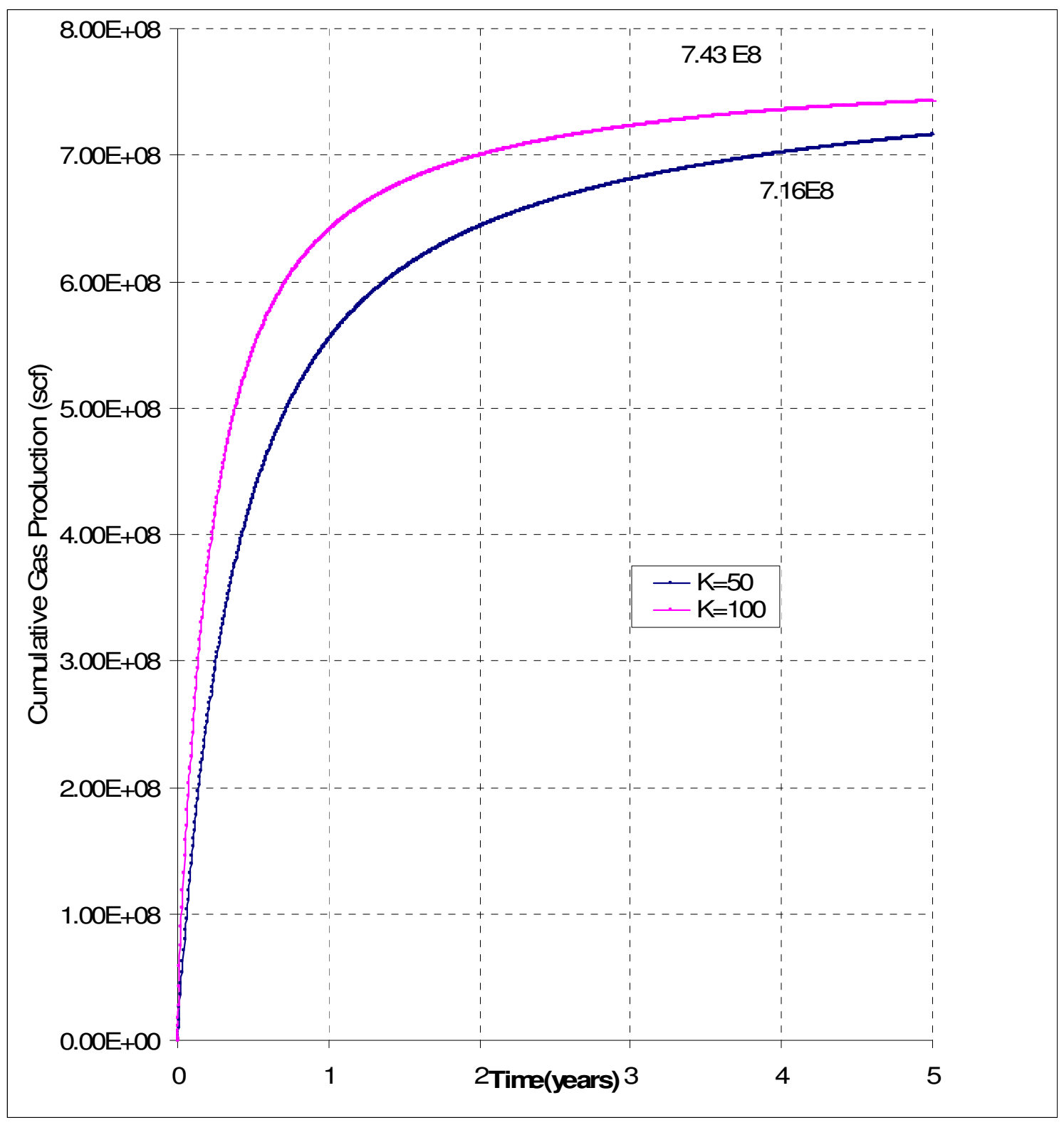

FIGURE 3-22: EFFECT OF RESERVOIR PERMEABILITY ON TOTAL GAS PRODUCTION.

A marginal increase (2.7E7) in overall gas production is seen (Figure 3-22) with the increase in reservoir permeability but sector wise distribution is different (Figure 3-23). 




FIGURE 3-23: EFFECT OF RESERVOIR PERMEABILITY ON SECTOR WISE GAS PRODUCTION.

Because of high permeability in gas zone, the production is higher and for the same reason there is more migration of dissociated gas into the lower zone thus less production from the hydrate zone (Figure 3-24). 


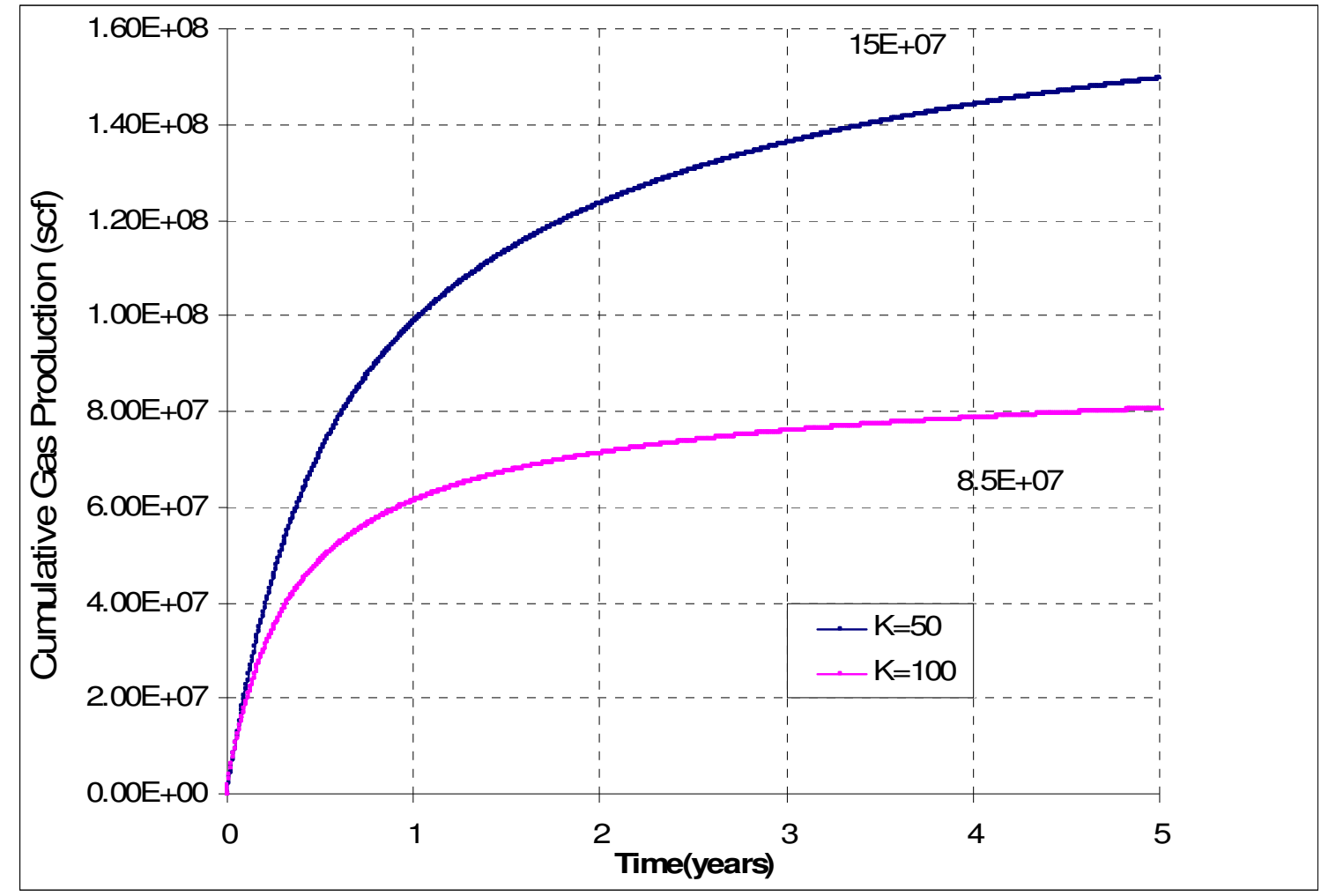

FIGURE 3-24: EFFECT OF RESERVOIR PERMEABILITY ON HYDRATE ZONE GAS PRODUCTION.

The water production is decreased because of the increased gas production (Figure 3-25). After 3.5 years when the gas production stabilizes, water production increases for a short time before stabilizing (Figure 3-25 and Figure 3-26). 


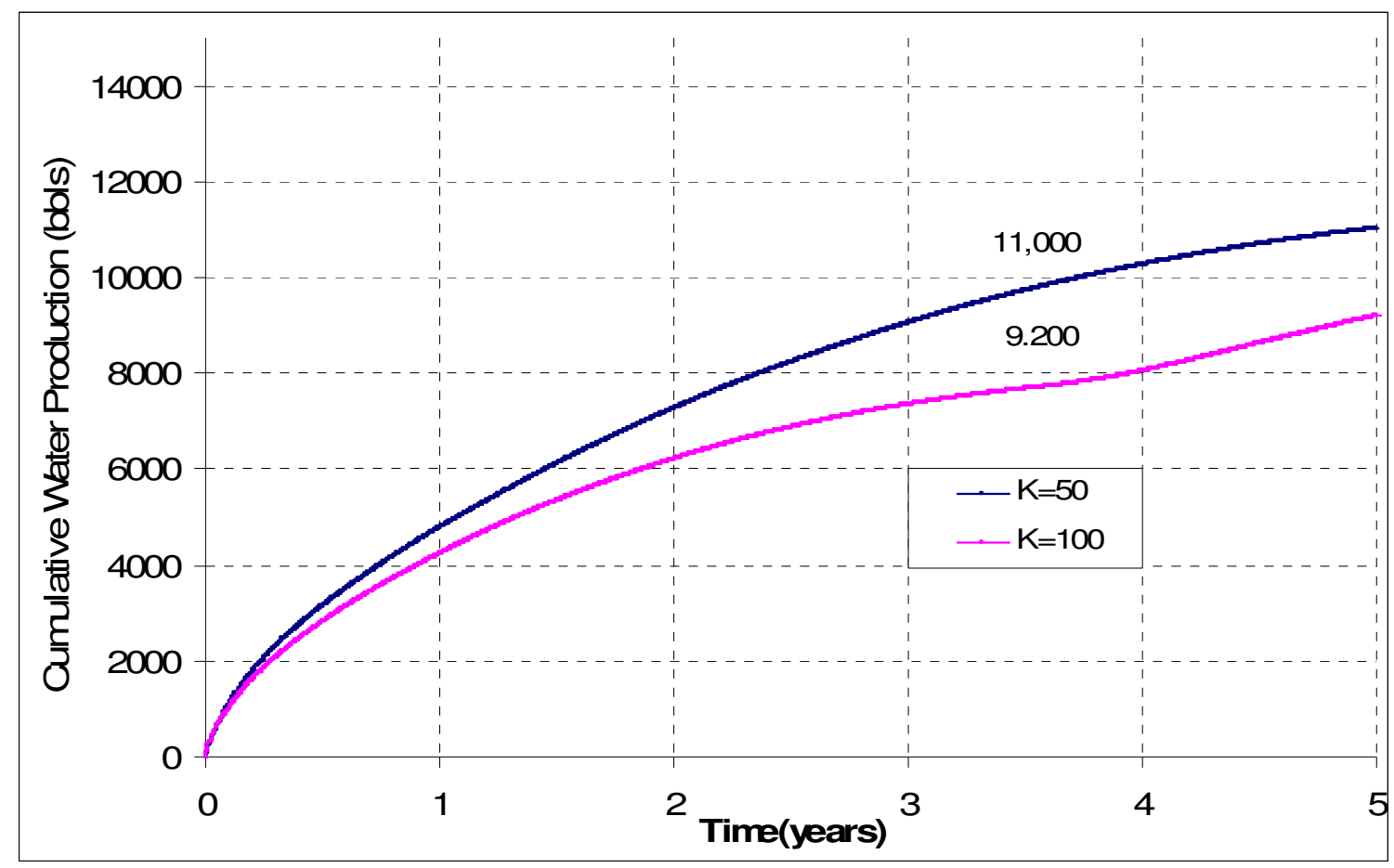

FIGURE 3-25: EFFECT OF RESERVOIR PERMEABILITY ON TOTAL WATER PRODUCTION.

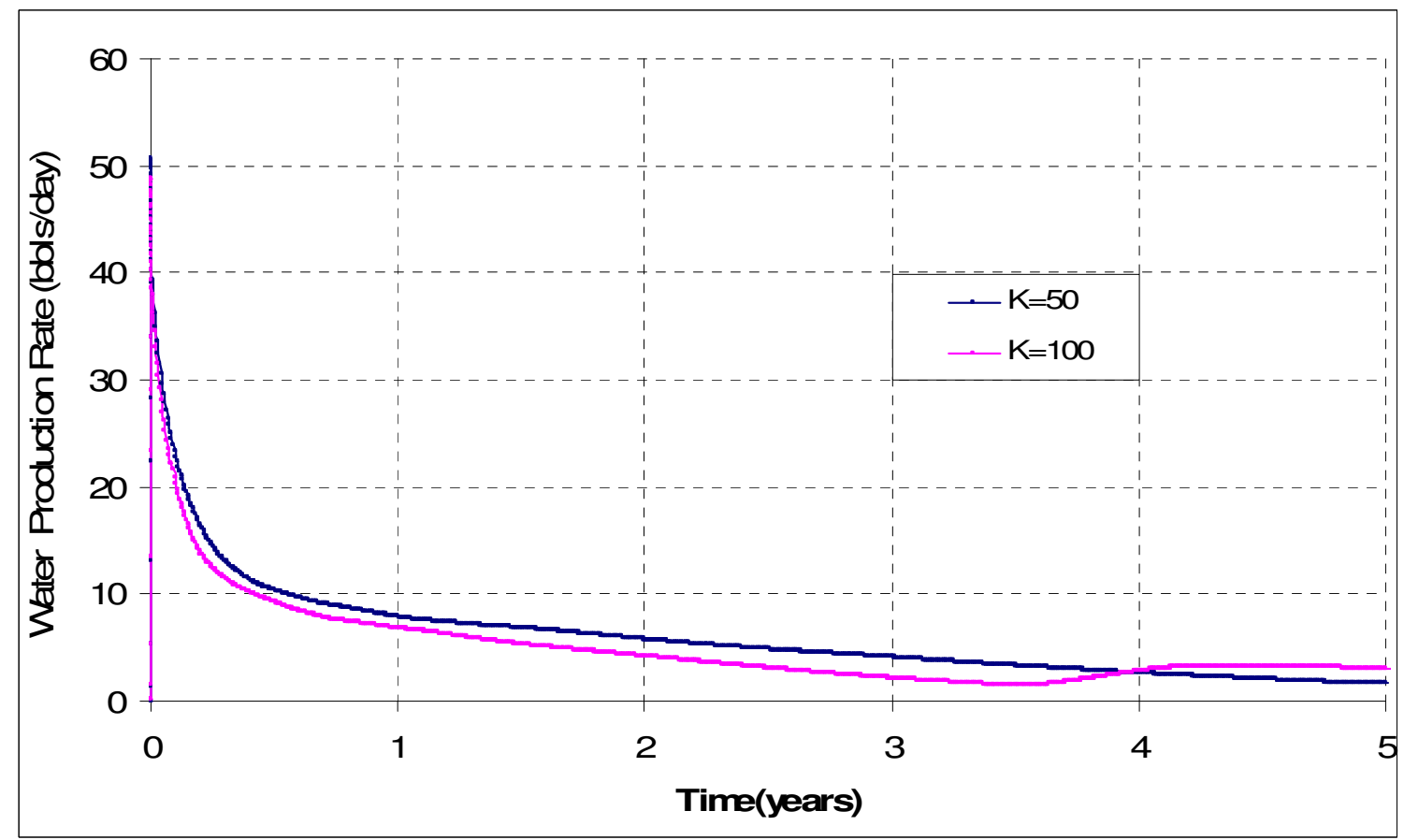

FIGURE 3-26: EFFECT OF RESERVOIR PERMEABILITY ON WATER PRODUCTION RATE. 


\subsection{Effect of Hydrate Permeability}

No data has been published on hydrate permeabilities to date. In this study, wide ranges $(0.01$ to $100 \mathrm{md}$ ) of values were used in order to understand their effect on the production potential of hydrate formations. The amount of total gas produced doesn't vary much for permeabilities used in this study except for $K=100$ md (Figure 3-27). However, the amount of gas that's being produced from different zones varies a lot.

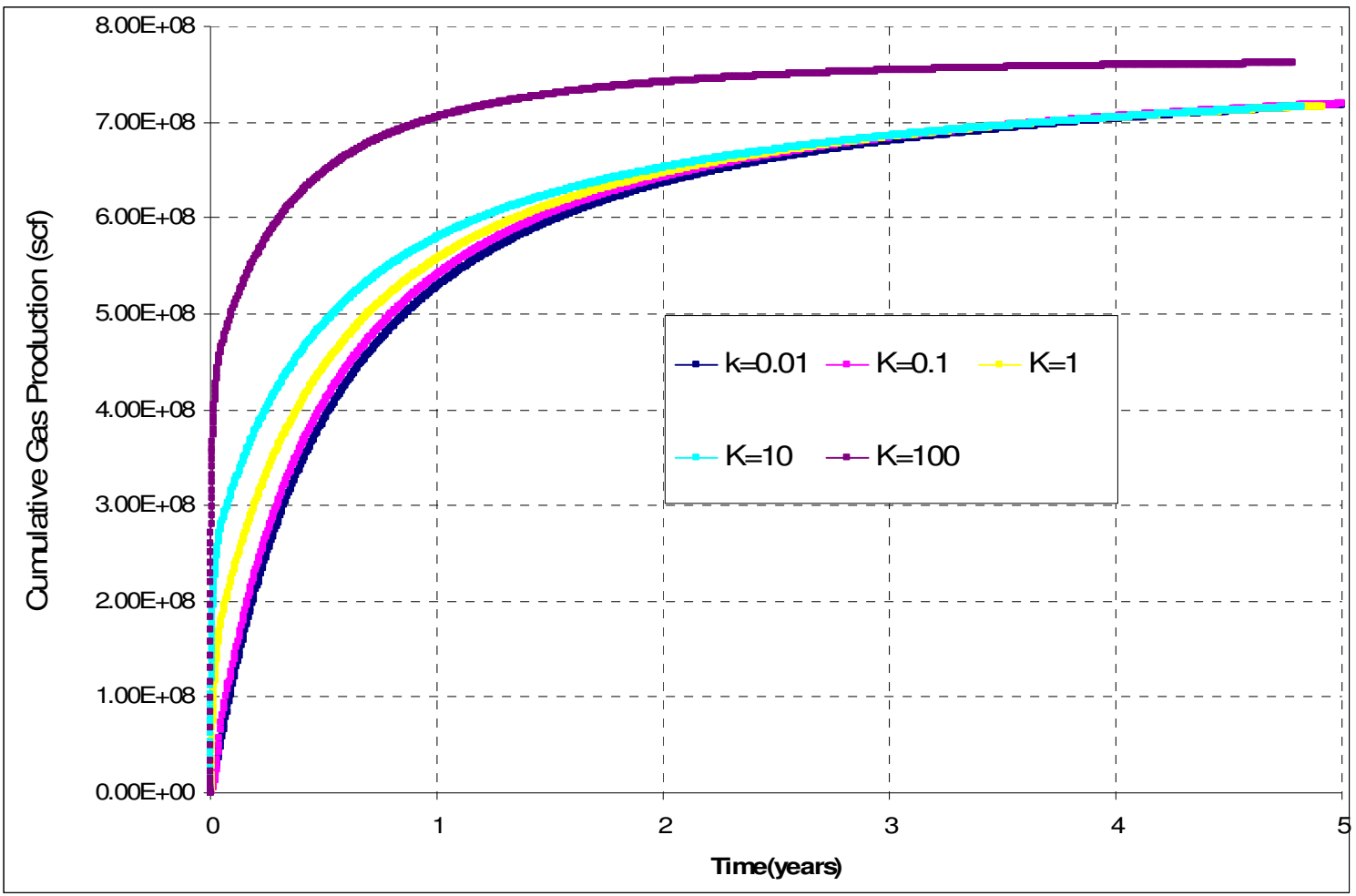

FIGURE 3-27: EFFECT OF HYDRATE PERMEABILITY ON TOTAL GAS PRODUCTION.

The hydrates generally appear to plug the pores hence might initially have very low permeabilities. The hydrates at the gas-hydrate interface and near the wellbore start dissociating first and the interface moves to the other parts by absorbing heat from the surrounding blocks and depressurization caused by gas production. Once the hydrates dissociate the formation will have greater permeability because of the flow of the dissociated gas and water flowing downwards. 


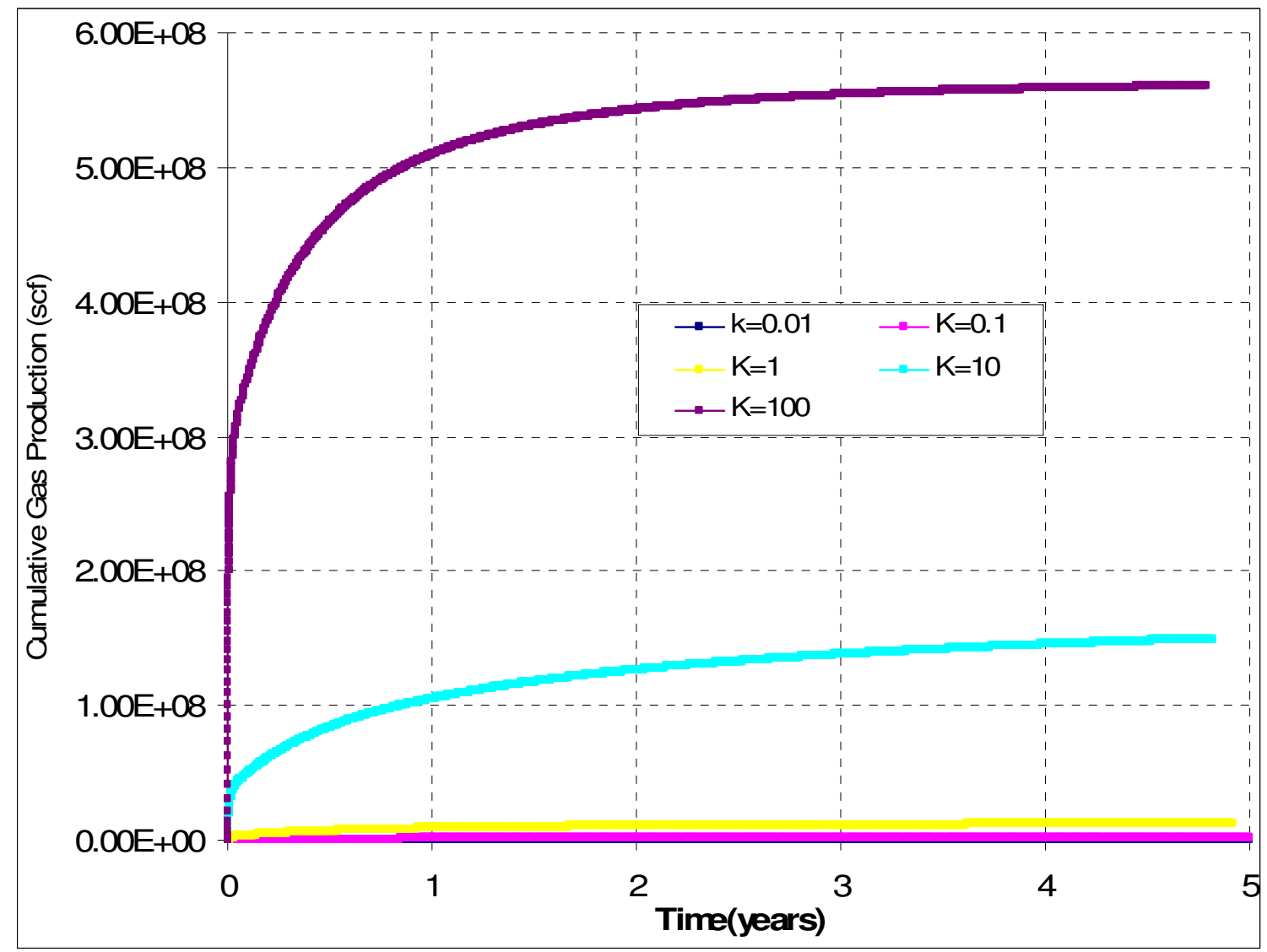

FIGURE 3-28: EFFECT OF HYDRATE PERMEABILITY ON HYDRATE ZONE GAS PRODUCTION.

The amount of gas produced from the hydrate zone with $0.01 \mathrm{md}, 0.1 \mathrm{md}$ and 1 md permeabilities are negligible (Figure 3-28). However, most of the dissociated gas is migrated and produced from the gas zone as seen in Figure 3-29. The 100 md hydrate permeability produces more from hydrate zone hence less from the gas zone compared to other cases. The cumulative gas production in all the cases is almost the same with a maximum difference of $4.2 \mathrm{E}+07 \mathrm{scf}$ between $0.01 \mathrm{md}$ and $100 \mathrm{md}$. However rate of production increases with permeability. 




FIGURE 3-29: EFFECT OF HYDRATE PERMEABILITY ON GAS ZONE GAS PRODUCTION.

As seen in Figure 3-30, the water production increased with the increase in hydrate zone permeability. 




FIGURE 3-30: EFFECT OF HYDRATE PERMEABILITY ON TOTAL WATER PRODUCTION. 


\section{Conclusion and Future Work}

\subsection{Limitations}

The dearth of information on the fundamental properties of hydrate bearing reservoirs and their thermodynamic behavior, no reliable measurements of the permeability, porosity and saturation of natural hydrate deposits is a serious limitation. An area of concern was the lowering of reservoir temperature due to endothermic hydrate dissociation reaction and Joule-Thompson effect as this can result in freezing of water, plugging the formation and preventing the efficient depressurization. Limitation of STARS to operate below 33F which in reality can be the case and attempting to recalculate the last step to keep the temperature above the minimum leads to approximations. Another limitation was its inability to differentiate the gas being produced from the hydrate dissociation resulting in a very less recovery in the production graph which is obviously not true. This should not be interpreted as the lack of confidence in the numerical simulation. The fact that no representative undisturbed sample of natural hydrates has been obtained till date indicates the magnitude of the problem.

\subsection{Conclusions}

Even with the current lack of data, numerical simulation makes it possible to establish the envelopes of possible solutions and identifying promising target zones of hydrates for development. Inspite of the limitations of the input data, approximations and imprecision of STARS, useful conclusions can be still drawn from the study. Though STARS couldn't differentiate the gas production from different zones, it was clear that hydrates produce considerably large amounts of gas. The amount of extra gas that can be produced from hydrate bearing formations promises a good rate of return in a broader sense. The results were promising and give encouragement to continue the efforts into hydrate research. 
The results generated from the simulations indicate:

- Amount of gas produced because of dissociation of hydrates is significantly higher compared to a non hydrate-bearing reservoir.

- The total recovery of the gas over 20 years is low (25\%) suggesting depressurization with single well alone is not sufficient for a complete recovery.

- Porosity and reservoir thickness have no effect on the gas production directly. They change the initial volumes in place and hence the production. The total gas production changed proportionally with porosity and reservoir thickness.

- Total gas production is inversely proportional to the initial water saturation. Increase in initial water saturation decreases the initial gas volume hence lower production. In addition, more gas is produced from hydrate zone due to less migration because of more water in the gas zone. Cumulative water production increased with increase in initial water saturation and hydrate saturation.

- Changes in the permeability of the hydrate zone effect the rate of gas production as a result of slow migration of gas from hydrate zone to gas zone. Lower hydrate permeabilities result in less production directly from the hydrate zone but the overall gas production is almost the same for the reservoir due to migration of dissociated gas. However, higher hydrate permeabilities result in significant production directly from the hydrate zone.

- Gas production rate increased with both hydrate permeability and reservoir permeability. Though the cumulative production over time was almost the same for cases studied, reservoirs with higher permeabilities produced at a faster rate.

- Completing the well throughout does not significantly increase on the total gas production. However, the water production is effected by the completion interval. It is advisable to complete $75 \%$ of the wellbore to decrease the water production and clogging of wellbore by water settling at the bottom of the reservoir. 


\subsection{Recommendations for further work}

1. Relative permeability data is to be determined through laboratory experiments.

2. Running simulations on specifically designed to model hydrate dissociation, as TOUGH2 simulator would add more certainty to the results.

3. Additional geological characterization of the hydrates, refinement of input data to be determined to more accurately develop the reservoir and reduce the uncertainty of the study.

4. Variations with the completions, number of wells, placing of wells, injectors or any other methods can be studied for a better recovery. 


\section{References}

1. http://www.netl.doe.gov/scngo/NaturalGas/hydrates/index.html.

2. Kvenvolden, K.A.: "Gas Hydrates as a Potential Energy Resource", U.S. Geological Survey Professional Paper 1570, pg. 555-561, 1993.

3. Collet: "Energy Resource Potential of Natural Gas Hydrates" - AAPG Bulletin 1995, 2002.

4. National Methane Hydrate Multi-Year R\&D Program Plan - U.S. Department of Energy - 1999.

5. http://www.fossil.energy.gov/fred/feprograms.jsp?prog=Gas/Oil++ Gas+Hydrates

6. http://emd.aapg.org/technical areas/gas hydrates/resource toc.cfm

7. Thomas E. Williams, Keith Millheim, Bill Liddell: "Methane Hydrate Production from Alaskan Permafrost”, DOE final report, Maurer Technology Inc. and Anadarko Petroleum Corp., TX-March 2005.

8. Schlumberger Oil Field Review: "Growing Interest in Gas Hydrates", Summer 2000.

9. Mallik International Symposium Report-8 December 2003, Japan.

10. http://gsc.nrcan.gc.ca/gashydrates/canada/index e.php

11. USGS project review: Gas Hydrates of Northern Alaska, June 2004.

12. http://woodshole.er.usgs.gov/project-pages/hydrates

13. Jianchun Dai , Haibin Xu, Fred Snyder, and Nader Dutta: "Detection and Estimation of Gas Hydrates Using Rock Physics and Seismic Inversion: Examples from the Northern Deepwater Gulf of Mexico" The Leading Edge, pg. 60-66, January 2004.

14. Carolyn Ruppel: http://gtresearchnews.gatech.edu/newsrelease/gashydrates.htm , March 21, 2005

15.John Toon : "Ice that Burns", Georgia Institute of technology- research news, July 11, 2002

16.Jean Laherrere: "Oceanic Hydrates: More Questions Than Answers", Energy Exploration and Exploitation, May 3, 2000. 
17. Kamath, V.A. and Godbole, S.P.: "Evaluation of Hot Brine Stimulation Technique for Gas Production from Natural Gas Hydrates," JPT, pg 137988, 1987.

18. M.R. Islam: "A New Recovery Technique for Gas Production from Alaskan Gas Hydrates", presented at the $66^{\text {th }}$ Annual Technical Conference and Exhibition, Dallas, TX, October 6-9, 1991.

19. Makogon, Y. F., Makogon, T. Y., and Holditch, S. A.: "Gas Hydrate Formation and Dissociation with Thermodynamic and Kinetic Inhibitors," paper SPE 56568 presented at the Annual Technical Conference and Exhibition, Houston, October 3-6, 1999.

20. Robert Hunter: "Methane Hydrate Project Review for BP Exploration (Alaska)", DOE Hydrate Conference, September 29, 2003.

21.T. Zhu, B.P. McGrail: "Development of a Thermodynamic Model and Reservoir Simulator for $\mathrm{CH}_{4}, \mathrm{CO}_{2}$ and $\mathrm{CH}_{4}-\mathrm{CO}_{2}$ Gas Hydrate system" (SPE 93976) presented at the 2005 SPE Western Regional Meeting, Irvin, CA, 30-March-1 April 2005.

22. http://www.mh21japan.gr.jp/english/index.html

23. Holder, G. D. and Angert, P. F.: "Simulation of Gas Production from a Reservoir Containing Both Gases Hydrates and Free Natural Gas," paper SPE 11105 presented at the Annual Fall Technical Conference and Exhibition, New Orleans, September 26, 1982.

24. Holder, G.D, et al., "A Thermodynamic Evaluation of Thermal Recovery of Gas from Hydrates in the Earth", JPT, pg. 1127-32, May 1982.

25. McGuire, P.L.: "Recovery of Gas from Hydrate Deposits Using Conventional Technology," paper SPE/DOE 10832 presented at Unconventional Gas Recovery Symposium, Pittsburgh, PA, May 1982.

26. McGuire, P.L.: "Methane Hydrate Gas Production: An Assessment of conventional production technology as applied to hydrate gas recovery." Los Alamos National Laboratory report LA-9102-MS, 1981. 
27. Bayles, G. A. et al.: "A Steam Cycling Model for Gas Production from a Hydrate Reservoir," Chemical Engineering Communications, V. A7, No. 2, p. 224-245, 1986.

28. Burshears, T. J. et al:: "A Multi-Phase, Multi-Dimensional, Variable Composition Simulation of Gas Production from a Conventional Gas Reservoir in Contact with Hydrates," paper SPE 15246 presented at the Unconventional Gas Technology Symposium, Louisville, May 18-21, 1986.

29. Yousif, M. H. et al., "Experimental and Theoretical Investigation of Methane Gas Hydrate Dissociation in Porous Media," SPE Reservoir Engineering, February 1991.

30. Moridis, G. et al.: "EOSHYDR: A TOUGH2 Module for $\mathrm{CH}_{4}-\mathrm{Hydrate}$ Release and Flow in the Subsurface," Earth Sciences Division, Lawrence Berkley National Laboratory, September 1998.

31.G.J. Moridis "Numerical Studies of Gas production From Methane Hydrates", paper SPE 75691 presented at SPE Gas Technology Symposium, Calgary, Alberta, Canada, 30 April-2 May, 2002.

32. Ahmadi, G. et al.: "A Simple Model for Natural Gas Production from Hydrate Decomposition", National Energy Technology Laboratory,1999

33. Masuda, Y., et al.: "Modeling and Experimental Studies on Dissociation of Methane Gas Hydrates in Berea Sandstone Cores", Department of Geosystem Engineering, University of Tokyo, Japan-1999

34. Swinkels, J.A.M., et al.: "Thermal Reservoir Simulation Model of Production from Naturally Occurring Gas Hydrate Accumulations," paper SPE 56550 presented at the Annual Technical Conference and Exhibition, Houston, October 3-6, 1999.

35. Howe, S.J.: "Production Modeling and Economic Evaluation of a Potential Gas Hydrate Pilot Production Program on the North slope of Alaska". M.S Thesis, University of Alaska Fairbanks, AK, 2004. 
36. S. L. Patil: "Economic Analysis and Feasibility Study of Gas Production from Alaskan North Slope Gas Hydrate Resources" paper presented at the AAPG Hedberg Conference, Vancouver, BC, Canada, September 12-16, 2004.

37.W. K. Sawyer et al.: "Comparative Assessment of Natural Gas Hydrate Production Models", paper SPE 62513 presented at the SPE/CERI Gas Technological Symposium, Calgary, Alberta, Canada, 3-5 April 2000.

38. www.cmgroup.com/software/stars.htm

39. www.knovel.com

40. Pooladi-Darvish "A Numerical Study on Gas Production from Formations Containing Gas Hydrates", paper CIPC 2003-60 presented at the Canadian International Petroleum Conference, Calgary, Canada, 10-12, June 2003. 